

\section{DISCLAIMER}

This report was prepared as an account of work sponsored by an agency of the United States Government. Neither the United States Government nor any agency thereof, nor any of their employees, makes any warranty, express or implied, or assumes any legal liability or responsibility for the accuracy, completeness, or usefulness of any information, apparatus, product, or process disclosed, or represents that its use would not infringe privately owned rights. Reference herein to any specific commercial product, process, or service by trade name, trademark, manufacturer, or otherwise does not necessariiy constitute or imply its endorsement, recommendation, or favoring by the United States Government or any agency thereof. Theviews and opinions of authors expressed herein do not necessarily state or reflect those of the United States Government or any agency thereof.

This report has been reproduced directly from the best available copy.

Available to DOE and DOE contractors from the Office of Scientific and Technical Information, P.O. Box 62, Oak Ridge, TN 37831; prices available from (615) 576-8401.

Available to the public from the National Technical Information Service, U.S. Department of Commerce, 5285 Port Royal Road, Springfield, VA 22161. 
KEY WORDS:

Thermal Analysis

Heat Transfer

Fluid Flow

DWPF

Storage Vaults

Glass Melter

RETENTION PERIOD: LIFETIME

\title{
THERMAL ANALYSIS OF THE FAILED EQUIPMENT STORAGE VAULT SYSTEM (U)
}

\author{
By \\ Jeff Jerrell, Si-Young Lee, and Andy Shadday \\ ISSUED: MAY 1995
}

SRTC SAVANNAH RIVER TEChNOLOGY CENTER, AIKEN, SC, 29808 WESTINGHOUSE SAVANNAH RIVER COMPANY

Prepared for the U. S. Department of Energy under Contract DE-AC09-89SR18035 


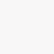




\section{DOCUMENT: WSRC-TR-95-0228}

\section{TITLE:}

\section{THERMAL ANALYSIS OF THE FAILED EQUIPMENT STORAGE VAULT SYSTEM (U)}

\section{APPROVALS:}

Ieff lerrell

Jestiferred, Author

D A T E : $8 / 14 / 95$

Engineering Modeling \& Simulation, Applied Technology Section

iftergeke.

Si-Yowng Lde, Author

D A T E : $8 / 4 / 45$

Engineering Modeling \& Simulation, Applied Technology Section

Andy Shadday, Author
Engineering Modeling \& Simulation, Applied Technology Section

Stperrey

Jamesch. Pelfrey,Group Manager

D A T E :

Engineering Modeling \& Simulation, Applied Technology Section

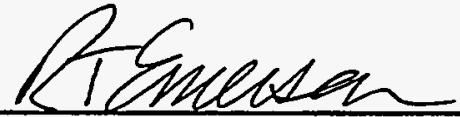

D A T E :

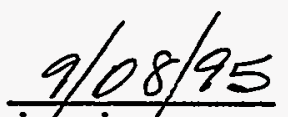

Richard T. Emerson, Customer, DWPF Facility Engineering

A T E :

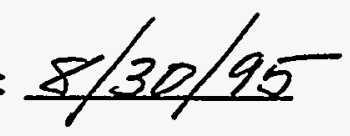

Applied Technology Section, Applied Science and Engineering Technology Department 



\section{Contents}

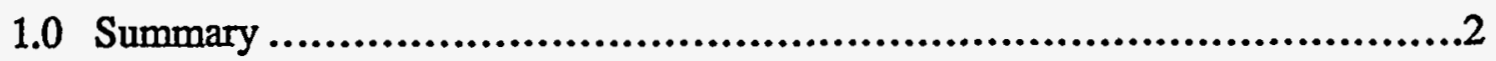

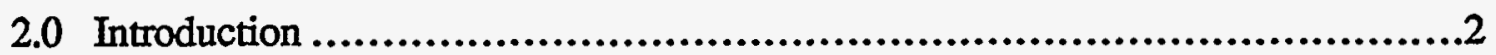

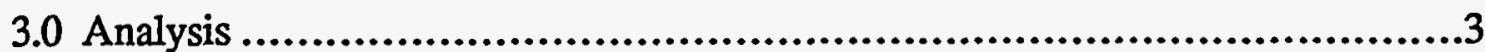

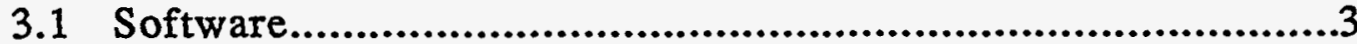

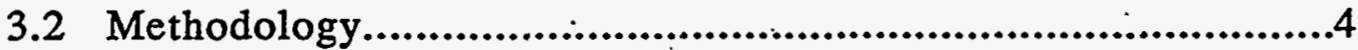

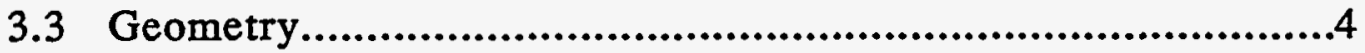

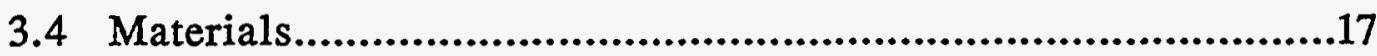

3.5 Boundary Conditions..................................................18

3.5.1 Temporal Aspects................................................18

3.5.2 Ambient Air Temperature ......................................19

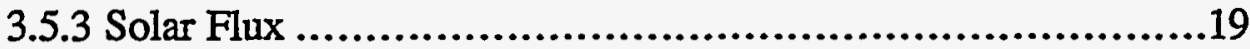

3.5.4 Radiative Loss to Sky ...........................................19

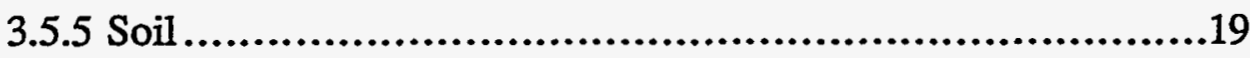

3.5.6 Heat Generation..............................................20

3.5.7 Convective Heat Loss........................................20

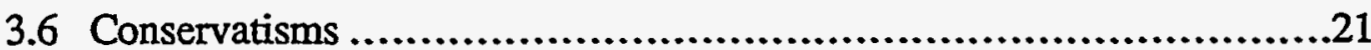

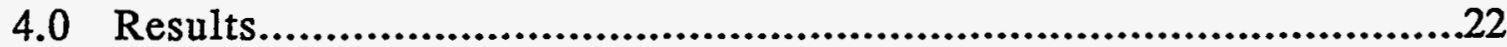

4.1 FLOW3D Conduction/Convection Model.........................................22

4.2 P/THERMAL Conjugate Heat Transfer Model ...............................39

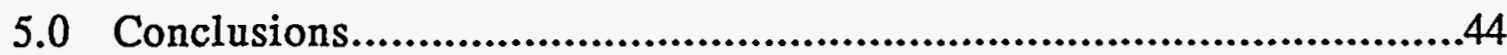

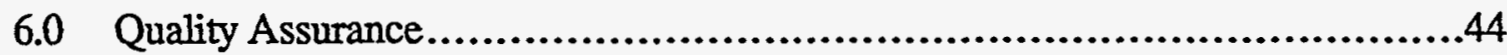

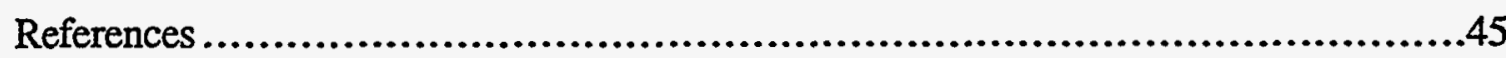

APPENDIX A

Variation of Temperature with Time............................................46 APPENDIX B

Volume of Soil Surrounding Concrete ............................................53 APPENDIX C

Heat Transfer Coefficient Over Horizontal Flat Surface ...........................58 



\subsection{Summary}

As requested in HLW-DWPF-TTR-950037, temperature profiles in the Failed Equipment Storage Vault Structures have been generated using the FLOW3D software to model heat conduction and convection within the FESV/MSB system. Due to complexities in modeling radiation with FLOW3D, P/THERMAL software has been used to model radiation using the conduction/convection temperature results from FLOW3D. The final conjugate model includes heat transfer by conduction, convection, and radiation to predict steady-state temperatures. Also, the FLOW3D software has been validated as required by the technical task request.

The temperatures produced by the conjugate model indicate that the FESV/MSB system components remain below the specified temperature limits for a pair of full failed melters, each generating $3 \mathrm{~kW}$, yielding a total heat generation of $6 \mathrm{~kW}$ for the FESV/MSB system. The glass pool and MSB remain well below their temperature limits by margins of $280^{\circ} \mathrm{F}$ and $490^{\circ} \mathrm{F}$, respectively. The concrete common wall attains a maximum temperature of $147^{\circ} \mathrm{F}$, slightly below the $150^{\circ} \mathrm{F}$ temperature limit. The concrete exceeds the overall temperature limit of $150^{\circ} \mathrm{F}$ in only a portion of the center of the floor, where the temperature reaches $153^{\circ} \mathrm{F}$. The region exceeding $150^{\circ} \mathrm{F}$ is localized, having a diameter of approximately 10 feet and a depth of one foot. The upper concrete temperature limit for localized regions of $200^{\circ} \mathrm{F}$ is not reached.

$\begin{array}{lcc}\text { Component } & \text { Limit }\left({ }^{\circ} \mathrm{F}\right) & \text { Maximum Prediction }\left({ }^{\circ} \mathrm{F}\right) \\ \text { Waste Glass } & 824 & 542 \\ \text { MSB } & 650 & 155 \\ \text { Concrete } & & \\ \quad \text { overall } & 150 & <150 \\ \quad \text { localized } & 200 & 153\end{array}$

\subsection{Introduction}

A storage facility for failed glass melters is required for radioactive operation of the Defense Waste Processing Facility (DWPF). It is currently proposed that the failed melters be stored in the Failed Equipment Storage Vaults (FESV's) in S area. The FESV's are underground reinforced concrete structures constructed in pairs, with adjacent vaults sharing a common wall. Each vault is approximately 28 feet long, 24 feet deep, and 17 feet wide. Including the 18-inch thick concrete lid, the vault extends about 27 inches above the ground. A failed melter is to be placed in a steel Melter Storage Box (MSB), sealed, and lowered into the vault. A concrete lid is then placed over the top of the FESV. Two melters will be placed within the FESV/MSB system, separated by the common wall. There is no forced ventilation within the vault so that the melter is passively cooled.

The FESV and MSB must be adequate for storage of a melter containing a full charge of radioactive glass. It is estimated that isotopic decay in glass yields a maximum power of $3 \mathrm{~kW}$ for each of the two melters, or a total power of $6 \mathrm{~kW}$. The adequacy of the FESV/MSB system depends upon its ability to dissipate heat in such a way that the temperatures of the glass and structural components of the vault do not exceed their limiting values. The temperature sensitive components of the FESV/MSB system are the glass in the melter, steel of the MSB, and concrete of the FESV walls. The limiting glass temperature is $824^{\circ} \mathrm{F}$ as set by the Waste Acceptance Product Specifications (WAPS). The limiting temperature of the steel 
of the MSB is $650^{\circ} \mathrm{F}$, established to prevent loss of structural strength. The limiting average concrete temperature of $150^{\circ} \mathrm{F}$ for extended periods in structural elements and the limiting local temperature of $200^{\circ} \mathrm{F}$ are also set to prevent loss of structural strength.

Exceeding the temperature limits of the FESV/MSB system is a concern due to the combined effect of several factors:

1. No forced ventilation;

2. Sealed air space between the melter and MSB;

3. Confined air space between the MSB and concrete;

4. Insulating effect of the soil surrounding the FESV;

5. Proximity of the melter to the walls of the MSB, and of the MSB to the concrete walls;

6. Storing a melter full of glass in an adjacent FESV.

Temperatures for the FESV/MSB system have been determined by developing a three-dimensional finite difference model using the FLOW3D and P3/THERMAL analysis codes. Steady state temperatures have been calculated by modeling heat transfer by conduction, radiation, and natural convection within the FESV/MSB system.

\subsection{Analysis}

\subsection{Software}

All three modes of heat transfer - conduction, convection, and radiation, are significant and must be considered in modeling the FESV/MSB system. Heat is transported by conduction through all materials including the air spaces between materials, although natural convection and radiation are the dominant modes in the air spaces. A CFD model is necessary to accurately calculate temperatures within the system due to the buoyant effect of air flow on the heat transfer. FLOW3D was chosen as the CFD code. P/THERMAL was chosen to model the radiation because it is considerably more efficient than FLOW3D for modeling radiation in complicated systems such as the FESV/MSB.

\section{FLOW3D}

FLOW3D (version 3.3) is a commercial computational fluid dynamics (CFD) computer code developed by AEA Technology Engineering Software, Inc. with technical support and marketing services in Pittsburgh. FLOW3D, a finite difference code, simultaneously solves the equations governing conduction and convection heat transfer. Radiation heat transfer is solved by an interactive FLOW3D module, RAD3D. FLOW3D and RAD3D exchange heat fluxes and temperatures until a converged solution is found for the conjugate model with conduction, convection, and radiation heat transfer.

FLOW3D predictions have been extensively benchmarked against known solutions by the vendor. AEA Technology is the first major CFD vendor to obtain ISO 9001 approval, covering all aspects of its software development and verification.

\section{P/THERMAL}

P/THERMAL (version 2.6a) is a commercial conduction heat transfer computer code marketed by the MacNeal-Schwendler Corporation. P/THERMAL translates a 
WSRC-TR-95-0288

pg. 4 of 60 .

finite element model into a thermal resistor-capacitor network to solve for model temperatures. A companion radiation module to P/THERMAL is P/VIEWFACTOR, which calculates radiation shape factors when radiation is present. Radiation in the thermal model appears as additional resistors in the network. Because P/THERMAL is a heat conduction code, heat transfer by convection can only be considered by applying convection correlations as boundary conditions. P/THERMAL is not a CFD code because it does not solve the equations governing fluid flow.

P/THERMAL has been approved for use at SRS as Nuclear Safety (NS) grade software[1].

\subsection{Methodology}

FLOW3D has been used to calculate the temperature gradients resulting from heat transfer by conduction and convection. Since P/THERMAL cannot model natural convection within the air spaces by solving the governing equations, it is necessary to simulate the effect of natural convection heat transfer. Natural convection causes the air to mix due to buoyant forces. The mixing rapidly reduces temperature gradients throughout the air spaces. To simulate mixing of the air in the P/THERMAL model, the thermal conductivity of air has been enhanced. The conductivity has been increased to the amount necessary to match temperature gradients between the FLOW3D and P/THERMAL models.

The temperature profiles are matched using temperatures obtained from the FLOW3D conduction/convection analysis to temperatures obtained by a pure conduction analysis from P/THERMAL. Enhancing the P/THERMAL model air conductivity to match the FLOW3D results effectively makes the P/THERMAL conduction model a conduction/convection model, similar to the FLOW3D model. Once the P/THERMAL conduction/convection model has been established, radiation within the air spaces is added to make the P/THERMAL model a fully conjugate heat transfer model. This procedure is illustrated in Figure 1.

\subsection{Geometry}

The components included in the FLOW3D model include the waste glass, failed melter, carbon steel MSB, concrete vault (with lid), and a portion of the earth surrounding the vault. Also included are three air spaces: (1) within the melter; (2) between the melter and MSB; and (3) between the MSB and concrete vault. The vaults are constructed in pairs so that the FESV/MSB system geometry is symmetric about a plane passing through the wall common to the concrete vaults. A second symmetry plane exists at the mid-plane between the front and back vault walls, passing the center of the melter. The FESV/MSB system, excluding the surrounding earth, is shown in figures 2 (front view) and 3 (end view) with detailed dimensions. The entire FESV system is illustrated from the top view in Figure 4. Figure 5 shows the elevation for each of the material layers of the FESV/MSB system. 
WSRC-TR-95-0288

pg. 5 of 60 .

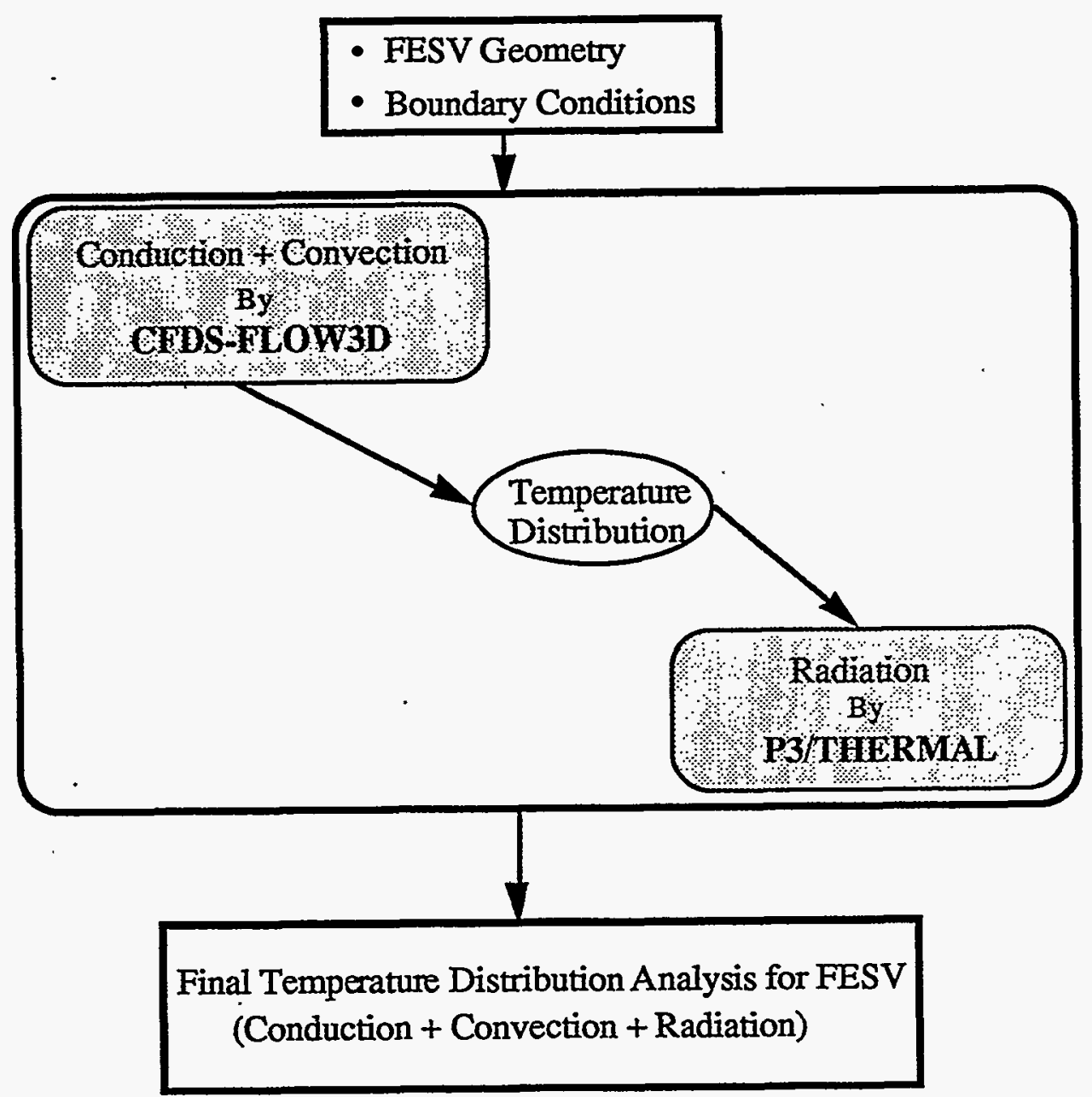

Figure 1: Solution Methodology for Thermal Analsis of the Failed Equipment Storage Vault (FESV) Structure using the CFDS-FLOW3D and P3/THERMAL codes. 
WSRC-TR-95-0288

pg. 6 of 60 .

$26^{\prime}$

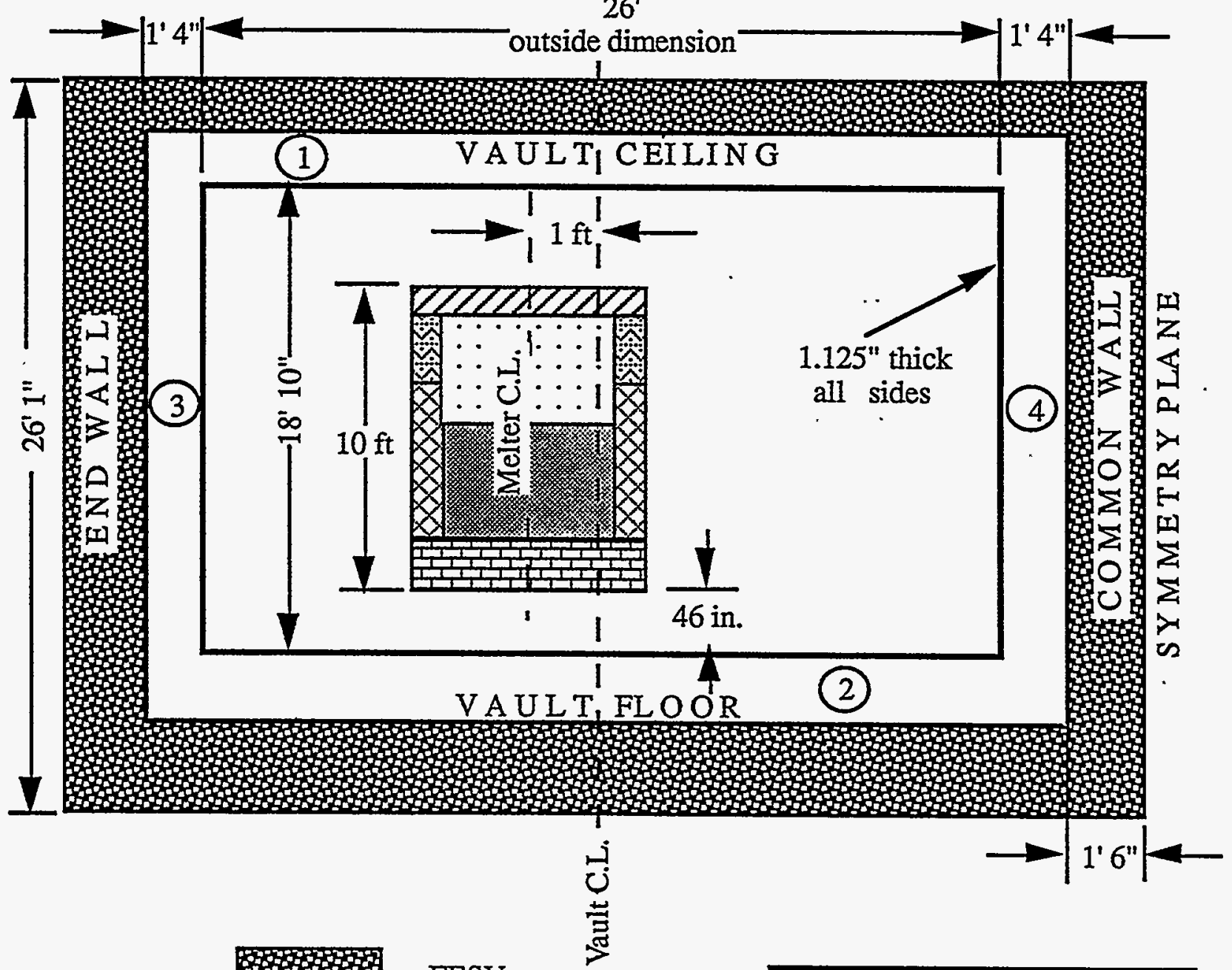

\begin{tabular}{|ll|l|}
\hline & FESV & Air Spaces \\
& MSB & (1) Top of MSB/vault.ceiling \\
& Bottom (melter) & $(2)$ Bottom \\
\hline & Side Bottom (melter) & $(3,4)$ End Wall/ common Wall \\
\hline & Side Top (melter) & Notes : \\
\hline & Top (melter) & $\begin{array}{l}\text { Drawing Not to Scale } \\
\text { Earth not shown for clarity }\end{array}$ \\
\hline
\end{tabular}

Figure 2 : FESV/MSB System : Front View 
WSRC-TR-95-0288

pg. 7 of 60.
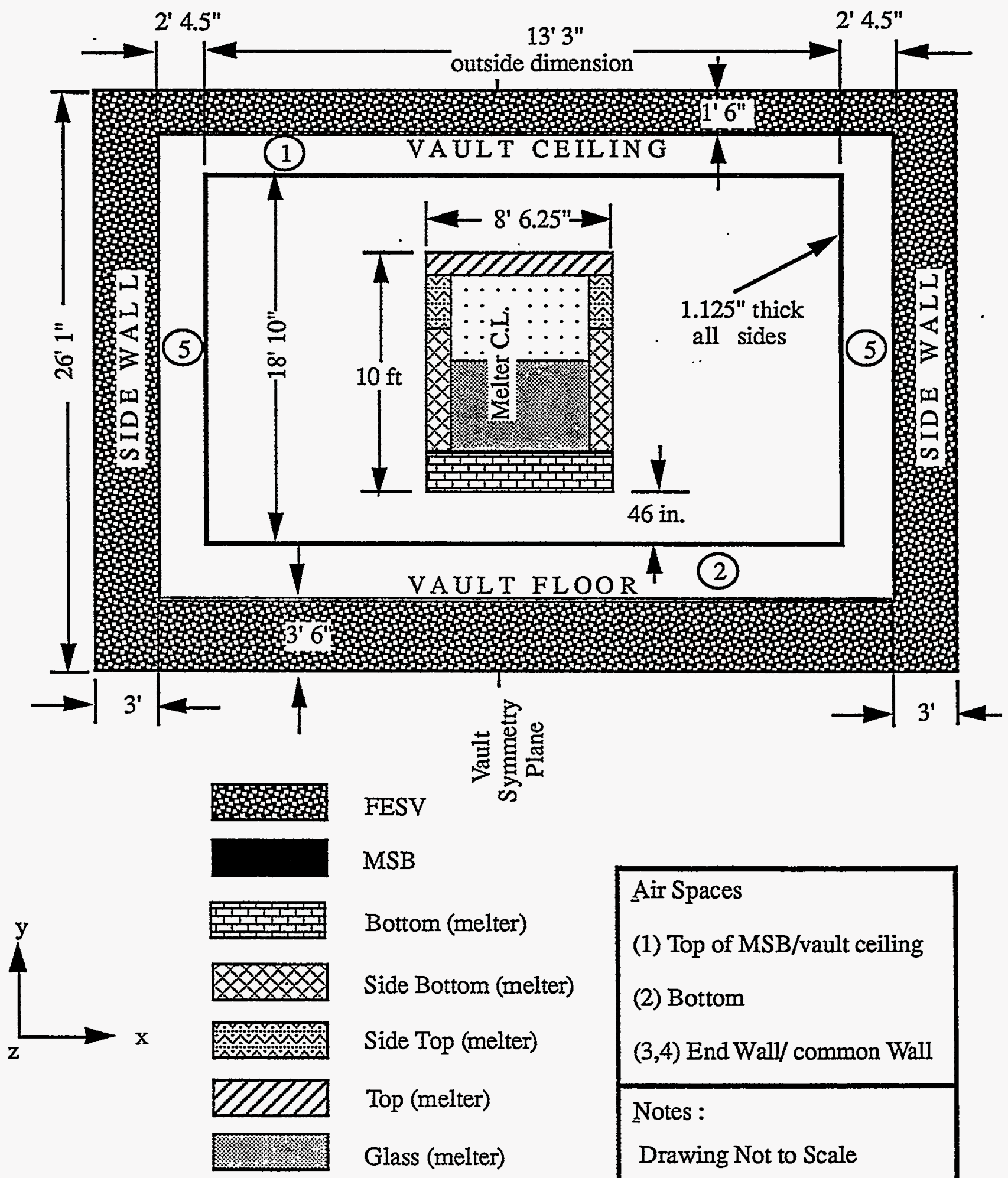

Air Spaces

(1) Top of MSB/vault ceiling

(2) Bottom

$(3,4)$ End Wall/ common Wall

Notes :

Drawing Not to Scale

Earth not shown for clarity

Figure 3 : FESV/MSB System : End View 
WSRC-TR-95-0288

pg. 8 of 60 .

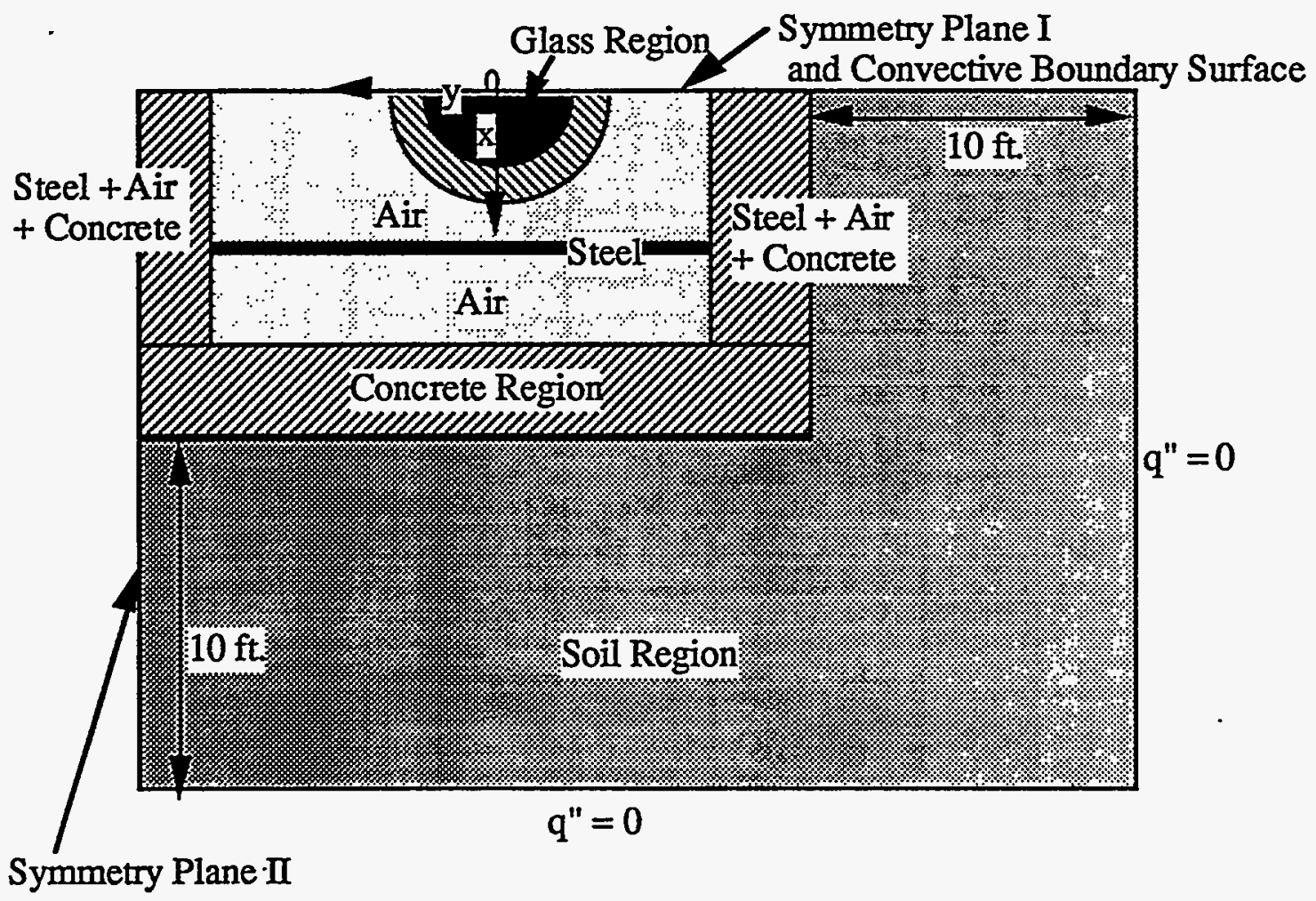

Figure 4: Top View of the CFDS-FLOW3D Model 


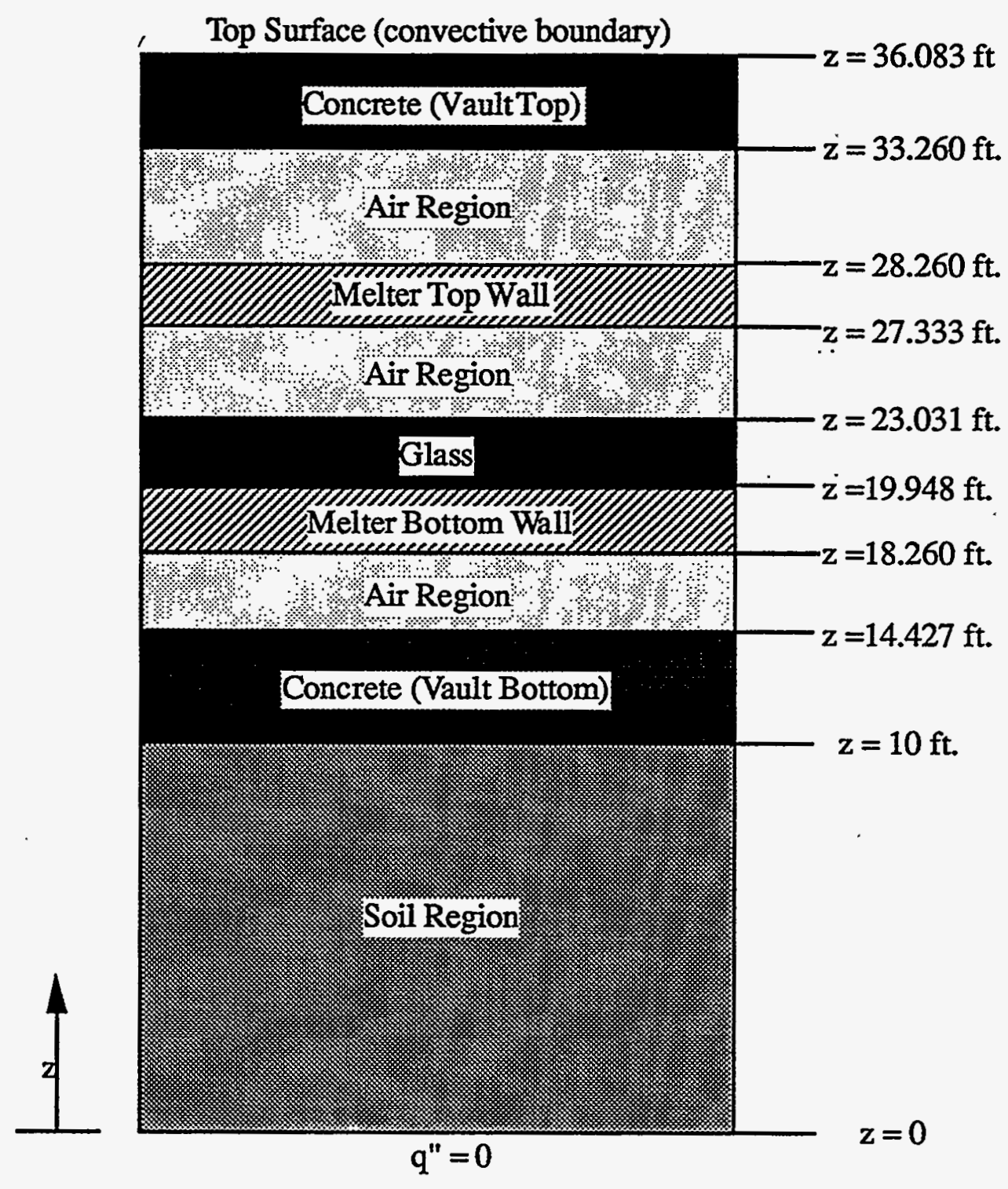

Figure 5 : Vertical View of the CFDS-FLOW3D Model along the melter Center Line.

The computer model FESV/MSB system has been simplified while retaining geometry significant to the thermal analysis. Simplifying the computer model is necessary so that it is of a reasonable size and complexity which can be accommodated on the available hardware. The 3-dimensional computer model contains both solid (i.e. concrete, MSB, surrounding soil) and fluid regions (air spaces between system components) all which must be divided into a grid of finite volumes or cells. Solving for the convective heat transfer within the air spaces requires a relatively fine grid, which then must be propagated through the solid regions. The MSB is very thin (1.125 inches) compared to the overall dimensions of the model ( 36 feet). To avoid numerical convergence difficulties the remainder of the model must be discretized using the cell size for the MSB as the basis. The fine mesh required for the air spaces and the fine cell size set by the MSB result in a 
FLOW3D computer model with approximately 63,000 cells. Non-uniform mesh grids on the $x-y$ plane of the present model are illustrated in figure 6 . Figure 7 presents the 3-dimensional grid ( 62611 cells) as modeled in the FLOW3D code. Previous experience has shown that a model with 100,000 cells is the practical limit for problems that can be solved on the available hardware.

The primary simplifications made in developing the FLOW3D computer model were elimination of the melter structural supports, combining several of the air spaces with the sides of the MSB and concrete, and ignoring features such as the lifting trunions, the lifting lugs, and air filters. The P/THERMAL computer model is identical to the FLOW3D computer model, except that all air spaces have been explicitly included. The mesh for the P/THERMAL model is illustrated in figure 8, where red represents the waste glass and green represents the melter. The MSB is shown in magenta, and the concrete appears in dark yellow. The soil and air regions are not shown for clarity.

Inside the MSB the melter rests upon a support structure, composed of widely spaced steel I-beams. The beams are spaced far apart and do not impede air flow within the MSB. The steel members absorb and emit thermal radiation but do not strongly influence the overall system temperatures. Because the support structure has an inconsequential effect on system temperatures, it has not been included in the model. The melter has been positioned within the MSB, however, as if it were resting upon the support structure. This is necessary to accurately calculate the heat flux to each of the four walls, floor, and ceiling.

The melter is modeled as an annulus with a flat top and bottom. The pour spout is not included. The inside of the melter contains a cylindrical glass heat source and air space above the glass. The simplified melter is shown in Figure 9. For computational efficiency, several of the melter materials were combined to find average thermal properties, resulting in four regions :

\author{
Bottom \\ stainless steel (1.125 inches) \\ fiberfrax (1.25 inches) \\ zirmul ( 6 inches) \\ $\mathrm{K}-3$ (12 inches)
}

$\quad$ Side Top
stainless steel ( 0.375 inches)
air $(0.5$ inches)
stainless steel ( 1.5 inches)
fiberfrax ( 0.25 inches)
korundal (11 inches)

\author{
Top \\ stainless steel ( 0.375 inches) \\ air (0.5 inches) \\ stainless steel (1.125 inches) \\ fiberfrax ( 1 inch) \\ korundal (9 inches) \\ Side Bottom \\ stainless steel ( 0.375 inches) \\ air (0.5 inches) \\ stainless steel (1.5 inches) \\ fiberfrax ( 0.75 inches) \\ $\mathrm{K}-3$ (12 inches)
}


WSRC-TR-95-0288

pg. 11 of 60 .

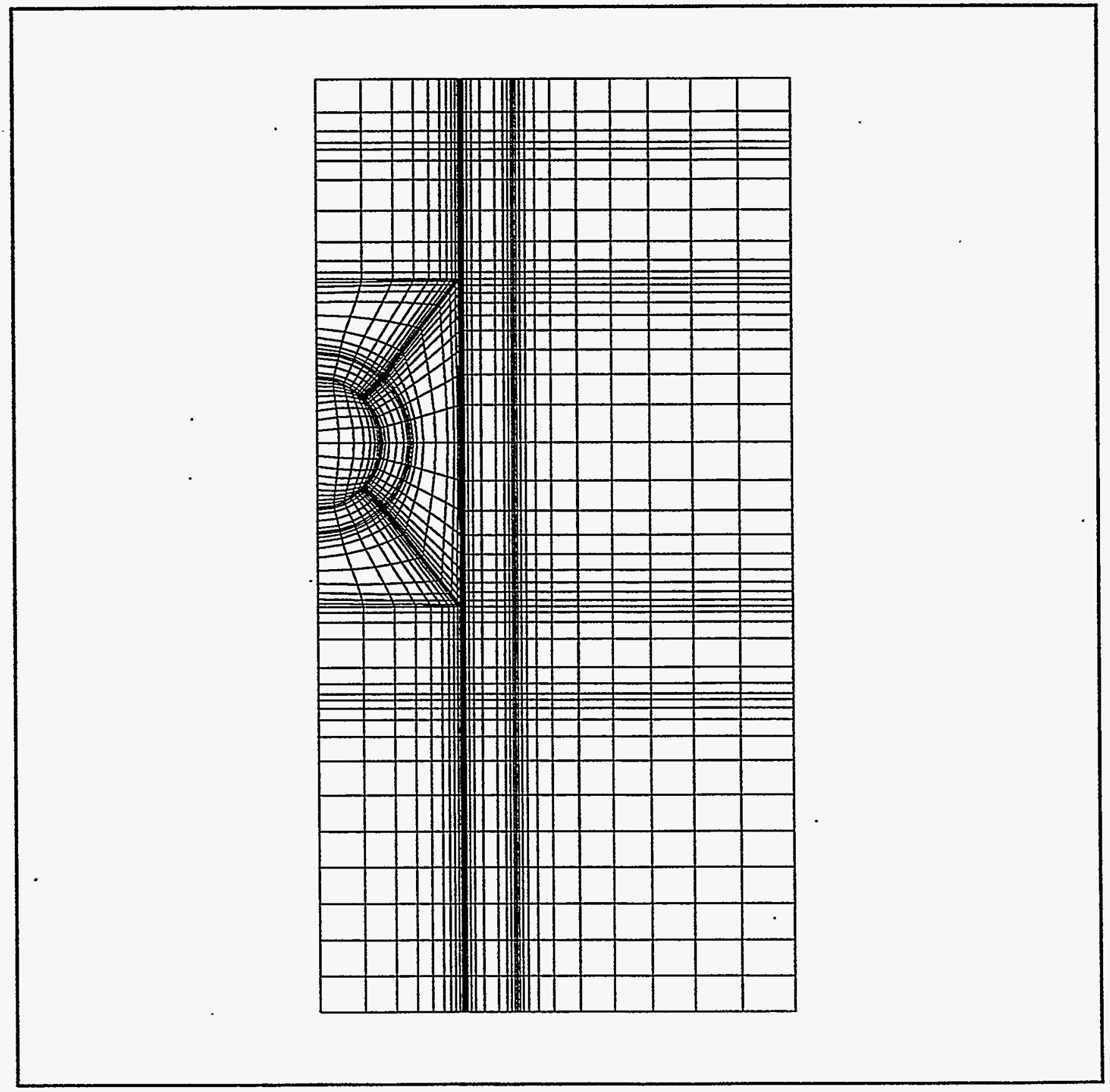

Figure 6 : FLOW3D Mesh of the $x-y$ plane for the FESV/MSB System (Top View) 
WSRC-TR-95-0288

pg. 12 of 60 .

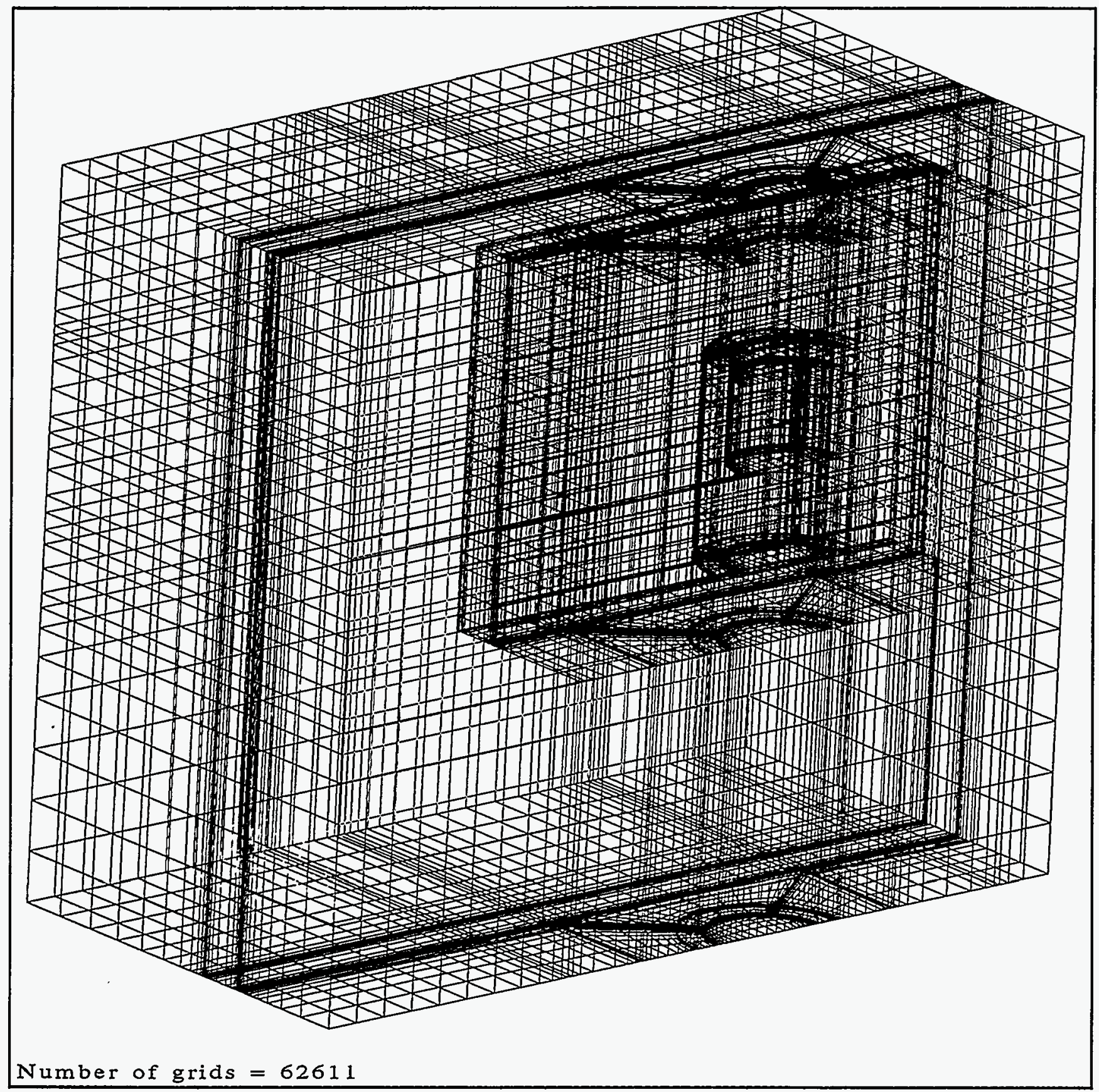

Figure 7 : FLOW3D Mesh for the FESV/MSB System (3D view) 


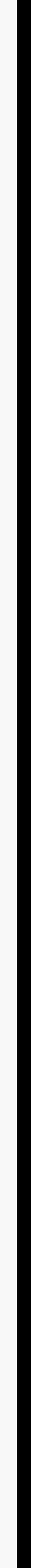


WSRC-TR-95-0288

pg. 13 of 60 .

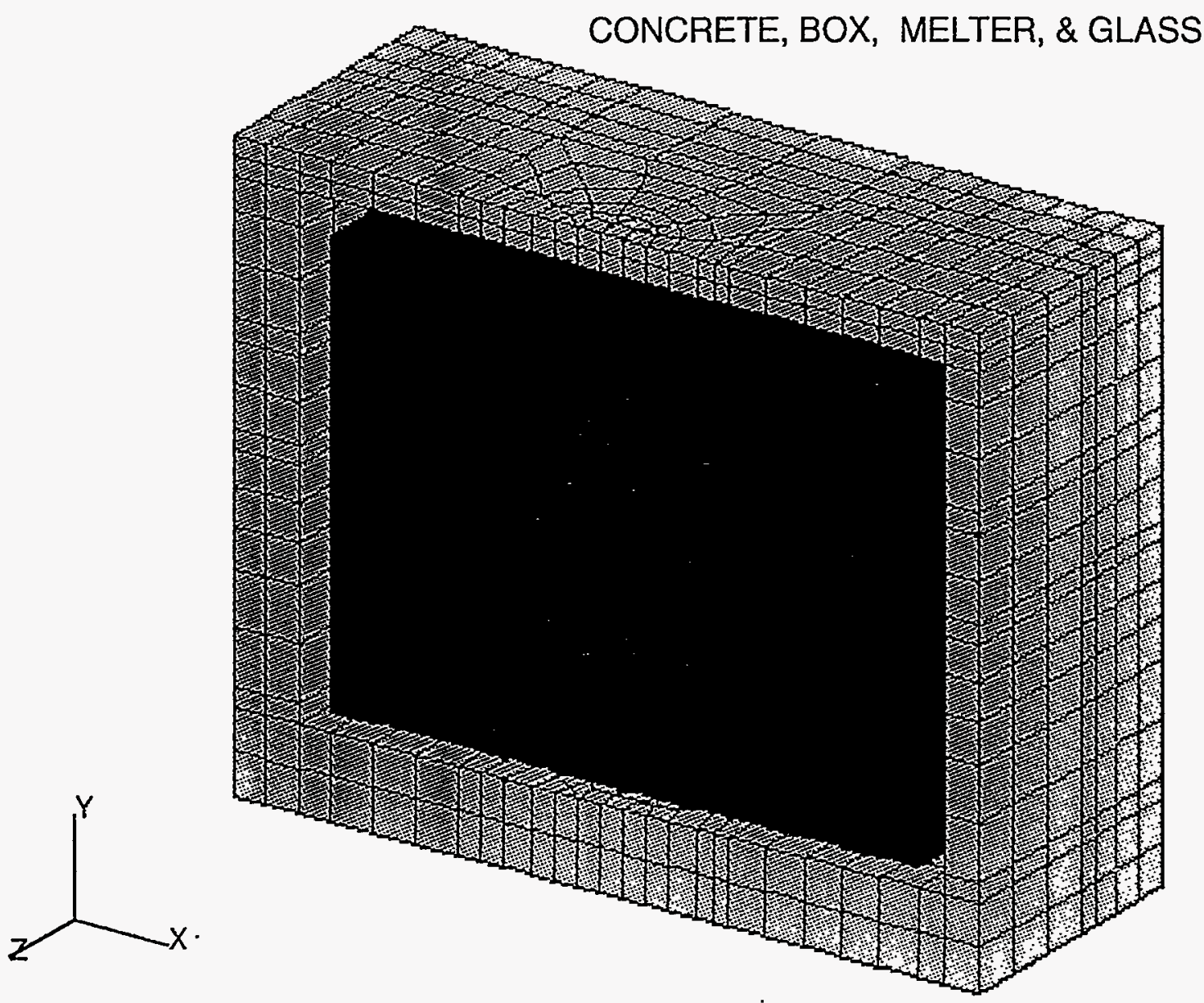

Figure 8 : P/THERMAL Mesh for the FESV/MSB System 


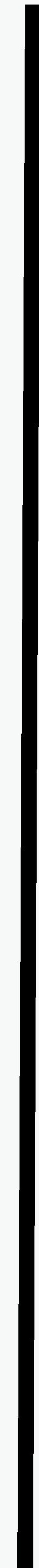


WSRC-TR-95-0288

pg. 14 of 60 .

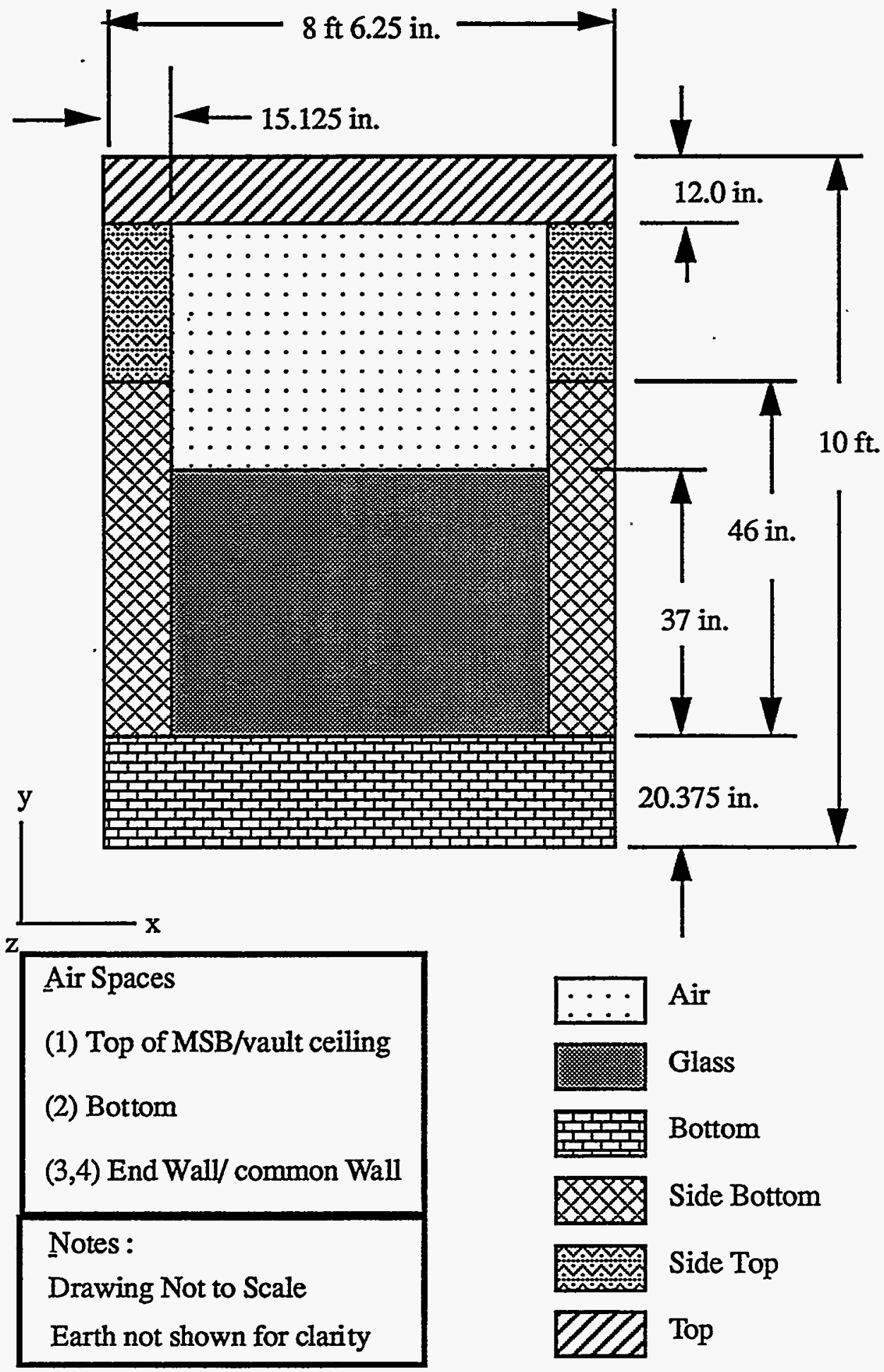

Figure 9 : Simplified Melter 
WSRC-TR-95-0288

pg. 15 of 60.

Air Spaces

There are three significant air spaces in the FESV/MSB system which have been addressed in the model : (1) the air space within the melter above the glass; (2) the air space between the melter and inside of the MSB; and (3) the air space between the MSB and concrete vault.

Preliminary analyses showed that natural convection in the first air space has a notable effect on temperatures throughout the melter wall. Accurate melter wall temperatures are required to correctly distribute the heat flux within the MSB. The air within the melter was retained as a fluid region so that natural convection would be modeled in this space.

The second air space between the melter and inside of the MSB is large and relatively unobstructed so that natural convection has a major influence on the heat transfer. The air within the MSB has also been retained as a fluid region as the effect of buoyant flow on heat transfer is significant.

Natural convection in the third air space serves to distribute the heat from the MSB to the concrete, eliminating local regions of relatively high temperatures. There are five general regions where the effect of buoyant flow on the heat transfer must be addressed. Natural convection is conservatively neglected in four of these regions; heat transfer is modeled by conduction alone where an equivalent thermal conductivity for the MSB steel wall, air, and concrete has been calculated. In the fifth region convection is included to predict realistic MSB and concrete vault temperatures. Each of these four air space regions where convection has been neglected is discussed below in detail and shown in Figure 10:

Top of the MSB and ceiling of the vault - region 10 (space of $1 \mathrm{ft}, 4 \mathrm{in}$.)

Heat generated from the melter will heat this air space from below, causing an unstable flow pattern. The top of the MSB is sufficiently far from the melter $(5 \mathrm{ft}$.) relative to the other MSB surfaces and will not experience a high localized heat flux.

Bottom - region 3 (space of 10 in.)

The MSB rests upon seven I-beams which in turn rest upon the concrete vault floor. The I-beams extend the full width of the MSB, approximately 13 feet. The air flow is blocked by the I-beams from moving lengthwise in the vault. Furthermore, the air in this space is heated by the melter from the top down, so that the air stratifies and reaches a stable configuration.

End wall - region 8 (space of $1 \mathrm{ft} 4 \mathrm{in}$ ) and Common wall - region 7 ( $1 \mathrm{ft} 3 \mathrm{in}$.) Approximately $16 \mathrm{ft}$ above the bottom of the vault floor, I-beams are attached along the side of the MSB and extend 11 inches into the air spaces. The Ibeams partially retard the buoyant flow, limiting the ability of the air to distribute heat by convection. Air flow in this region is restricted.

The largest of the five regions exists between the MSB and vault side wall, permitting the air to move freely in this region. The air space in this region is $2 \mathrm{ft}$, 4 inches wide. Furthermore, the melter will be positioned in the MSB much closer to the side walls ( $2 \mathrm{ft}, 4 \mathrm{in}$.) than to the end walls ( $8 \mathrm{ft}, 9 \mathrm{in}$.), providing a 
WSRC-TR-95-0288

pg. 16 of 60 .

I. Horizontal plane of FESV surrounded by 10-foot soil region:

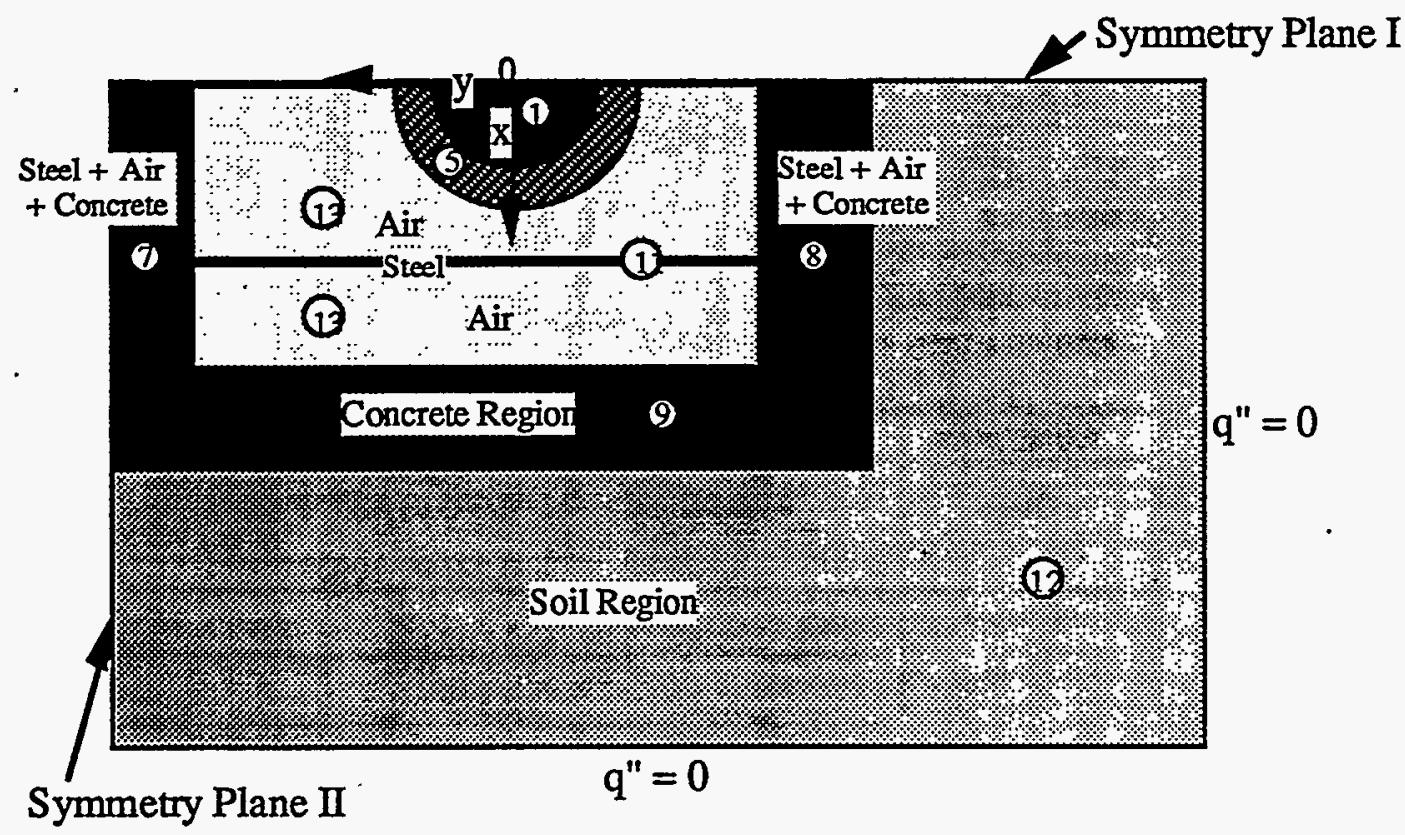

II. Verfical plane of FESV along the symmetry plane I:

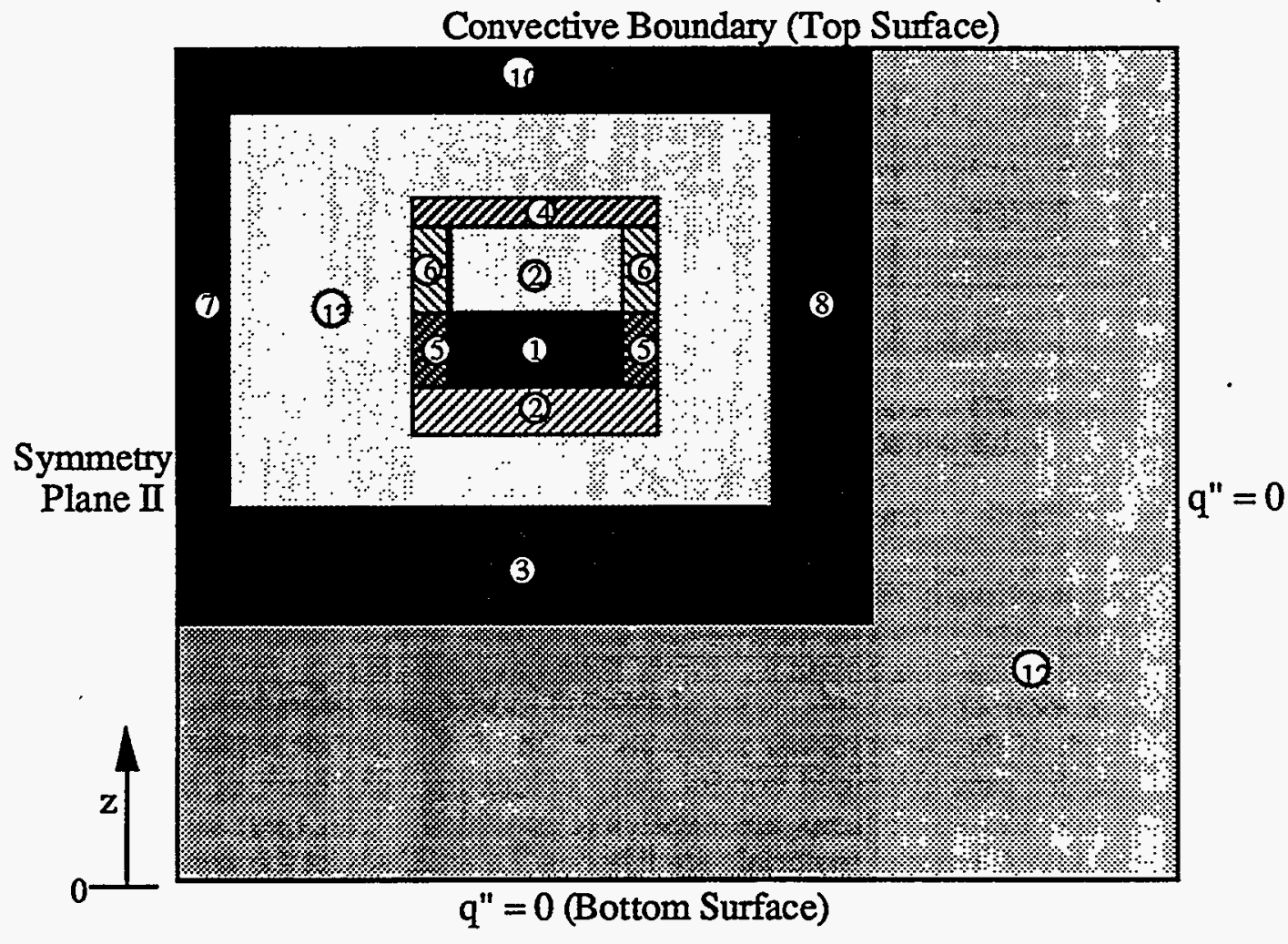

Figure $10:$ Material Zones in the CFDS-FLOW3D Model 
WSRC-TR-95-0288

pg. 17 of 60 .

higher localized heat flux in the side walls. Natural convection for this region cannot be ignored and is included in the model.

\subsection{Materials}

FESV/MSB system components, their basic materials and associated thermal properties required for the P/THERMAL analyses are shown in Table 1. Temperature dependent thermal conductivity was available for the waste glass, carbon steel MSB, and air. Linear interpolation was used to calculate conductivity at temperatures between those found in Table 1 .

\begin{tabular}{|c|c|c|c|}
\hline Component & Material & Conductivity (Btu/hr-ft- $\left.{ }^{\circ} \mathrm{F}\right)$ & Emissivity \\
\hline Glass & Waste Glass & $\begin{array}{l}0.605 @ 400^{\circ} \mathrm{F}[2] \\
0.823 @ 1000^{\circ} \mathrm{F}\end{array}$ & $1.0^{*}$ \\
\hline \multirow{5}{*}{ Melter } & Zirmul & $1.083[3]$ & - \\
\hline & $\mathrm{K}-3$ & $2.167[4]$ & $1.0^{*}$ \\
\hline & Korundal & $1.833[5]$ & $1.0^{*}$ \\
\hline & Fiberfrax & $0.0542[6]$ & $=$ \\
\hline & Stainless Steel & $9.4[7]$ & $0.6[9]$ \\
\hline MSB & Carbon Steel & $\begin{array}{l}26.5 @ 32^{\circ} \mathrm{F}[8] \\
26.0 @ 212^{\circ} \mathrm{F} \\
25.0 @ 572^{\circ} \mathrm{F} \\
22.0 @ 932^{\circ} \mathrm{F}\end{array}$ & $0.85[8]$ \\
\hline Air spaces & Air & $\begin{array}{l}0.014 @ 32^{\circ} \mathrm{F}[7] \\
0.018 @ 212^{\circ} \mathrm{F} \\
\end{array}$ & - \\
\hline Earth & Earth & 0.54 [8] & $0.9[8]$ \\
\hline Vault & Concrete (1-2-4 Stone) & $0.75[8]$ & $0.9[8]$ \\
\hline
\end{tabular}

${ }^{*}$ value conservatively estimated

Table 1: Basic Materials and Thermal Properties in the P/THERMAL Model

As previously discussed, it was necessary to simplify the melter into three material zones and combine four of the air regions with the adjacent concrete and carbon steel. The composite materials then have an average thermal conductivity of the component materials. The FLOW3D model uses averaged conductivity values for each of the three melter zones and each of the four air regions. The P/THERMAL model uses averaged conductivity values for only each of the three melter zones since the air regions are explicitly modeled. The thermal conductivity for the FLOW3D model materials are listed in Table 2, where the zone number corresponds to the material zone of figure 10 . 
WSRC-TR-95-0288

pg. 18 of 60.

\begin{tabular}{|c|l|c|}
\hline $\begin{array}{c}\text { Material Zone No. } \\
\text { in Fig. 10 }\end{array}$ & Structural Material Region & $\begin{array}{c}\text { Thermal Conductivity } \\
\left.\text { (Btu/hr-ft- }{ }^{\circ} \mathrm{F}\right)\end{array}$ \\
\hline (1) & Glass region & 0.714 \\
\hline (2) & Melter bottom wall & 0.595 \\
\hline (3) & Vault bottom wall & 0.088 \\
\hline (4) & Melter top wall & 0.262 \\
\hline (5) & Melter side wall (lower region) & 0.406 \\
\hline (6) & Melter side wall (upper region) & 0.452 \\
\hline$\dot{(0)}$ & Common vault wall & 0.0392 \\
\hline (8) & Vault side wall & 0.0577 \\
\hline (9 & Vault side wall (concrete) & 0.7502 \\
\hline (10) & Top vault wall & 0.0409 \\
\hline (11) & Carbon steel & 25.5047 \\
\hline (12) & Soil region & 0.5421 \\
\hline (13) & Air region & 0.0183 \\
\hline
\end{tabular}

Table 2. Themal Properties for Each Material Zone in the FLOW3D Model.

\subsection{Boundary Conditions}

\subsubsection{Temporal Aspects}

The temperature of the FESV/MSB system varies throughout the year depending upon the season and environmental conditions The system has a large thermal mass which causes the temperatures within the FESV to lag considerably behind those of the immediate environment ( such as air and earth temperature ). The rise or fall of temperature within the FESV is affected by system energy storage. Although the maximum system temperatures are expected to occur during the summer months, the thermal inertia of the system will tend to moderate the temperature increase due to the lower temperatures of the winter months. The seasonal temperature variations suggest transient analysis of the FESV/MSB system. Diurnal variations in air temperature and the solar flux are short relative to the thermal inertia of the FESV/MSB system and can be averaged for a 24-hour period without an appreciable impact on system temperatures, as described in Appendix A. 
Although temperatures within the FESV/MSB system will change over the seasons, a steady-state analysis will yield conservative temperatures. The steady-state analysis ignores heat stored in materials and simulates an infinite summer condition using a chosen air temperature. To predict maximum system temperatures, a steadystate model with an air temperature representative of summer conditions has been chosen for analysis. To predict more realistic system temperatures, the steady-state model using the yearly average air temperature has also been run.

\subsubsection{Ambient Air Temperature}

Monthly average temperatures for SRS have been recorded and tabulated for the period between 1961 to 1992[10]. The average seasonal temperatures are shown below:

$\begin{array}{ll}\text { Winter } & 58.5^{\circ} \mathrm{F} \\ \text { Spring } & 76.3^{\circ} \mathrm{F} \\ \text { Summer } & 90.6^{\circ} \mathrm{F} \\ \text { Fall } & 76.4^{\circ} \mathrm{F} \\ \text { Yearly average } & 75.5^{\circ} \mathrm{F}\end{array}$

\subsubsection{Solar Flux}

The solar radiation impinging upon the concrete vault lid and surrounding soil has been determined from a solar map giving constant mean daily solar radiation in the continental United State for June [11]. The solar radiation constant does not vary drastically over small geographical areas; for example, the mean daily solar radiation constant for Atlanta is $2074 \mathrm{Btu} / \mathrm{ft}^{2}$ and for Charleston it is $2081 \mathrm{Btu} / \mathrm{ft}^{2}$. Using the higher value for Charleston, the solar radiation averaged over a 24-hour day is $86.7 \mathrm{Btu} / \mathrm{hr}-\mathrm{ft}^{2}(2081 / 24)$. A constant heat flux of $86.7 \mathrm{Btu} / \mathrm{hr}-\mathrm{ft}^{2}$ has been applied to the concrete vault lid and soil to simulate solar radiation. The solar absorptivity of $0.6[8]$ was assigned to both the concrete and soil.

\subsubsection{Radiative Loss to Sky}

The top of the concrete lid and soil surface radiate heat to the sky. The sky temperature has been conservatively estimated at $54^{\circ} \mathrm{F}$ [12], which is for warm, cloudy-sky conditions. For comparison the sky temperature on a clear, cold night can be taken to be $-45^{\circ} \mathrm{F}$. In this analysis a sky temperature of $54^{\circ} \mathrm{F}$ is used to minimize radiative losses to the environment and predict maximum FESV/MSB temperatures. Radiative loss to the sky is independent of the incident solar flux.

\subsubsection{Soil}

The earth surrounding the vault has been estimated to be composed of an $80 \%$ sand, $20 \%$ clay-sand mixture [13] with a $40 \%$ to $60 \%$ moisture content. Test wells in $S$ area monitored by the Environmental Monitoring Section also show that the water table is typically between 35 to 40 feet below grade. Temperatures for the water table and ambient are also measured at these wells. At the end of the first quarter (3/31) of 1994 an average water temperature (based upon four wells) of $63^{\circ}$ $\mathrm{F}$ was obtained with a $53^{\circ} \mathrm{F}$ ambient temperature. At the end of the third quarter $(9 / 31)$ of 1994 an average water temperature (based upon two wells) of $70^{\circ} \mathrm{F}$ was obtained with a $75^{\circ} \mathrm{F}$ ambient temperature. Not all wells are tested each quarter.

Heat is conducted from the concrete vault into the surrounding earth. The outer boundary of the earth is insulated in the computer model to provide conservative temperature predictions. It is likely that the moving ground water will also 
WSRC-TR-95-0288

pg. 20 of 60.

transport heat from the vault by advection. However, this phenomena is difficult to quantify without significant effort, and is ignored in the model since it will only lower temperatures within the FESV/MSB system.

Insulating the earth boundary forces all $3000 \mathrm{~W}$ of heat generated within the melter to leave the system by convection to the atmosphere. As shown in Appendix B, including 65 feet of soil around the vault walls provides a sufficient surface area for heat convection. Using a lesser amount of soil would tend to increase the model temperatures. Because of computational limitations, only 10 feet of soil from the vault walls and floor was included in the FLOW3D model. To test temperature sensitivity to the amount of soil modeled, two P/THERMAL models were completed with 10 feet and 40 feet of soil surrounding the concrete. The P/THERMAL model with 40 feet of soil predicted temperatures about $10^{\circ} \mathrm{F}$ less than the model with 10 feet of soil. In the FLOW3D model, then, 10 feet is a computationally practical and conservative amount of soil for the conduction/convection model.

\subsubsection{Heat Generation}

The melter is modeled as if it were to fail with a melt pool full of waste glass. The height of the melt pool is 37 inches. The total decay power of the radioisotopes in the glass is $3000 \mathrm{~W}$ which is uniformly distributed.

\subsubsection{Convective Heat Loss}

Natural convection from the soil and concrete remove heat from the vault to the atmosphere. The atmosphere is assumed to remain constant at the ambient temperature. The convective coefficient has been estimated at $0.44 \mathrm{Btu} / \mathrm{hr}-\mathrm{ft}^{2}-^{\circ} \mathrm{F}$, which is slightly more than convection to stagnant air, representing a light wind of $2.5 \mathrm{mph}$. Data [14] taken at SRS show the average wind speed is $7.6 \mathrm{mph}$ during the summer and $9.2 \mathrm{mph}$ during the winter, measured 200 feet above the ground. At ground level these values reduce to approximately $5 \mathrm{mph}$ for the summer and 7 $\mathrm{mph}$ for the winter. Since the convective heat transfer increases with increasing wind, assuming a low wind speed of $2.5 \mathrm{mph}$ provides conservative FESV/MSB system temperatures.

\section{Convective Heat Transfer Coefficient}

The local heat transfer coefficient, $h_{x}$, was obtained using the integral momentum and energy balances for the boundary layer control volume on a horizontal flat surface to include the effect of wind speed. The derivation is given in full in Appendix C. The resulting equation for $h_{x}$ becomes

$$
h_{x}=0.3233\left(\frac{k}{x}\right)(\operatorname{Pr})^{0.333} \sqrt{\operatorname{Re}_{x}}
$$

where

$$
\operatorname{Re}_{\mathrm{x}}=\frac{\rho \mathrm{u}_{\infty} \mathrm{x}}{\mu}
$$

The present analysis used the heat transfer coefficient averaged over the length, $h_{\text {avg, that is, }}$ 


$$
\begin{aligned}
& h_{\text {avg }}=\frac{1}{L} \int_{0}^{x=L} h_{x} d x \\
& =0.6466\left(\frac{k}{L}\right)\left(P_{r}\right)^{0.333} \sqrt{R_{L}}
\end{aligned}
$$

Figure 11 shows the computed values for $h_{\text {avg }}$ as a function of ground wind speed $\left(u_{\infty}\right)$ for the present problem. From this result, our present number for $h_{\text {avg }}$ of

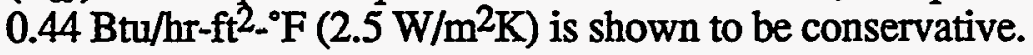

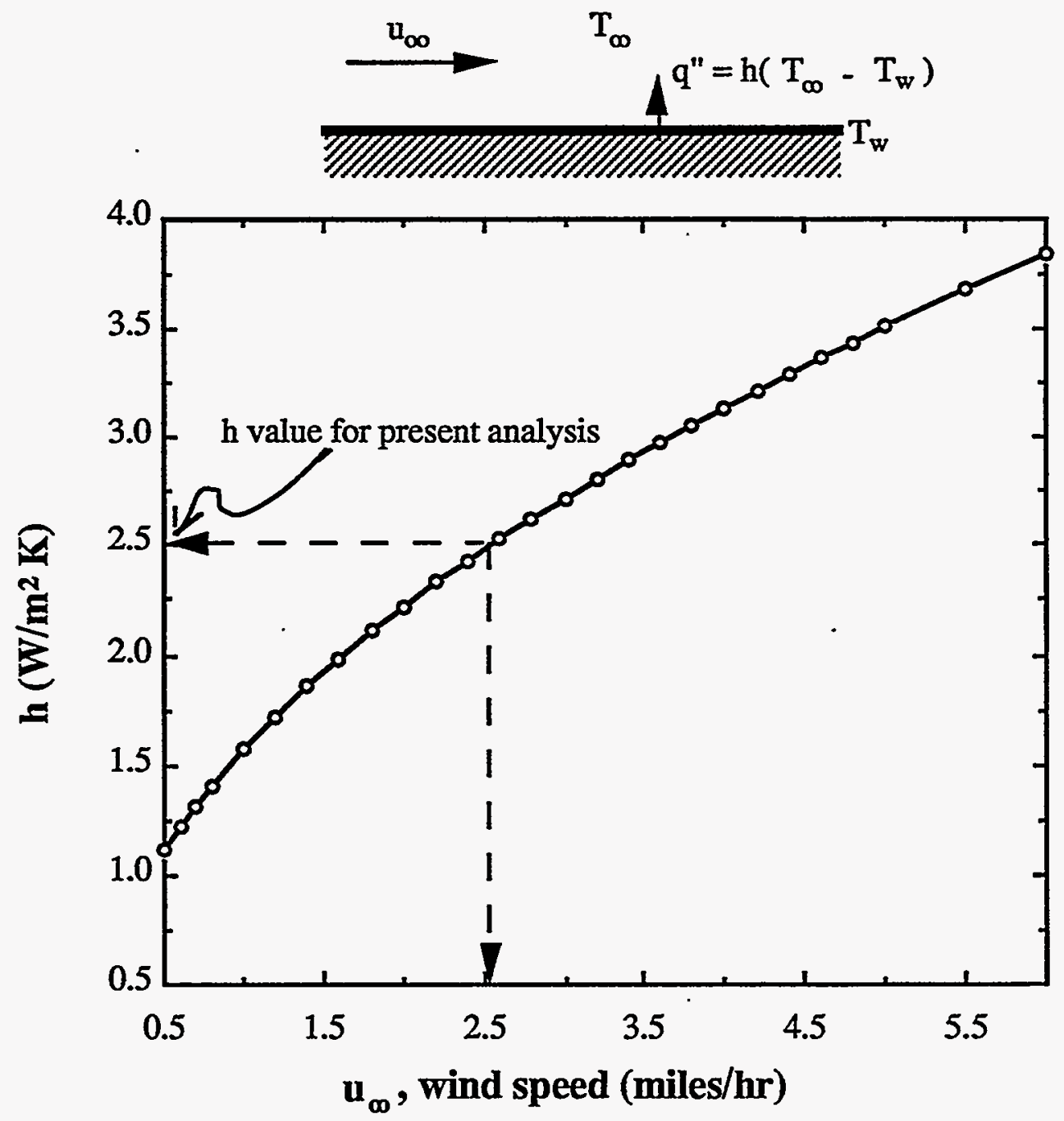

Figure 11 : Heat Transfer Coefficient on the Top Surface of FESV Structure 
WSRC-TR-95-0288

pg. 22 of 60.

\subsection{Conservatisms}

Several conservatisms in boundary conditions for the FESV/MSB models will cause temperatures to be predicted at their higher bounds. These conservatisms have been discussed in detail in the preceding sections and are itemized below to summarize :

(1) The earth boundary is insulated;

(2) the amount of soil surrounding the vault is limited to 10 feet for the FLOW3D model and 40 feet for the P/THERMAL model, where it has been estimated that the heat generated dissipates throughout 65 feet of earth;

(3) a minimum wind speed of $2.5 \mathrm{mph}$ is used for determining convective heat transfer,

(4) the summer solar flux is applied as the yearly average; and

(5) a sky temperature for warm, cloudy-sky conditions is used in determining radiative heat loss from the vault.

\subsection{Results}

4.1 FLOW3D Conduction/Convection Model

CFDS-FLOW3D (version 3.3) CFD code has been used to model the 3dimensional temperature distribution within the FESV structure. The CFD analysis was mainly made for the temperature distributions and the buoyancy-driven flow field induced by the temperature gradient within an enclosed environment. Air temperature decreases rapidly due to the convective cooling effect within a boundary layer region adjacent to the wall surface, as shown in the graphical results to follow. The boundary layer flow is a buoyancy-induced motion resulting from body forces acting on density gradients which, in turn, arise from temperature gradients in the fluid. For the present analysis, the natural convection regime within the FESV is assumed to be laminar.

Temperatures for the FLOW3D conduction/convection model are presented in Table 3 for an ambient air temperature of $90^{\circ} \mathrm{F}$. The temperatures shown in Table 3 do not include a solar flux or radiative heat loss to the sky. The three different material zones of the common wall region were modeled as a single homogeneous material zone composed of the carbon steel of the MSB, the concrete common wall, and the air region near the common wall. Concrete temperature of the wall was then computed by interpolation based upon material thickness using the series resistance concept [11].

\begin{tabular}{|c|c|c|l|l||}
\hline FESV/MSB & Temperature & \multicolumn{2}{|c|}{ Model Temperatures $\left({ }^{\circ} \mathrm{F}\right)$} & \multirow{2}{*}{$\begin{array}{c}\text { FLOW3D Model } \\
\text { Component }\end{array}$} \\
\cline { 3 - 4 } Limit $\left({ }^{\circ} \mathrm{F}\right)$ & Maximum & Minimum & Location of Maximum \\
\hline Concrete & $150 / 200$ & 169 & 95 & common wall \\
\hline MSB & 650 & 174 & 160 & side nearest common wall \\
\hline Glass & 824 & 843 & 450 & center of glass pool \\
\hline
\end{tabular}

Table 3 : FESV/MSB System Temperatures $\left({ }^{\circ} \mathrm{F}\right)$ for FLOW3D Model

The color codes of the following FLOW3D graphical results for the temperature contour and velocity vector plots are denoted in SI units. Figures 12 and 13 present 
WSRC-TR-95-0288

pg. 23 of 60 .

temperature contour plots at the $\mathrm{x}=0$ vertical plane (symmetry plane $I$ in figure 4) and the $y=0$ plane, respectively. The graphical result in Figure 12 shows that the common wall region is hotter than any of the other FESV vault walls. Natural convective velocity plots of the air regions corresponding to the temperature fields in figures 12 and 13 are shown in figures 14 and 15, respectively. The results clearly show that the hot gas near the glass region with the internal heat source travels upward due to buoyancy, mixes with air below the top surface of the MSB which is cooled by convection, and then goes downward along the cooler MSB wall. This is consistent with natural convection phenomena in the literature.

Figure 16 presents a temperature contour plot at the mid-height plane of the FESV $(\mathrm{z} \approx 13$ feet). Two-dimensional wall temperature contour plots for the MSB carbon steel wall and concrete inner surface of the common wall region are shown in figures 17 and 18, respectively. It is noted that the heat generated.within the glass waste region is mainly dissipated by the top surface having a convective boundary condition. Figure 19 shows the air velocity vector plots on the computational flow field for three different elevation heights (16', 23', and 31').

The temperature gradient at key locations throughout the FESV/MSB system are presented in the next seven figures. The origin for elevation (model z-direction) is the bottom of the earth surrounding the vault, as was shown in Figure 5. The origin for the model $\mathrm{x}$ - and $\mathrm{y}$-coordinates is the centerline of the glass pool.

The maximum temperature of the glass region is $843^{\circ} \mathrm{F}$ near the center of the glass pool as shown in Figure 20. It is noted that air temperature is uniform except for the thin boundary layer region near the wall surface as shown in the literature. Maximum temperatures for the carbon steel wall of MSB and concrete wall surface of the FESV structure occurred near the upper level of the common wall region (elevation height approximately $13 \mathrm{ft}$. from the bottom of FESV). The detailed results are shown in Figure 21.

As explained in section 3.0, in order to have a tractable computational model the air region outside of the MSB in the FLOW3D model includes only the largest air pocket. Figure 22 shows detailed temperature distributions along the z-direction for each of the different material zones : (1) along the melter wall closest to the MSB;

(2) along the MSB wall closest to the melter; and (3) along the concrete wall closest to the melter. In addition, Figure 23 presents the horizontal temperature distribution at the mid-height of the FESV structure. The buoyancy-driven velocity distribution corresponding to the temperature profile of Figure 23 is shown in Figure 24. Lastly, Figure 25 plots the temperature for the concrete lid top surface at the plane where $\mathrm{x}=0$. 
WSRC-TR-95-0288

pg. 24 of 60.

Temperature (K)

$7.2334 \mathrm{E}+02$
$6.5400 \mathrm{E}+02$
$5.8466 \mathrm{E}+02$
$5.1532 \mathrm{E}+02$
$4.4598 \mathrm{E}+02$
$3.7664 \mathrm{E}+02$
$3.0730 \mathrm{E}+02$

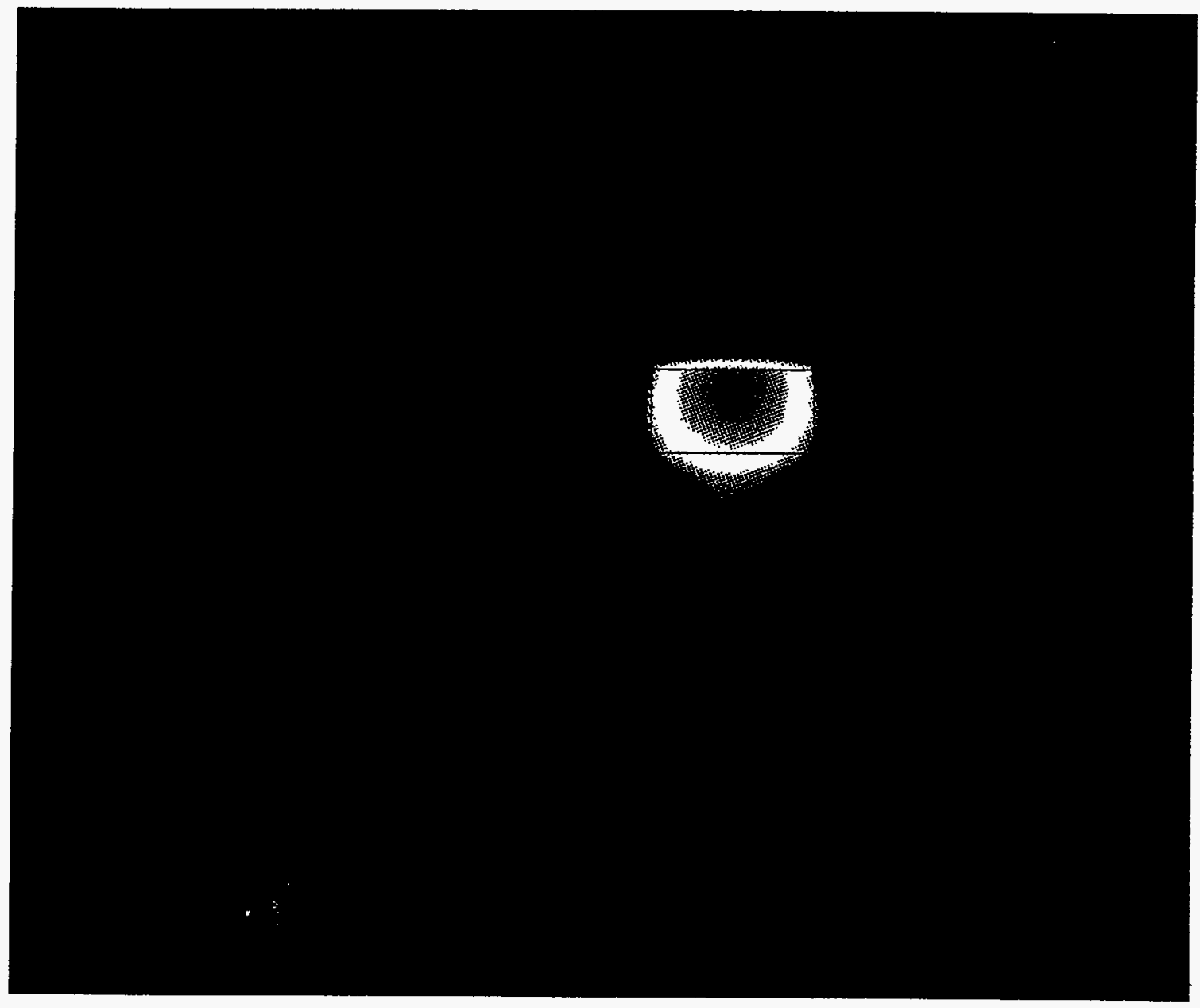

Figure 12 : Temperature Contour Plots at the $x=0$ Plane for the FLOW3D Model 

WSRC-TR-95-0288

pg. 25 of 60 .

Temperature (K)

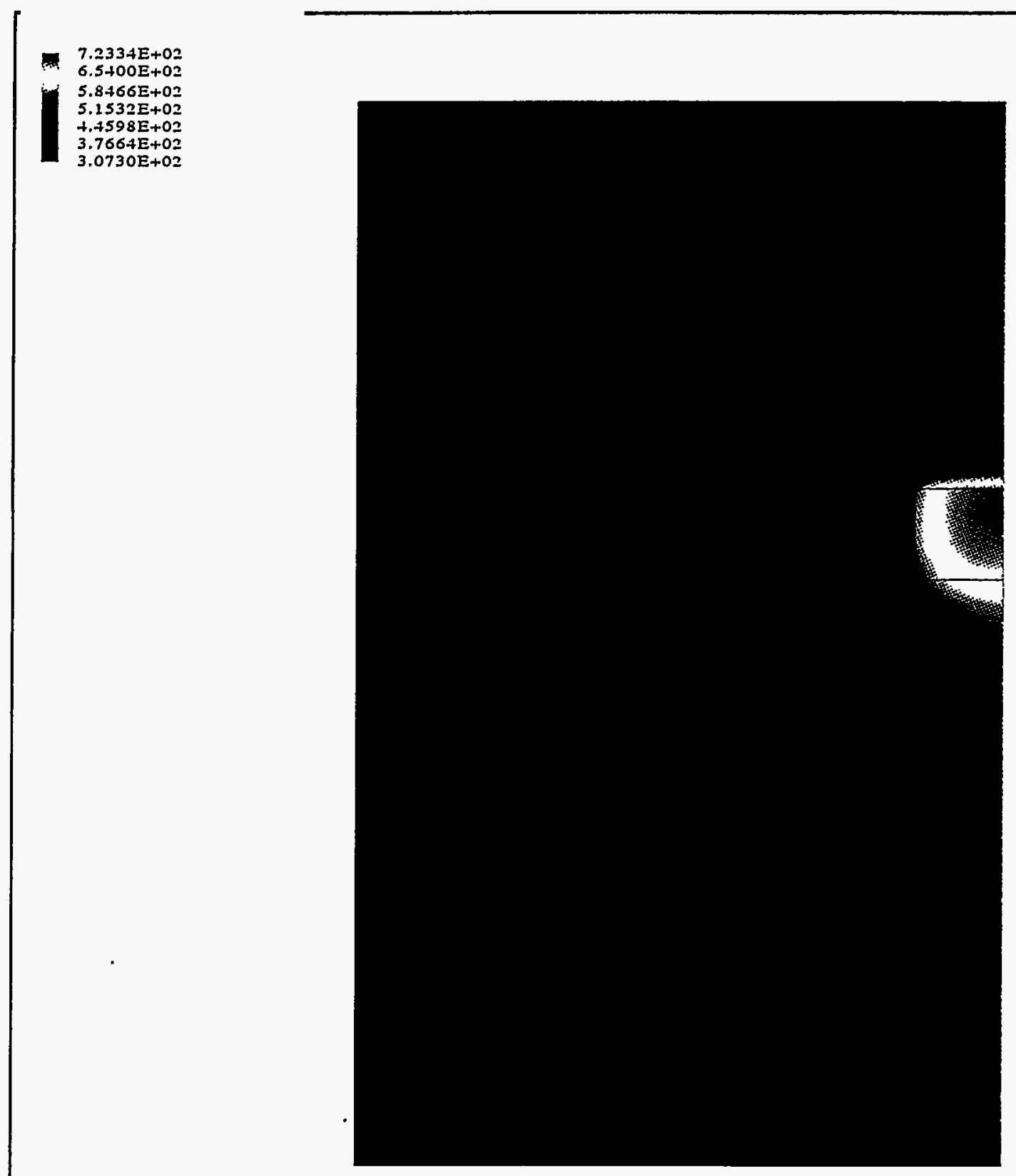

Figure 13 : Temperature Contour Plots at the $y=0$ Plane for the FLOW3D Model 

WSRC-TR-95-0288

pg. 26 of 60 .

\section{Velocity $(\mathrm{m} / \mathrm{s})$}

$7.883+E-01$

$6.5695 \mathrm{E}-01$

$5.2556 E-01$

3.9417E-01

$2.6278 \mathrm{E}-01$

$1.3139 \mathrm{E}-01$

$0.0000 E+00$

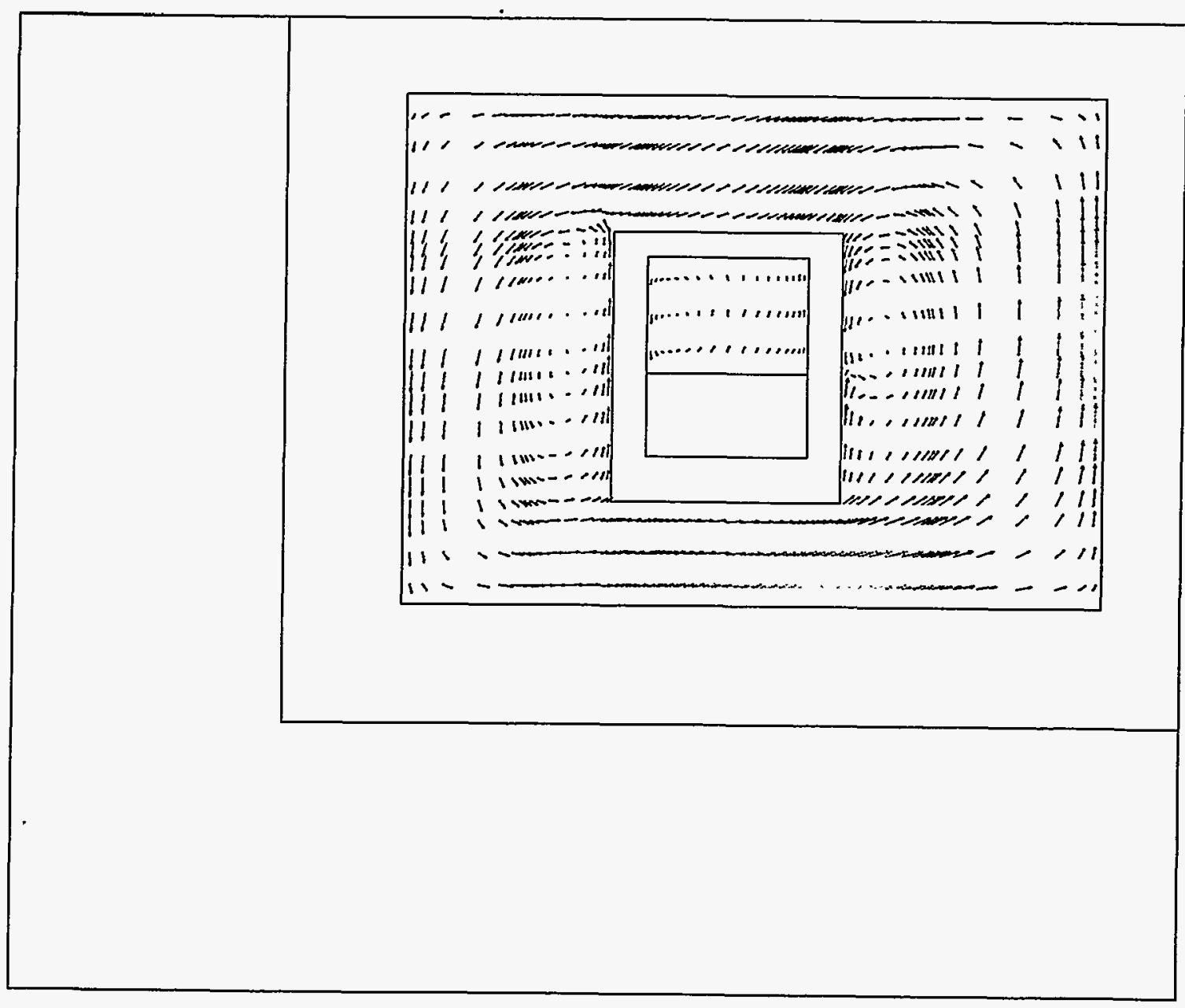

Figure 14 : Velocity Plots at the $\mathrm{x}=0$ Plane for the FLOW3D Model 

WSRC-TR-95-0288

pg. 27 of 60 .

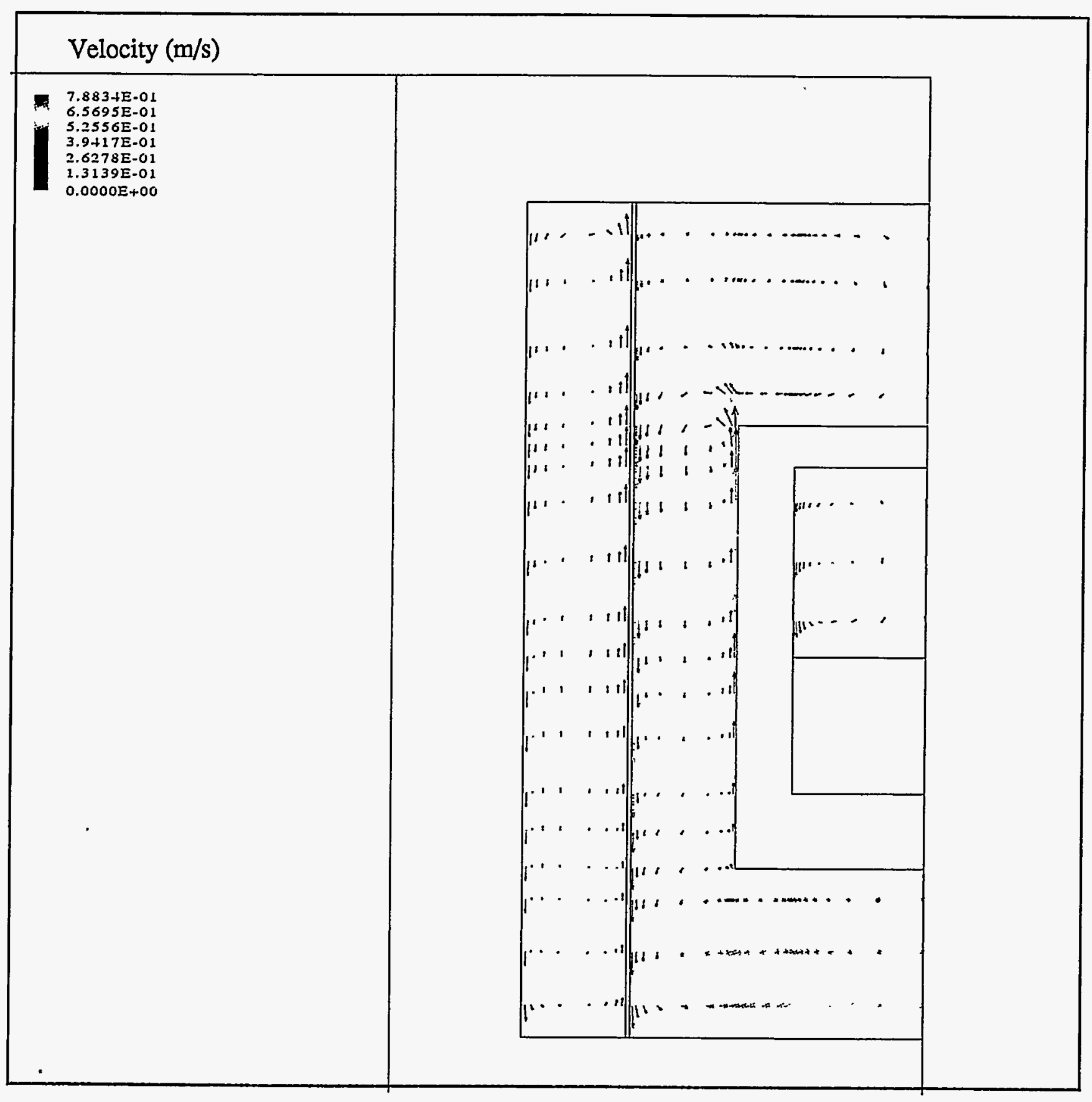

Figure 15 : Velocity Plots at the $y=0$ Plane for the FLOW3D Model 

WSRC-TR-95-0288

pg. 28 of 60.

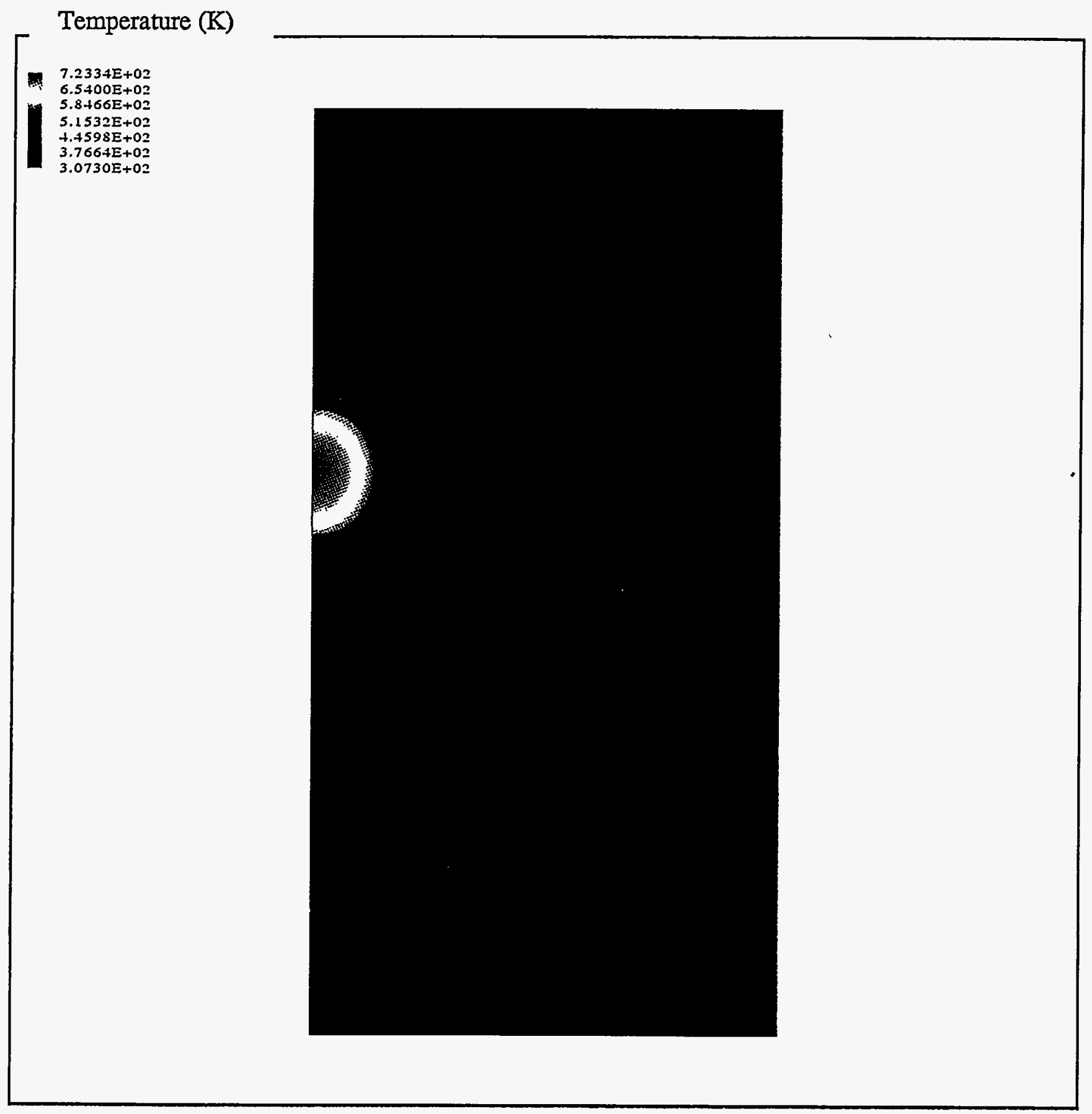

Figure 16: Temperature Plot at Mid-Height Plane for the FLOW3D Model 

WSRC-TR-95-0288

pg. 29 of 60.

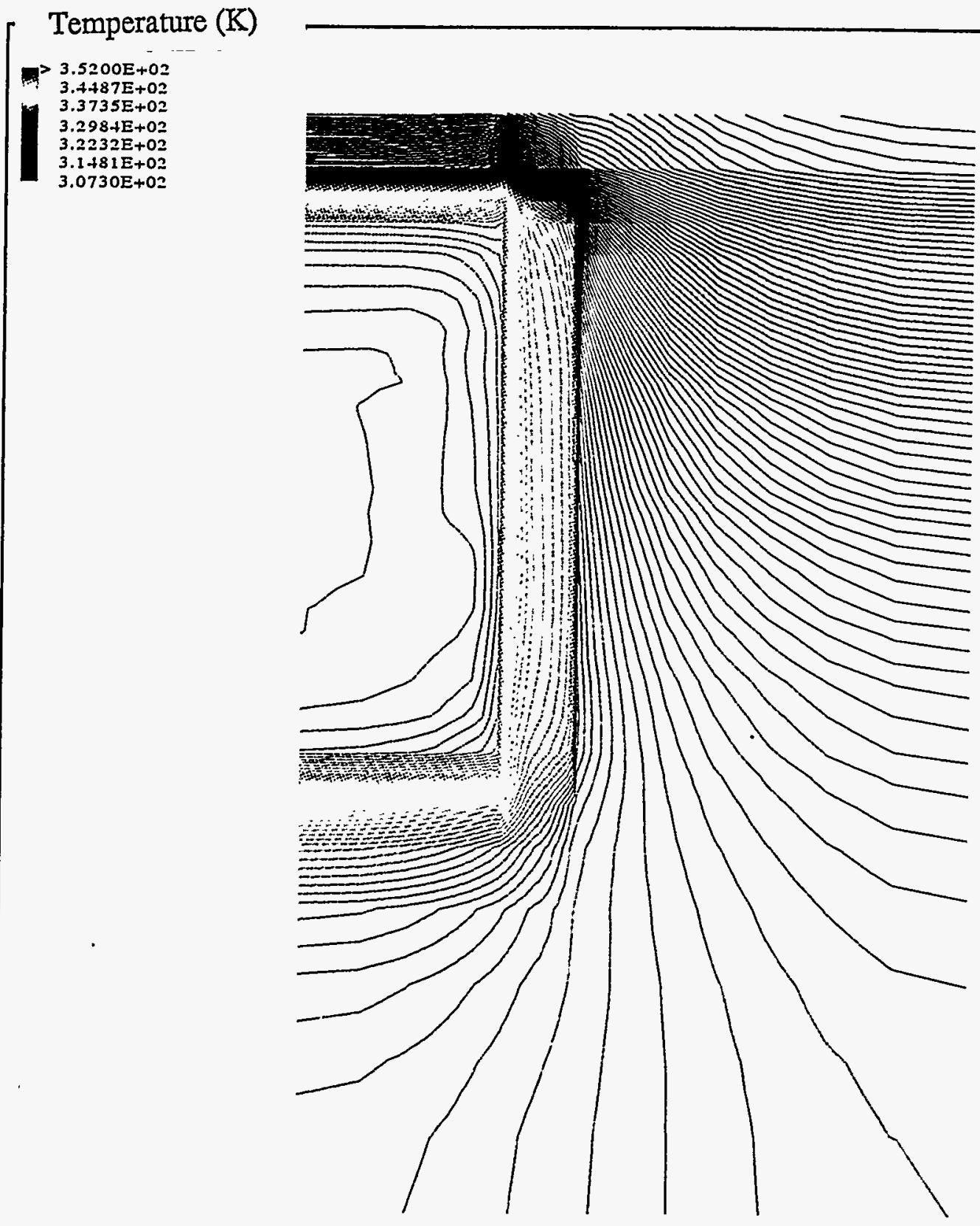

Figure 17 : Temperature Contour Plot for the MSB Side Closest to the Common Wall 


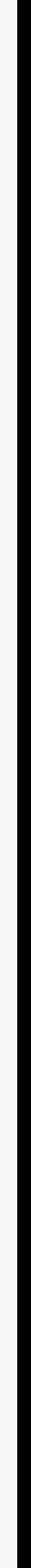


WSRC-TR-95-0288

pg. 30 of 60 .

\section{Temperature (K)}
$3,+800 E+02$
$3.4151 E+02$
$3.3466 \mathrm{E}+02$
$3.2782 E+02$
$3.2098 \mathrm{E}+02$
$3.1414 E+02$

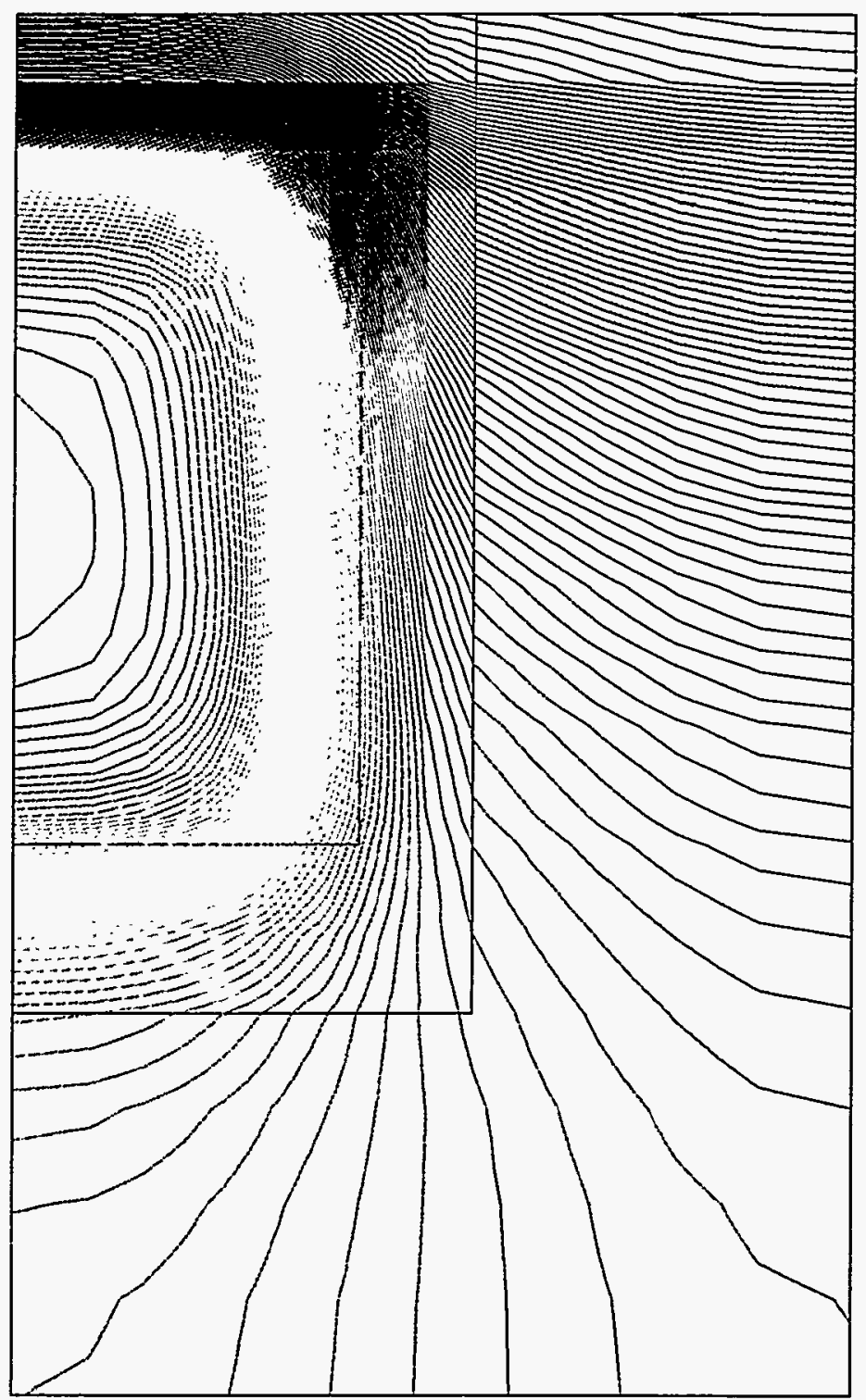

Figure 18 : Temperature Contour Plot at the Concrete Inner Surface of the Common Wall 


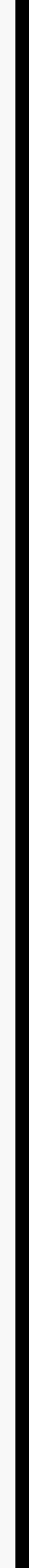


WSRC-TR-95-0288

pg. 31 of 60 .

\section{Velocity $(\mathrm{m} / \mathrm{s})$}

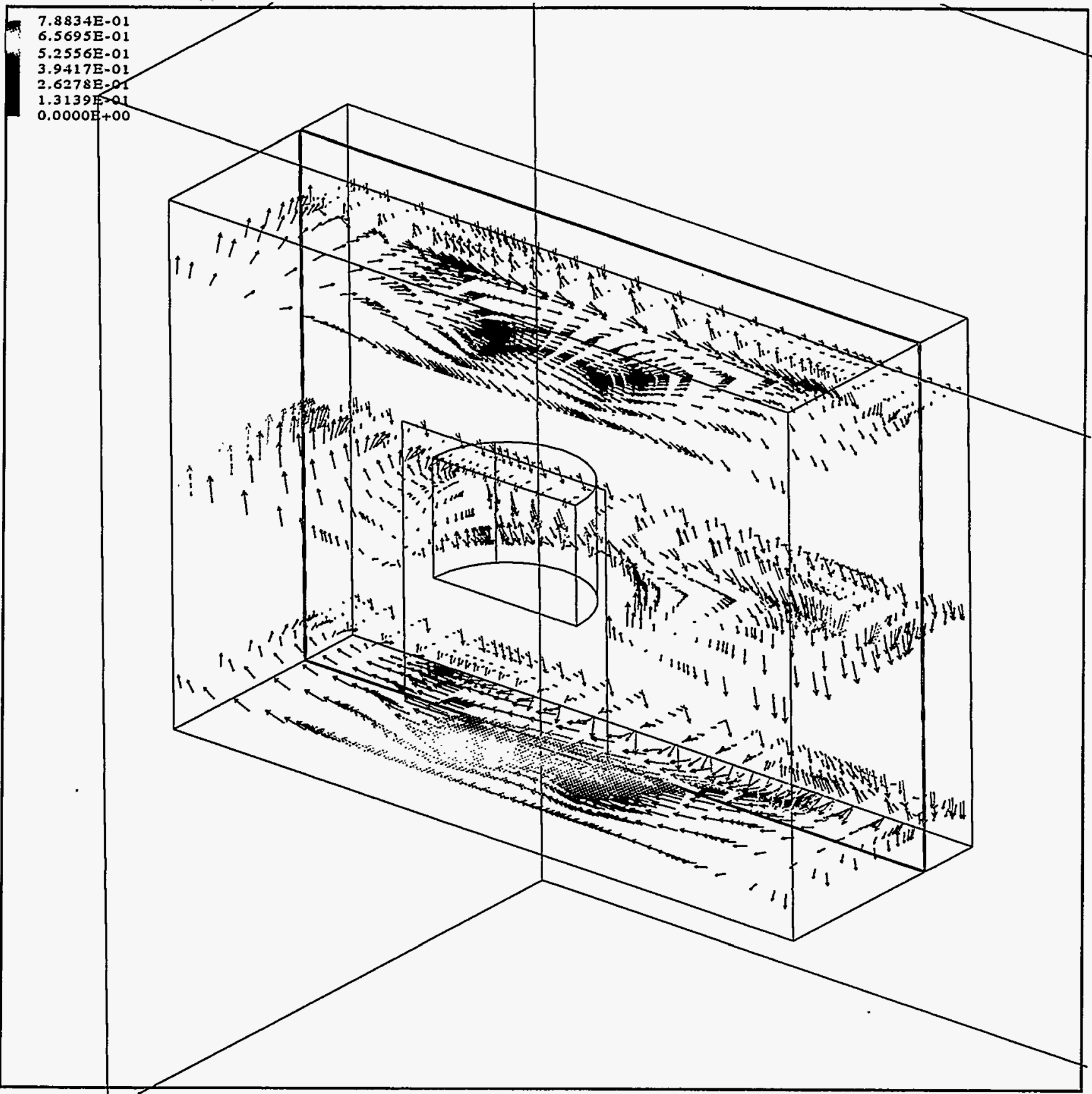

Figure 19 : Velocity Vector Plot at Three Elevation Heights $\left(16^{\prime}, 23^{\prime}, 31^{\prime}\right)$ 


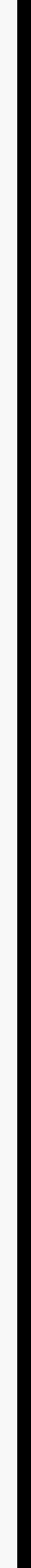


WSRC-TR-95-0288

pg. 32 of 60 .

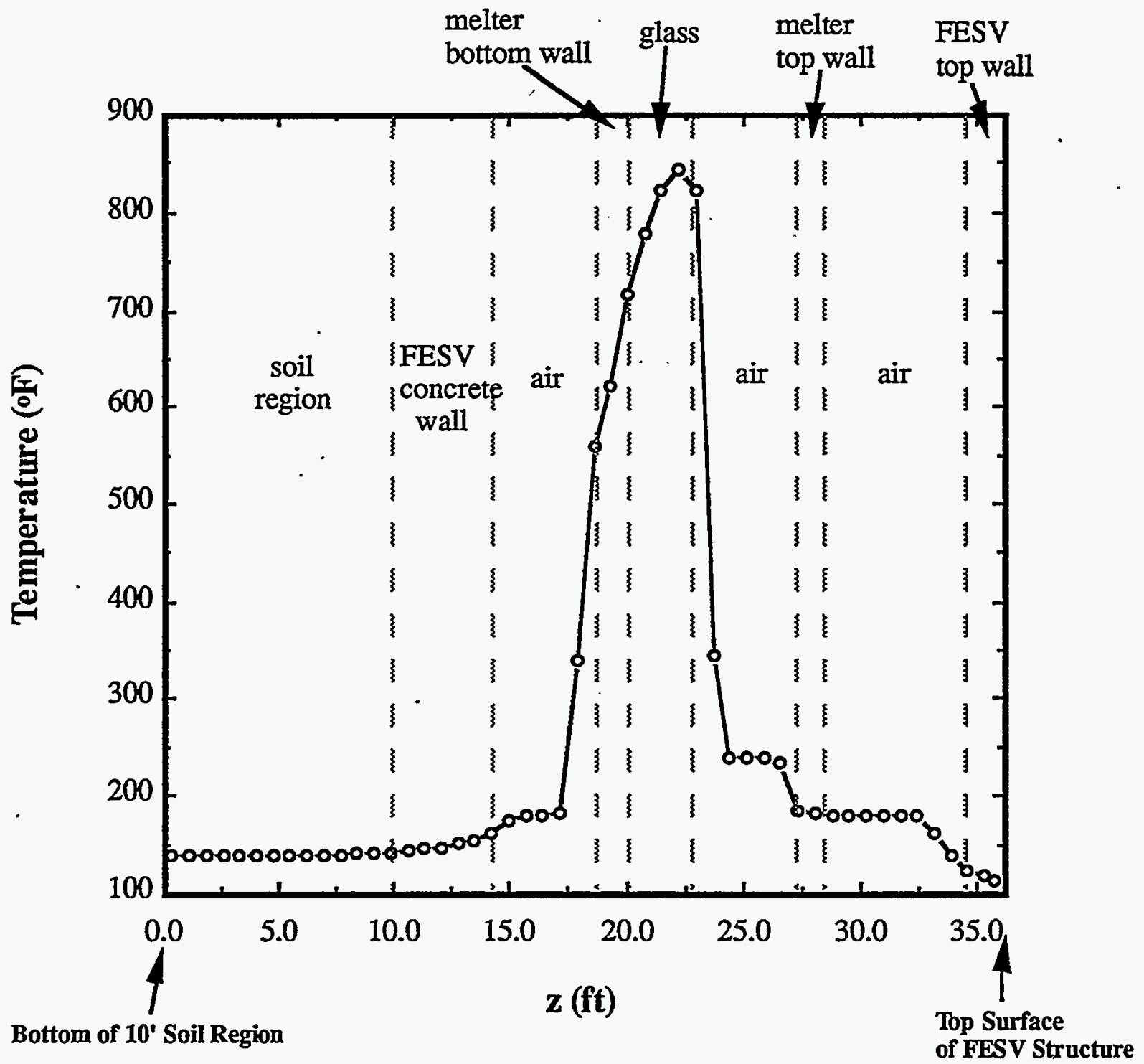

Figure 20: Temperature Profile along the Melter Centerline. 
WSRC-TR-95-0288

pg. 33 of 60 .

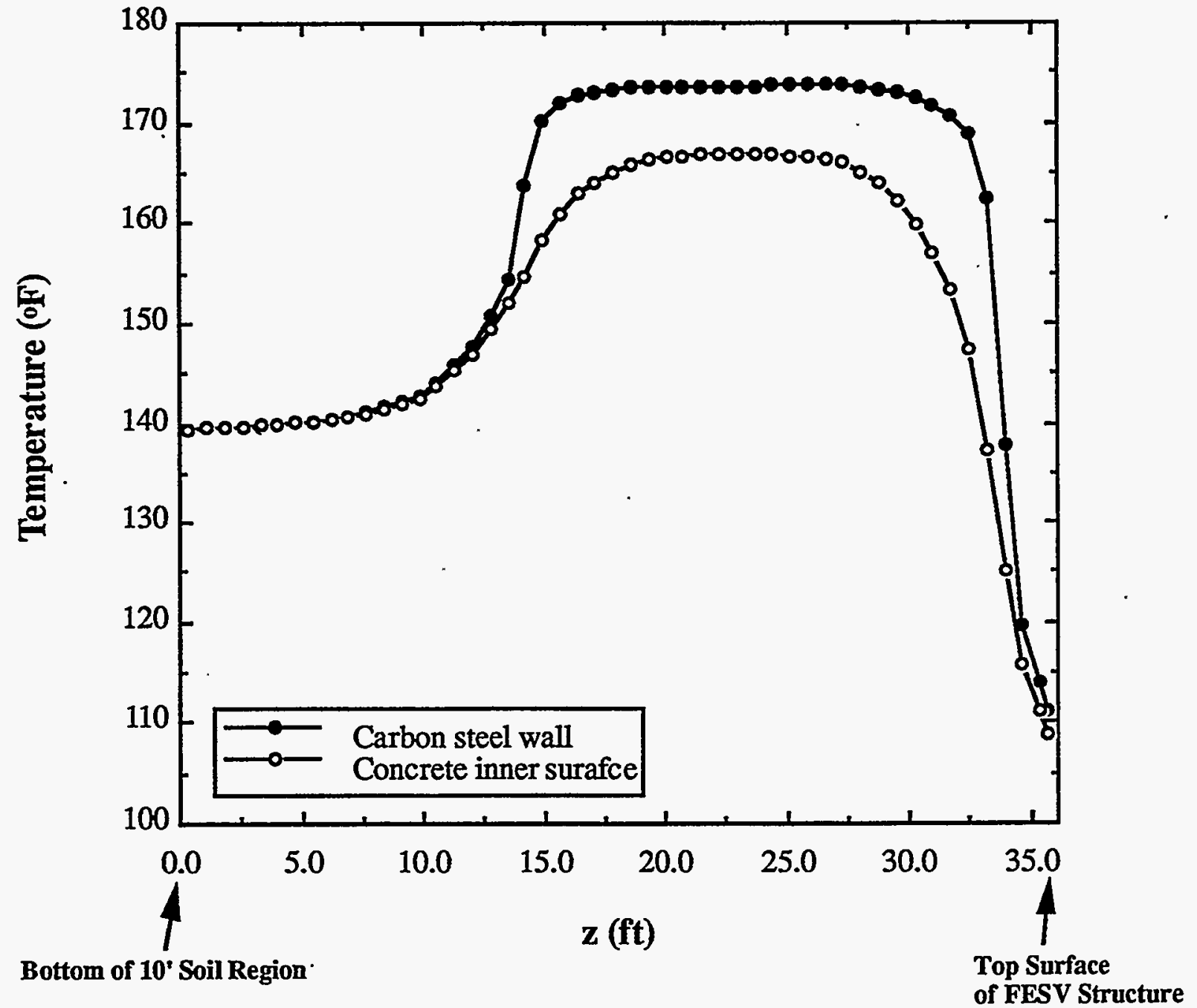

Figure 21: Vertical Temperature Distributions for Carbon Steel Wall and Concrete Inner Surface of the Common Wall Region. 
WSRC-TR-95-0288

pg. 34 of 60 .

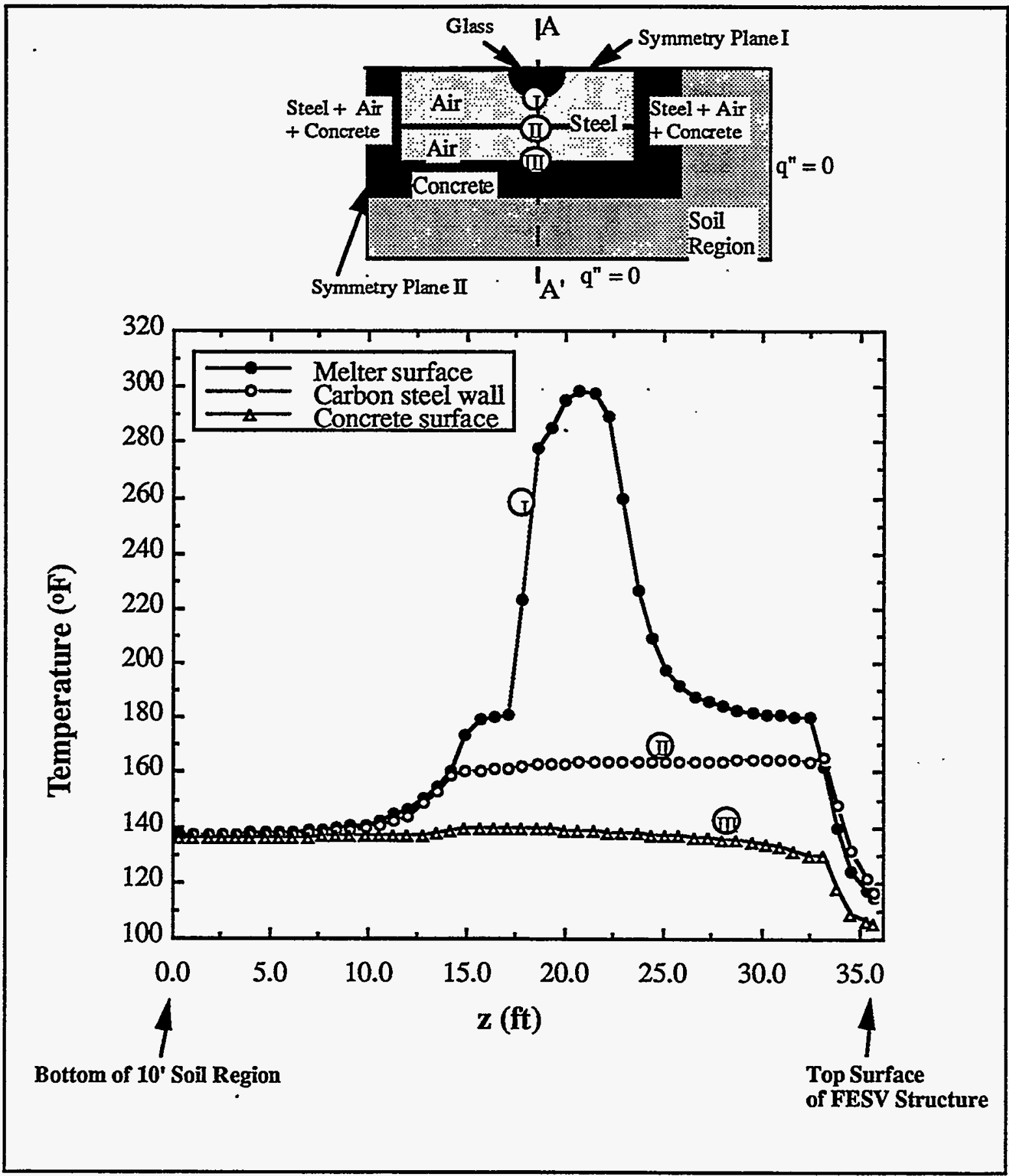

Figure 22: Vertical Temperature Distributions for Melter Surface, Carbon Steel Wall and Concrete Inner Surface at the $y=0$ Plane (A-A' plane) 


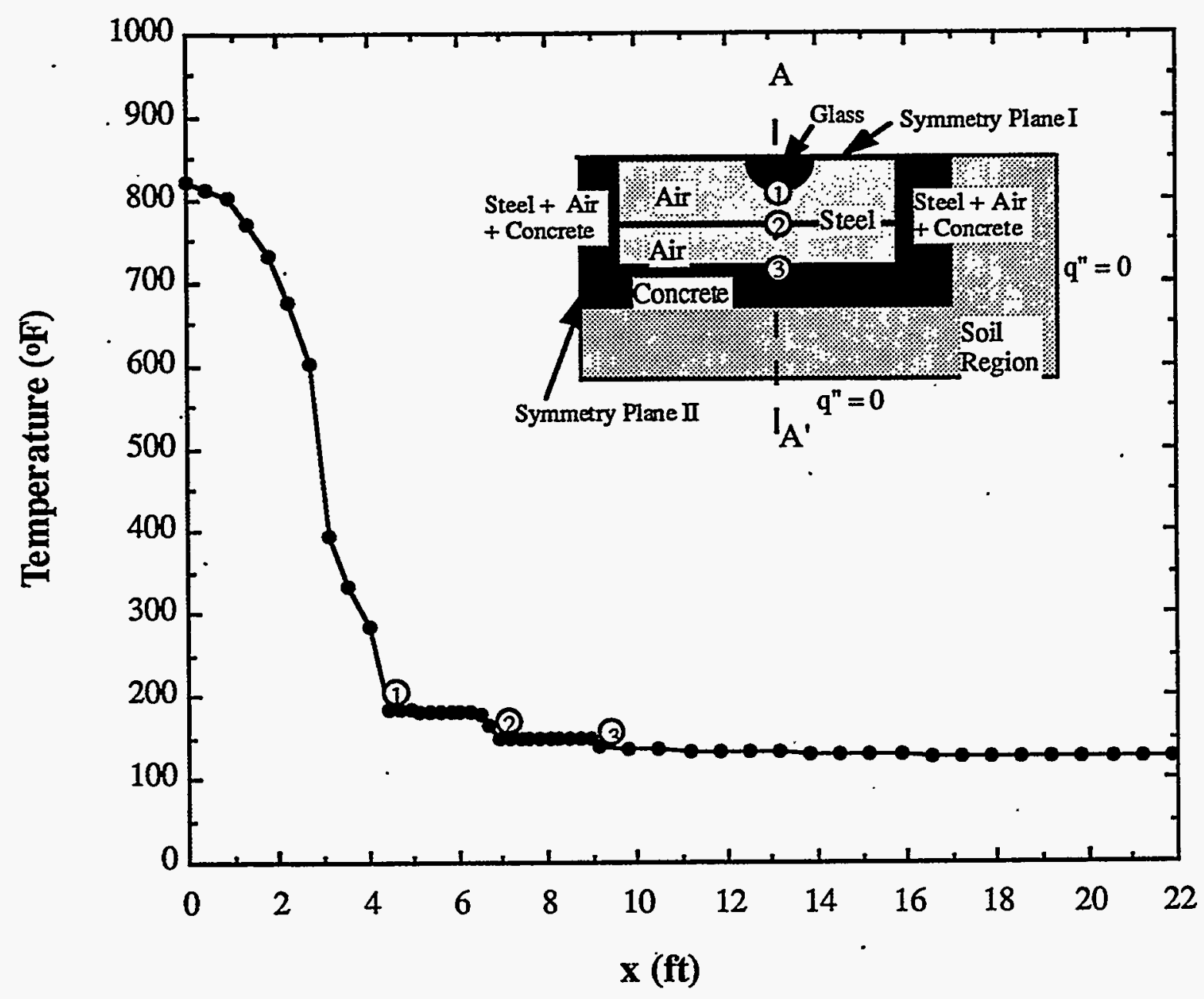

Figure 23: Temperature Distribution at the Mid-height Plane of FESV $\left(z=23^{\prime}\right.$ from the Bottom of $10^{\prime}$ soil region) along the line A-A'. 
WSRC-TR-95-0288

pg. 36 of 60 .

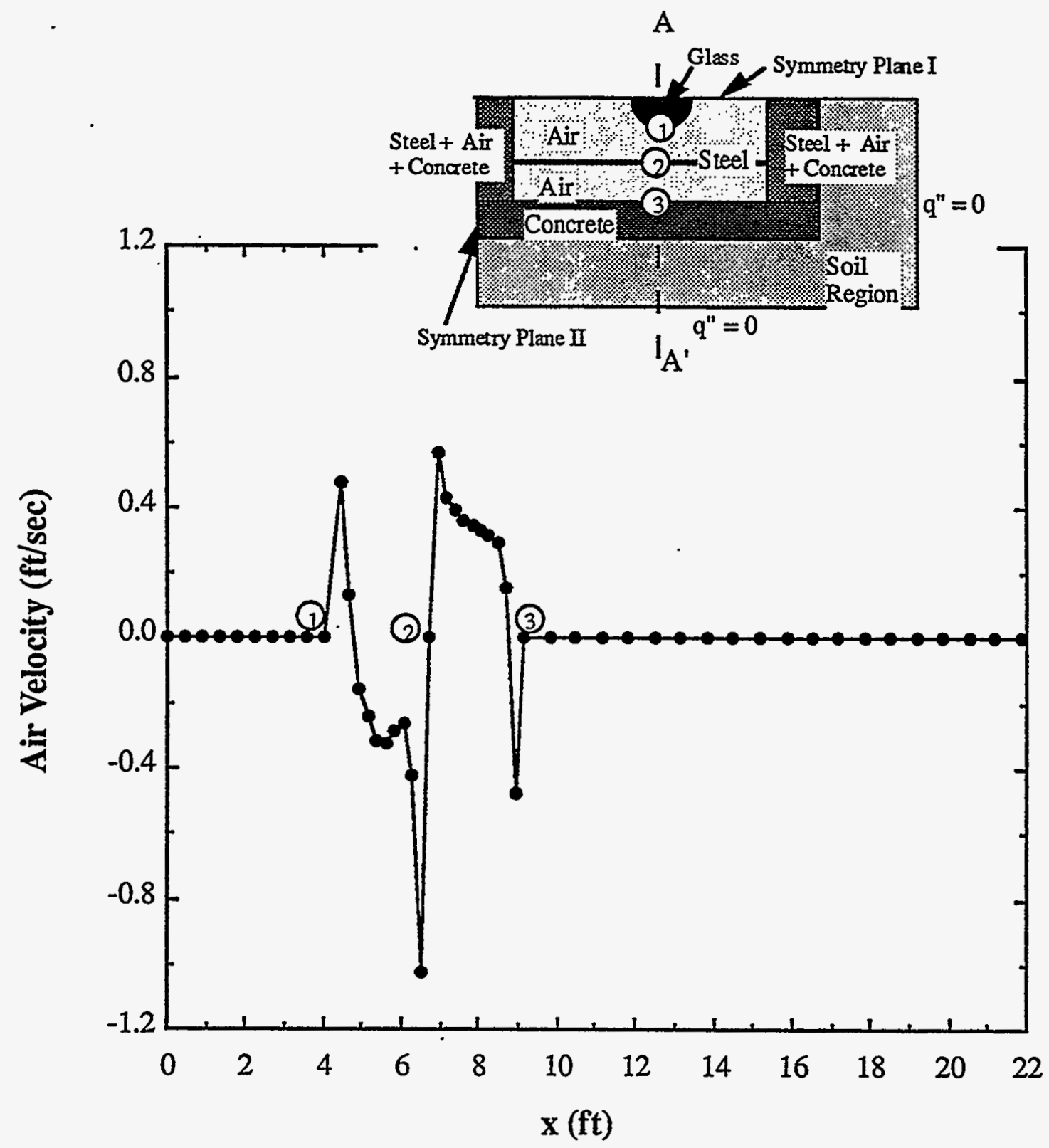

Figure 24: Air Velocity Profile at the Mid-height Plane of FESV $\left(z=23^{\circ}\right.$ from the Bottom of $10^{\prime}$ Soil Region) along the Line A-A'. 
WSRC-TR-95-0288.

pg. 37 of 60 .

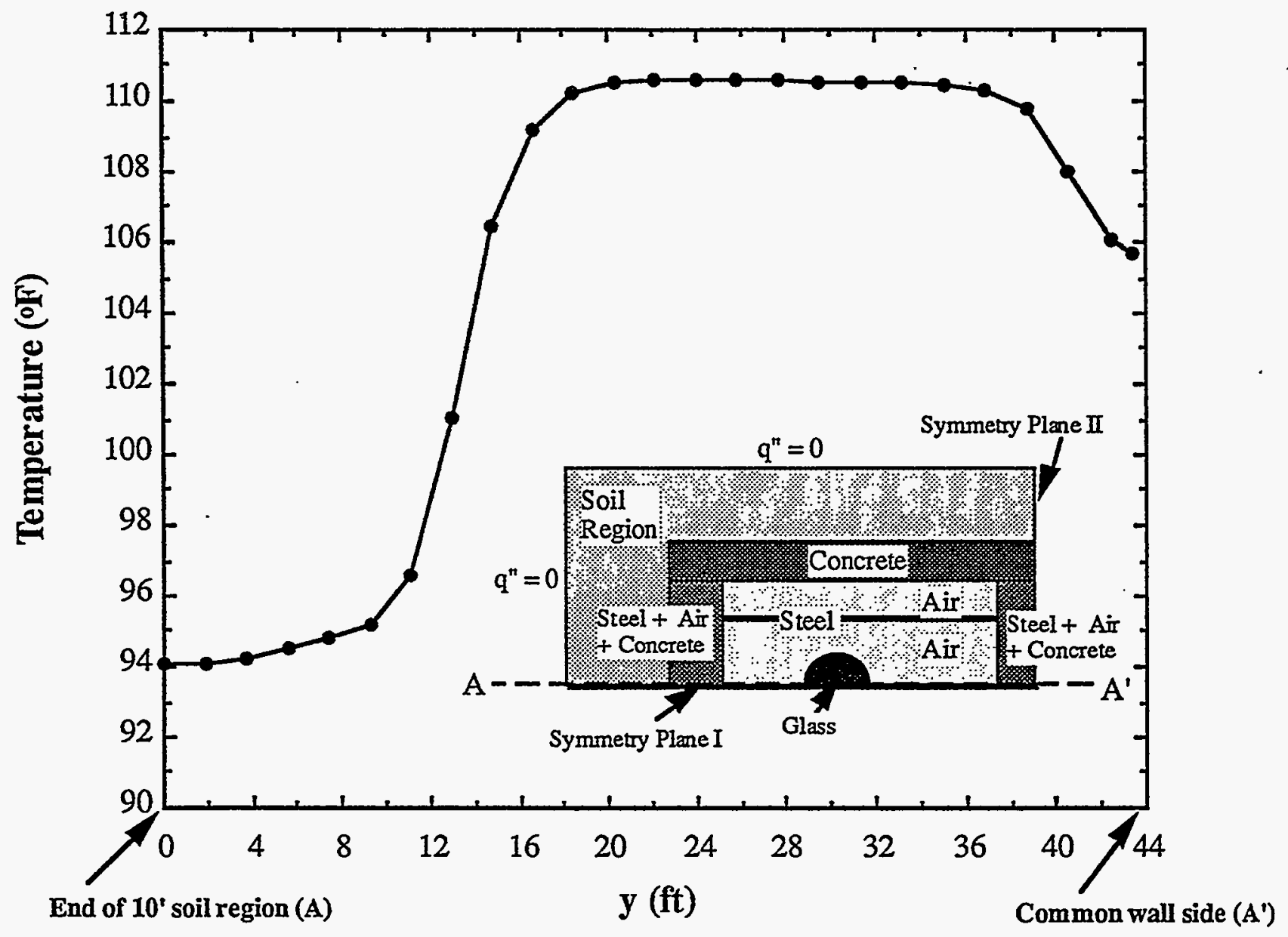

Figure $25:$ Temperature Distribution at the Top Sufface of the FESV Structure along the Line A-A'. 
The FLOW3D analysis was used to determine the enhanced air thermal conductivity for the P/THERMAL model. As previously discussed in section 3.0, temperatures were plotted at seven locations and compared for both the FLOW3D and P/THERMAL models. Several iterations were necessary to find the correct multiplier for the conductivity of the air in the P/THERMAL conduction model. Using a multiplier of 75.0 to increase the air conductivity provided temperature profiles that matched the FLOW3D profiles acceptably at the seven locations. Temperatures predicted by the P/THERMAL conduction model are shown in Figure 26 for the three locations plotted in figure 22. Although temperatures at seven locations were compared between the two models, only three are shown for brevity.

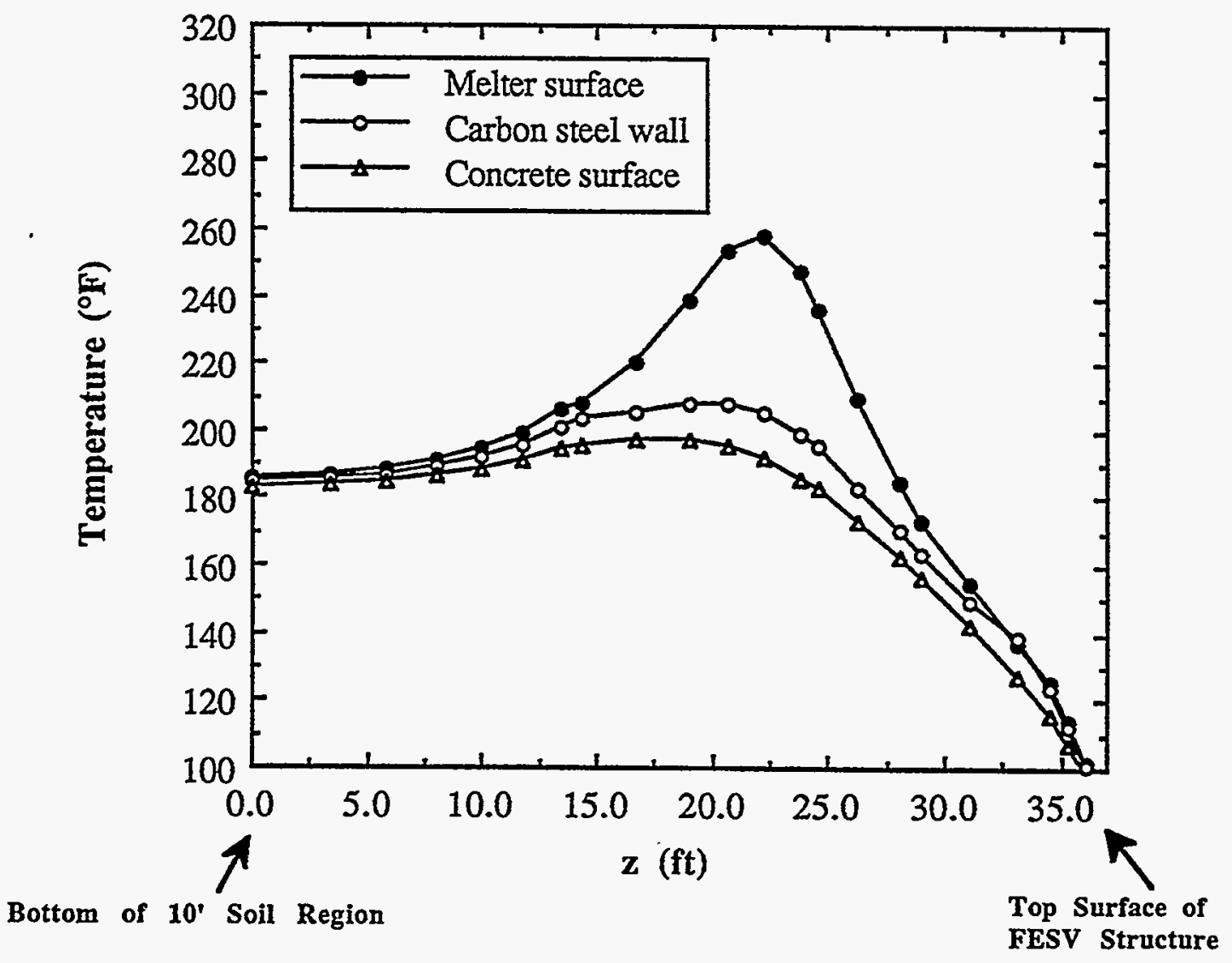

Figure 26: Three Temperature Profiles from the P/THERMAL Model Matched to FLOW3D Temperature Profiles at Identical Locations

Two disadvantages arise from using an enhanced conductivity for the air in the P/THERMAL model which tend to cause non-conservative temperature predictions. First, the concept of an enhanced thermal conductivity is not conservative for predicting temperatures because the FLOW3D and P/THERMAL models are matched for conduction and convection, but not for radiation. Once radiation heat transfer is modeled, the component surface temperatures decrease, lowering the driving force for natural convection. The multiplier for enhancing conductivity then becomes lower than the value used for conduction and convection alone. 
The second disadvantage in using an enhanced conductivity is that the temperatures are only approximately matched between the FLOW3D and P/THERMAL models. Assumptions in the model, however, such as the insulated earth boundary, minimum wind speed for determining convective heat transfer, and summer solar flux applied as the yearly average, tend to yield conservative model temperature predictions.

\subsection{P/THERMAL Conjugate Heat.Transfer Model}

Three cases have been completed with the P/THERMAL model: (1) summer ambient temperature with ten feet of earth; (2) yearly average ambient temperature with ten feet of earth; (3) yearly average ambient temperature with forty feet of earth. Cases (1) and (2) were completed to estimate the effect of the seasonal variation in air temperature. Case (3) was completed to evaluate the sensitivity of increasing the amount of earth surrounding the vault on the overall temperatures. Since the earth, in addition to the concrete lid, provides area for heat transfer to the atmosphere, it is expected that increasing the amount of surrounding earth will lower temperatures.

The maximum temperatures for the major components occur at identical locations in all three cases : at the center of the concrete floor, at the center of the bottom and side walls for the MSB, and at the center of the glass pool. The region of maximum localized temperature moves from the common wall in the FLOW3D model to the vault floor in the P/THERMAL model. This is expected, since the melter is approximately 56 inches from the bottom of the concrete floor, and radiation heat transfer is significant. Also, in each of the three cases the maximum temperatures reached by the MSB and glass are well below the specified limits. The concrete is the only FESV/MSB system component where the temperature limit is a concern, with some localized temperatures exceeding the specified limit of $150^{\circ} \mathrm{F}$.

Table 4 presents results for the most severe condition of a summer ambient temperature (case 1). Figure 27 shows temperature contours for the concrete where a localized region in the floor has a maximum temperature of $167^{\circ} \mathrm{F}$. The region of concrete having a temperature between $167^{\circ} \mathrm{F}$ to $162^{\circ} \mathrm{F}$ has a diameter of approximately 10 feet and a depth of two feet. The concrete temperature exceeds $150^{\circ} \mathrm{F}$ from the bottom floor to approximately two-thirds the height of the vault for the side and end walls. There is a drop in temperature at the wall intersections. All other concrete in the vault has a temperature less than $150^{\circ} \mathrm{F}$.

\begin{tabular}{|l|l|l|l|}
\hline FESV/MSB & Temperature & \multicolumn{3}{|c|}{ Model Temperatures $\left.{ }^{\circ} \mathrm{F}\right)$} \\
\cline { 3 - 4 } Component & Limit $\left({ }^{\circ} \mathrm{F}\right)$ & Maximum & Minimum \\
\hline Concrete & $150 / 200$ & 167 & 104 \\
\hline MSB & 650 & 168 & 140 \\
\hline Glass & 824 & 551 & 294 \\
\hline
\end{tabular}

Table 4: FESV/MSB System Temperatures $\left({ }^{\circ} \mathrm{F}\right)$ for P/THERMAL Model with Summer Ambient Temperature $\left(90^{\circ} \mathrm{F}\right)$ and 10 Feet of Surrounding Earth 
WSRC-TR-95-0288

pg. 40 of 60 .

Temperature results from case (2) are shown in Table 5 and Figure 28 for the concrete where the ambient air temperature is the yearly average of $76^{\circ} \mathrm{F}$. The temperature gradients predicted are similar to those predicted using the summer ambient temperature, with the exception of a drop of $4^{\circ} \mathrm{F}$ throughout the model. It can be concluded from cases (1) and (2) that the concrete temperatures are not strongly influenced by the seasonal air temperatures. It should be noted, however, that the convective heat transfer coefficient and incident solar radiation were not modified to reflect yearly average values, but were kept at values consistent for summer conditions.

\begin{tabular}{|l|l|l|l||}
\hline FESV/MSB & Temperature & \multicolumn{3}{|c|}{ Model Temperatures ( $\left.{ }^{\circ} \mathrm{F}\right)$} \\
\cline { 3 - 4 } Component & Limit $\left({ }^{\circ} \mathrm{F}\right)$ & Maximum & Minimum \\
\hline Concrete & $150 / 200$ & 163 & 100 \\
\hline MSB & 650 & 164 & 136 \\
\hline Glass & 824 & 548 & 290 \\
\hline
\end{tabular}

Table 5: FESV/MSB System Temperatures ( ${ }^{\circ} \mathrm{F}$ ) for P/THERMAL Model with Average Ambient Temperature $\left(76^{\circ} \mathrm{F}\right)$ and 10 Feet of Surrounding Earth

In case (3) the distance of earth surrounding the vault has been increased to 40 feet, from 10 feet in cases (1) and (2). Figure 29 and Table 6 report temperatures for case (3). The localized maximum concrete temperature decreases to $153^{\circ} \mathrm{F}$ in the vault floor. Although the region of concrete exceeding $150^{\circ} \mathrm{F}$ has a diameter of 10 feet, the penetration is less than one foot, where temperatures range from $150^{\circ} \mathrm{F}$ to $153^{\circ} \mathrm{F}$. All other regions of the vault remain below $150^{\circ} \mathrm{F}$. The concrete common wall attains a maximum temperature of $147^{\circ} \mathrm{F}$. Case 3 shows that, except for a small portion of the vault floor, providing 40 feet of earth around the vault allows the entire vault to remain below $150^{\circ} \mathrm{F}$.

\begin{tabular}{||c|c|c|c||}
\hline \hline FESV/MSB & Temperature & \multicolumn{2}{|c|}{ Model Temperatures $\left(^{\circ} \mathrm{F}\right)$} \\
\cline { 3 - 4 } Component & Limit $\left({ }^{\circ} \mathrm{F}\right)$ & Maximum & Minimum \\
\hline Concrete & $150 / 200$ & 153 & 99 \\
\hline MSB & 650 & 155 & 129 \\
\hline Glass & 824 & 542 & 283 \\
\hline
\end{tabular}

Table 6: FESV/MSB System Temperatures ( $\left.{ }^{\circ} \mathrm{F}\right)$ for P/THERMAL Model with Average Ambient Temperature $\left(76^{\circ} \mathrm{F}\right)$ and 40 Feet of Surrounding Earth 


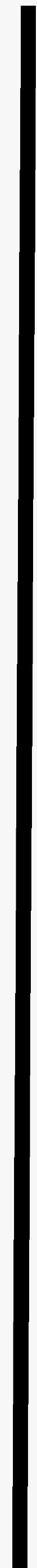



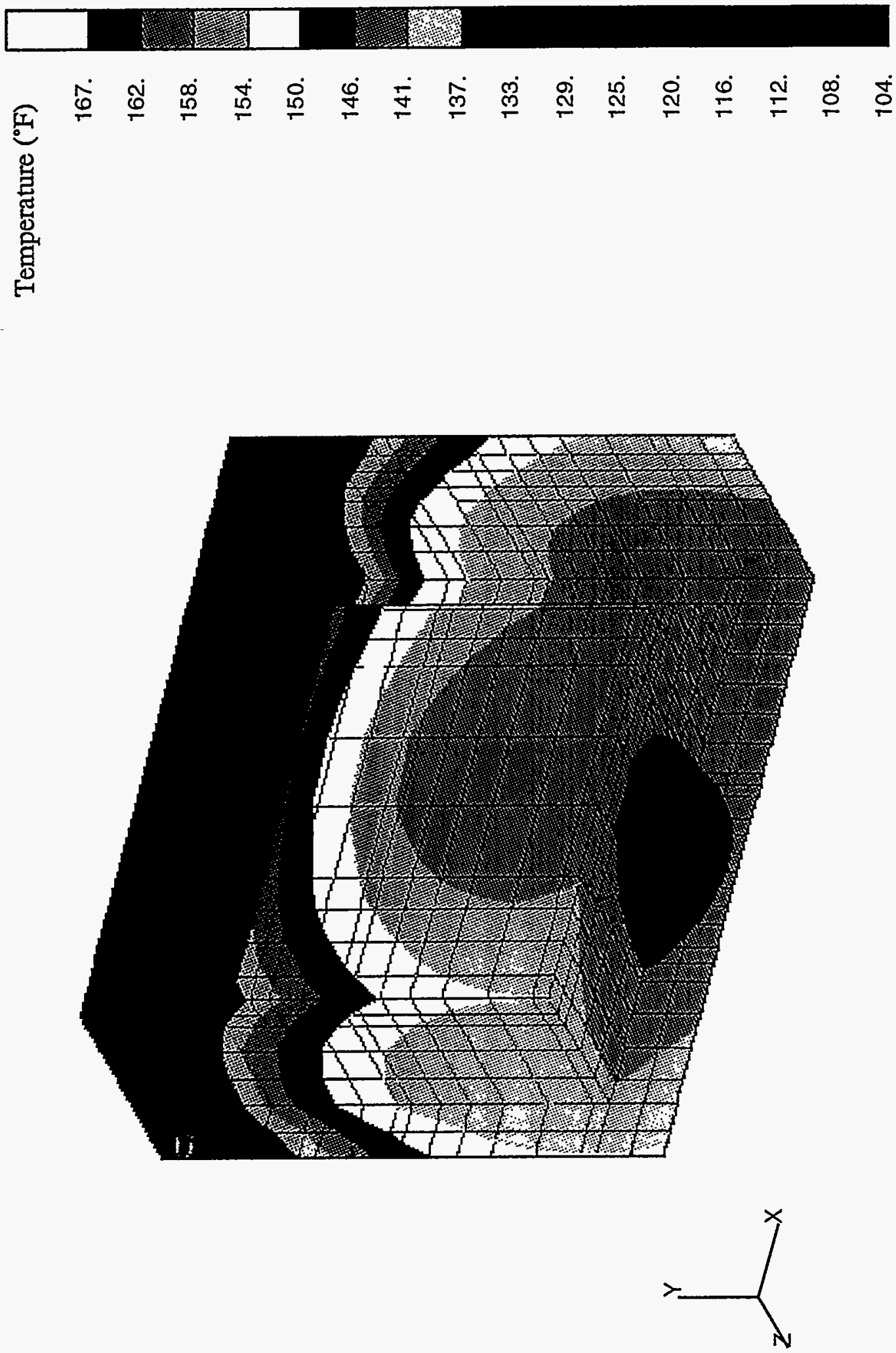

Figure 27 : Concrete Temperature Contours for P/THERMAL Model with Summer Ambient Temperature $\left(90^{\circ} \mathrm{F}\right)$ and 10 Feet of Surrounding Earth 


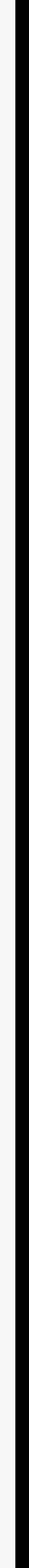




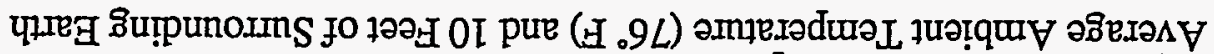

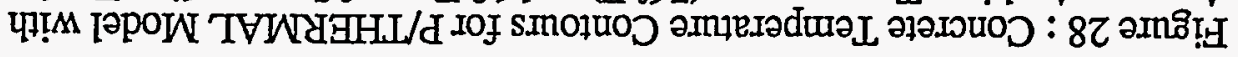
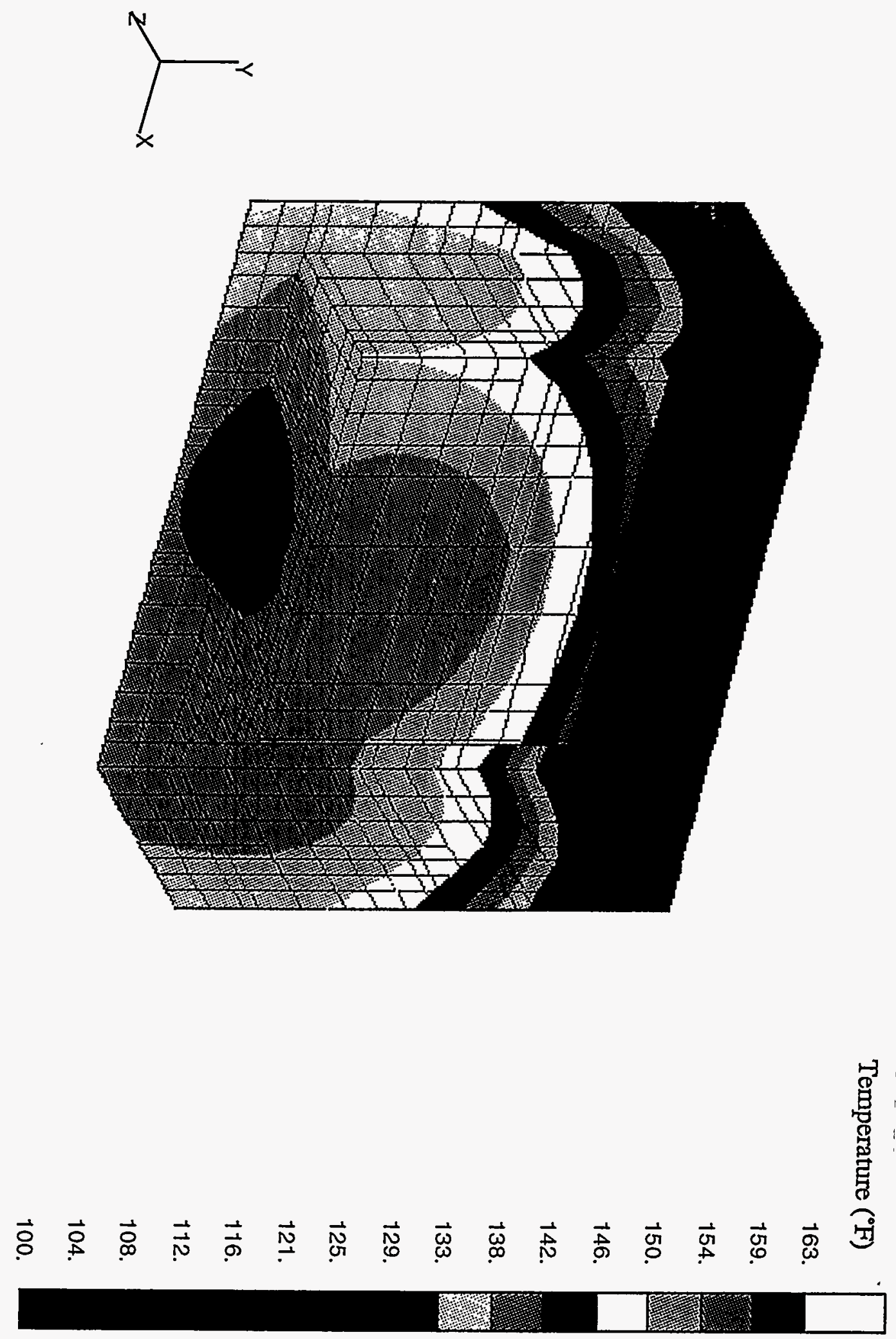


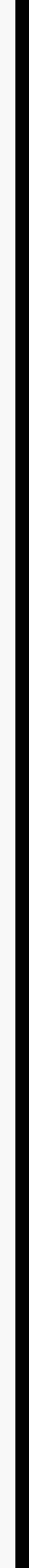



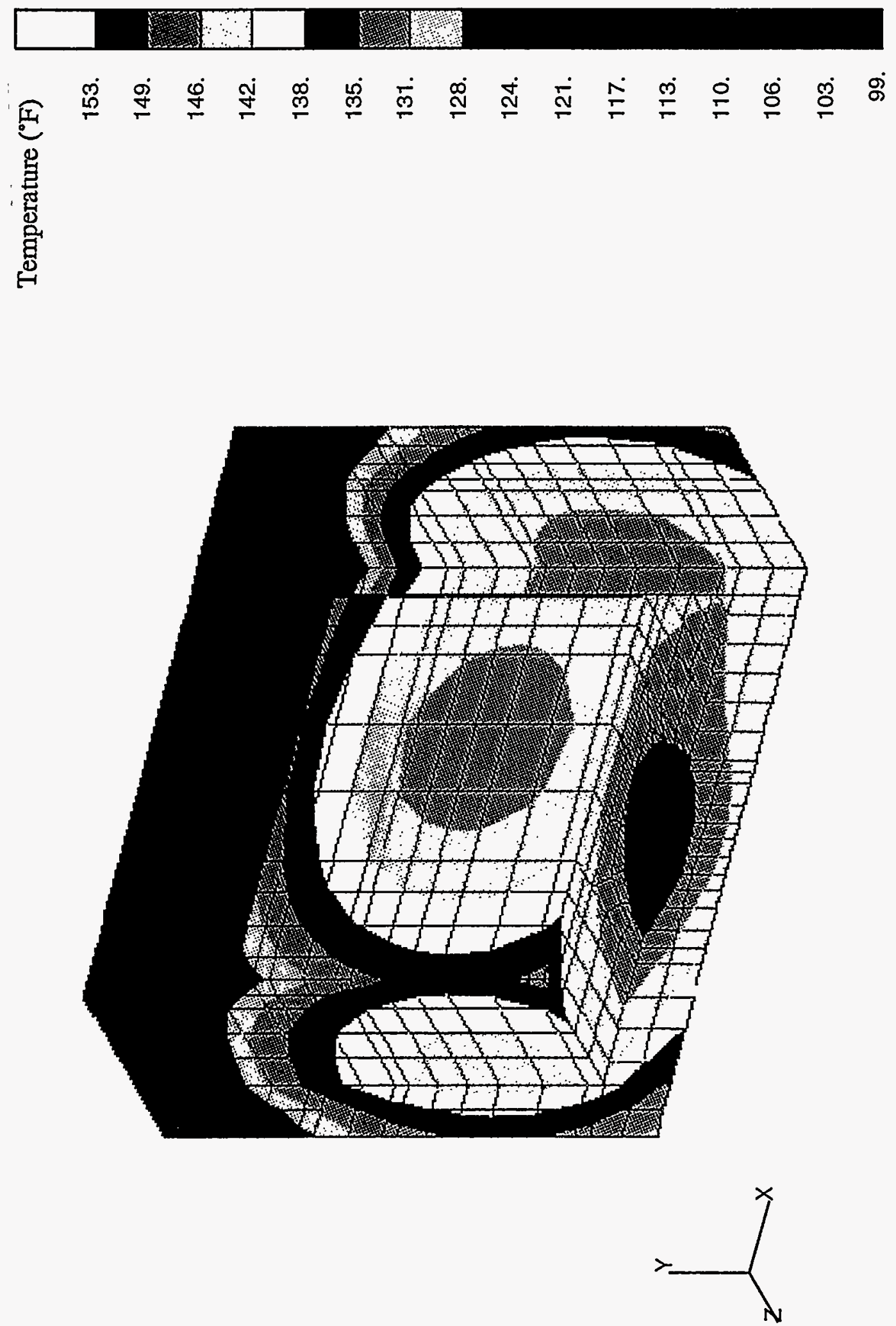

Figure 29 : Concrete Temperature Contours for P/THERMAL Model with Average Ambient Temperature $\left(76^{\circ} \mathrm{F}\right)$ and 40 Feet of Surrounding Earth 


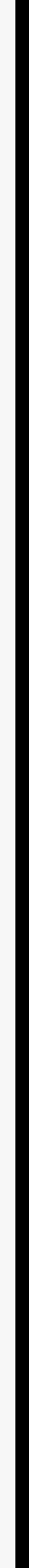


WSRC-TR-95-0288

pg. 44 of 60 .

\subsection{Conclusions}

Temperature profiles have been generated using the FLOW3D software to model heat conduction and convection within the FESV/MSB system. Due to complexities in modeling radiation with FLOW3D, P/THERMAL software was used to model radiation using conduction/convection temperature results from FLOW3D. The final P/THERMAL conjugate model includes heat transfer by conduction, convection, and radiation to predict steady-state temperatures.

The temperatures produced by the conjugate model indicate that the FESV/MSB system components remain below the specified temperature limits for a pair of failed melters, each generating $3000 \mathrm{~W}$. The glass pool and MSB remain well below their temperature limits by margins of $280^{\circ} \mathrm{F}$ and $490^{\circ} \mathrm{F}$, respectively. The concrete common wall attains a maximum temperature of $147^{\circ} \mathrm{F}$, slightly below the $150^{\circ} \mathrm{F}$ temperature limit. The concrete exceeds the overall temperature limit of $150^{\circ}$ $\mathrm{F}$ in only a portion of the center of the floor, where the temperature reaches $153^{\circ} \mathrm{F}$. The region exceeding $150^{\circ} \mathrm{F}$ is localized with a diameter of approximately 10 feet and a depth of one foot. The upper concrete temperature limit for localized regions of $200^{\circ} \mathrm{F}$ is not reached.

\subsection{Quality Assurance}

This project has been completed as a Level 1 confirmed calculation under the E7 Procedure Manual. Supporting calculations are documented in laboratory notebook WSRC-NB-93-180.

FLOW3D has also been approved for use at SRS as Nuclear Safety (NS) software[15], as has P/THERMAL. 
WSRC-TR-95-0288

pg. 45 of 60 .

\section{References}

1. Hensel, S. J., "Dedication Package for P3/THERMAL (U)" - SRT-EMS-950007, Westinghouse Savannah River Company, Aiken, S. C., February 7, 1995.

2. Schumacher, R. F., "Summary of DWPF Waste Glass Properties" - WSRC-RD-9111, Westinghouse Savannah River Company, Aiken, S. C.

3. Hardy, B. J., "Thermal analysis to Define Temperature Profiles in the FESV/MSB" WSRC-TR-94-00497, Westinghouse Savannah River Company, Aiken, S. C. October 11, 1994.

4. Monofrax Type K-3 Fused Cast Refractory, Product Information. The Carborundum Company, Refractories Division, Fused Cast Plant, 501 New York Avenue, Falconer, NY 14733. Form A-2850, November 1988.

5. Technical Data, Korundal XD, Harbison-Walker Refractories, One Gateway Center, Pittsburgh, PA 15222. March 1993.

6. Fiberfrax Specialties Products, Product Information. The Carborundum Company, Fibers Division, P. O. Box.808, Niagara Falls, NY 14302. Form C-1427, March 1990.

7. P3/THERMAL material library, MacNeal-Schwendler Corporation, 815 Colorado Blvd., Los Angeles, CA 90041.

8. ASHRAE Handbook, 1985 Fundamentals. American Society of Heating, Refrigerating and Air-Conditioning Engineers, Inc. 1791 Tullie Circle NE, Atlanta, GA 30329.

9. Lienhard, John H. A Heat Transfer Textbook, Prentice-Hall, Inc. Englewood Cliffs, N.J. 07632. 1981. pg. 446.

10. Hunter, C. H., "Meteorology and Air Quality Input for Spent Nuclear Fuel Environment Information Statement (ES) - Draft Chapter 5 on Affected Environment," SRT-ETS-930961, Westinghouse Savannah River Company, Aiken, S.C., October 8, 1993.

11. Kreith, Frank and Black, William. Basic Heat Transfer, Harper and Row Publishers, New York, 1980. pp. 5, 374.

12. Ozisik, M. Necati. Heat Transfer, A Basic Approach, McGraw-Hill Book Company, 1985. pg. 623.

13. Flach, G. P., "Nominal Sediment Characteristics for S-Area Vault Area" - SRTESS-95-316, Westinghouse Savannah River Company, Aiken, S.C., May 23, 1995.

14. Personal communication with Chuck Hunter, SRTC/ETS.

15. Dimenna, R. A., "CFDS-FLOW3D Dedication Package" - SRT-EMS-950045, Westinghouse Savannah River Company, Aiken, S. C., July 10, 1995. 
WSRC-TR-95-0288

pg. 46 of 60 .

APPENDIX A: Variation of Temperature with Time

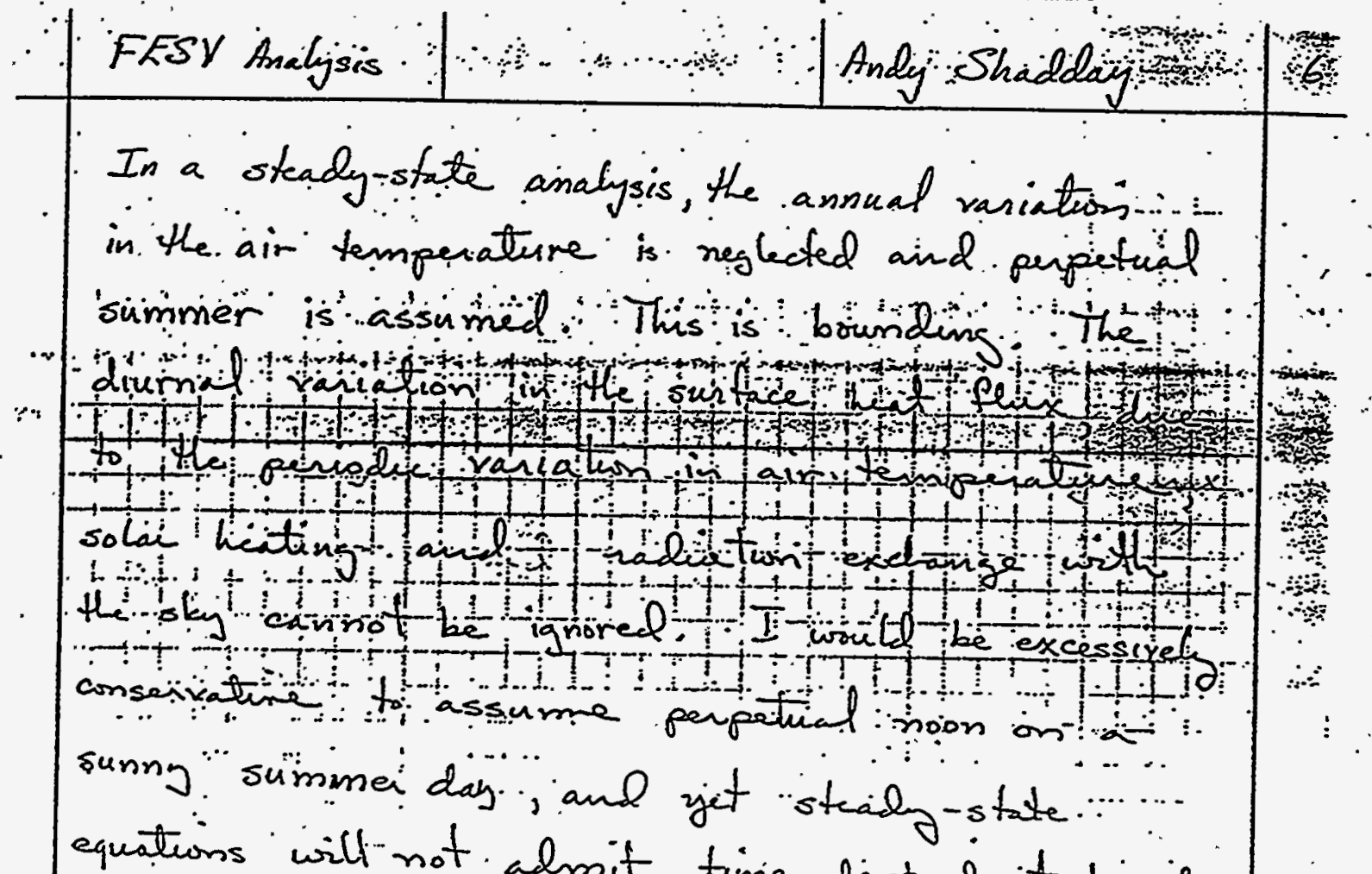
equations will not alsnit tissue dependent boundary conditions. I will attempt to determine a mean value for. a convector heat transfer coefficient; such that the: surface heat transfer in a stady-state calliculation con be formulated with Newton's haw of Cooling and the daily average air temperature. This will be aide with: I-D transeunt rode of the FESV ciricotet

For a specified gin the bottom surface tompenative of the conic rete will be calculated with a model that includes the 24. hour periodic top surface heat transfer rates.:-
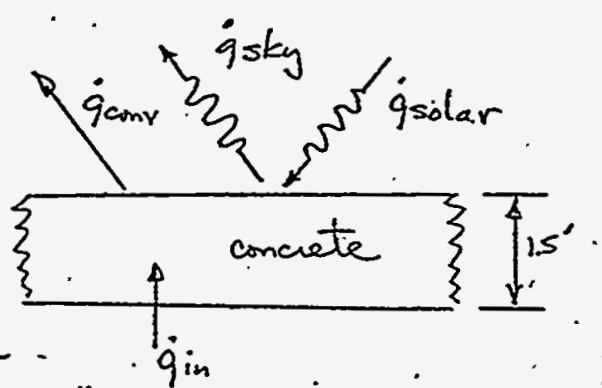


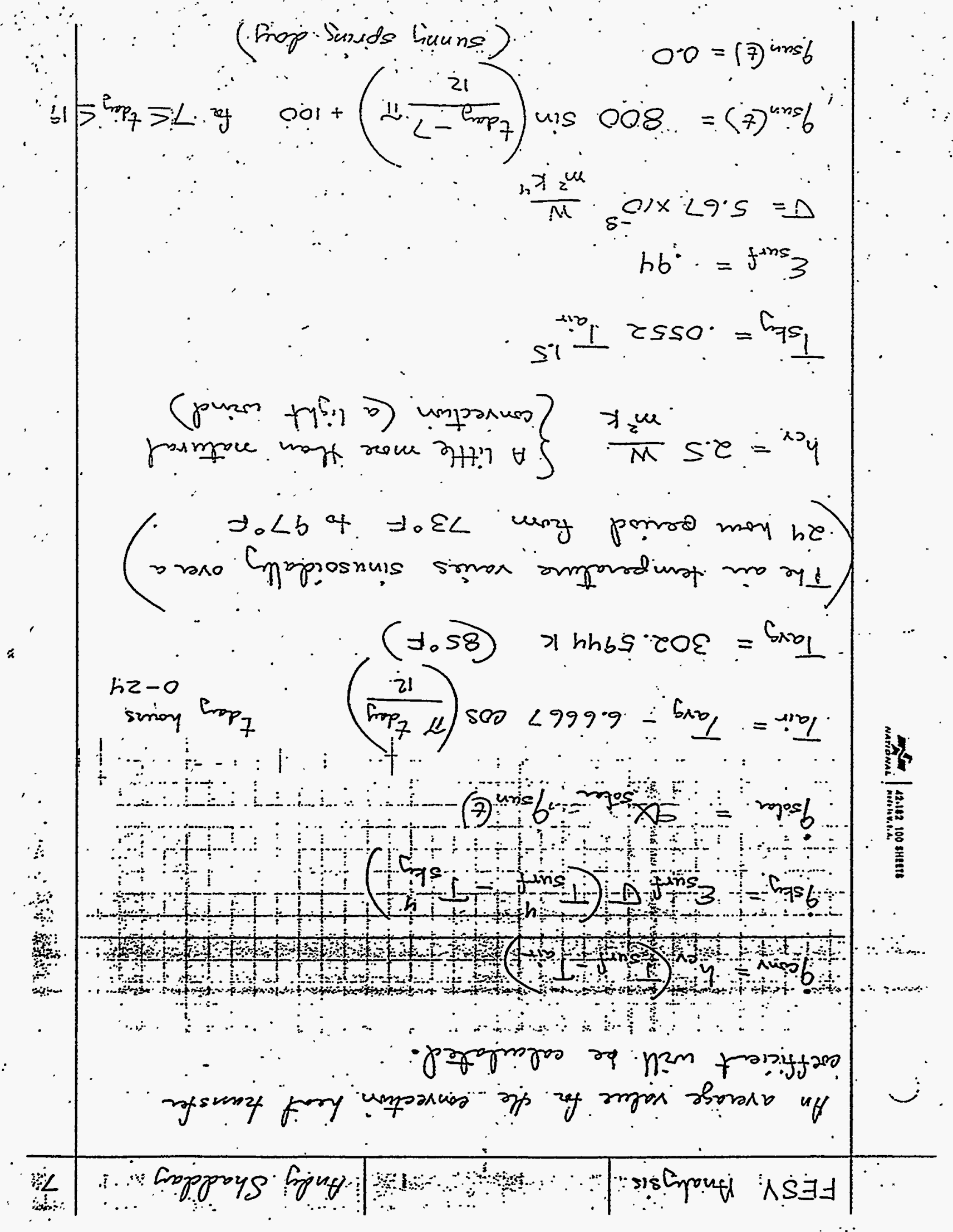


WSRC-TR-95-0288

pg. 48 of 60 .

APPENDIX A

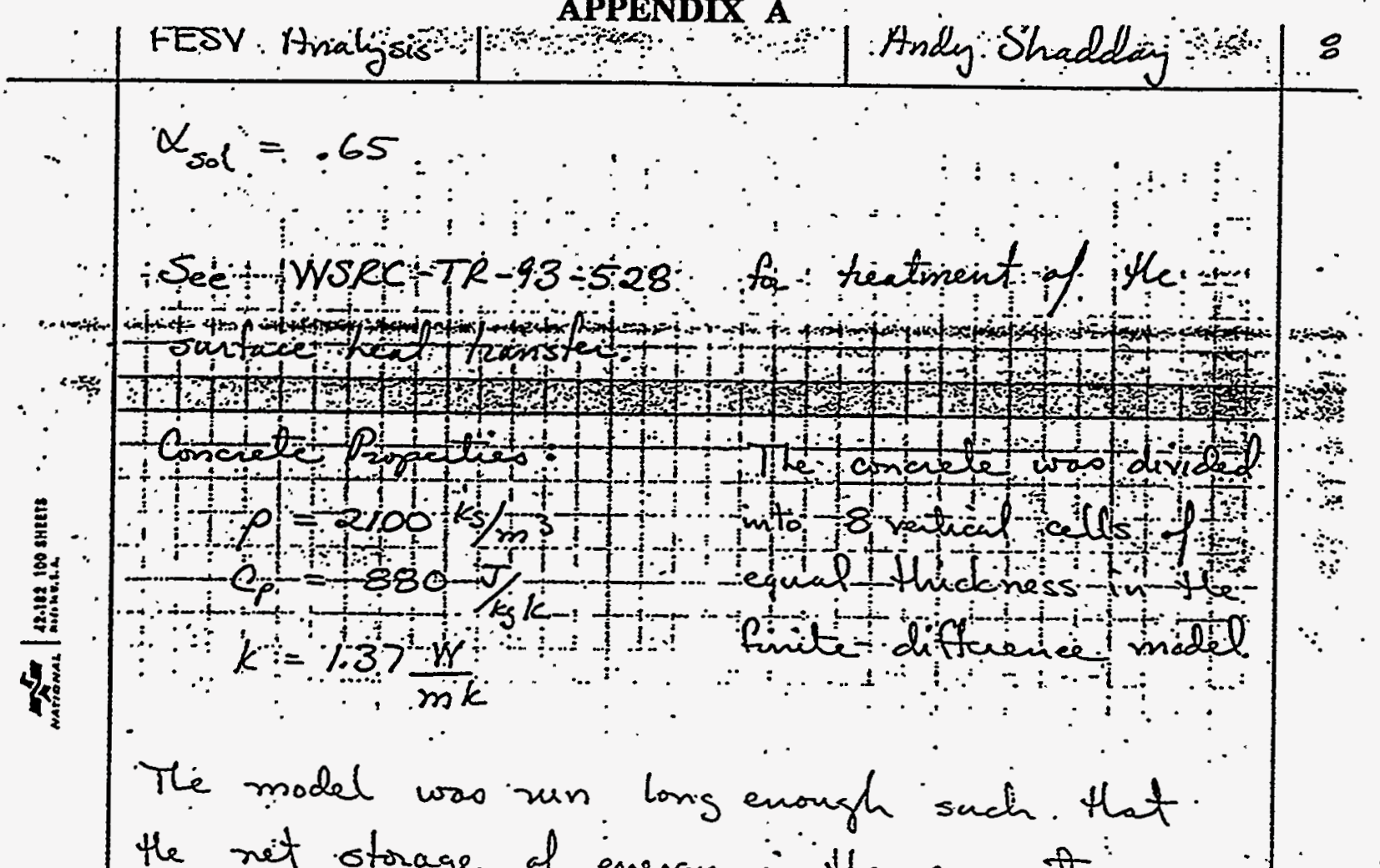

the nit storage of energy in the concrete over a 24 him shrivel was zero, and the. daily. average bottom surface temperature wo calculated.

Case \#:

$$
\begin{aligned}
& \dot{g}_{\text {in }}=95.538 \frac{\dot{w}}{\mathrm{~m}^{2}} \quad\left(\begin{array}{c}
\mathrm{kw} \text { for the } \\
\text { roof }
\end{array} 3^{\prime} \times 26^{\prime}\right) \\
& \bar{T}_{\text {air }}=302.5944 \mathrm{k} \cdot\left(85^{\circ} \mathrm{F}\right) \\
& \overline{\bar{T}}_{\text {bot. }}=356.5753 \mathrm{k} \quad\left(192.35^{\circ} \mathrm{F}\right)
\end{aligned}
$$

$$
\begin{aligned}
& \dot{q}=k \frac{\bar{T}_{\text {Bot }}-\bar{T}_{\text {surf }}}{\Delta z} \\
& \bar{T}_{\text {surf }}=\bar{T}_{\text {Bot }}-\frac{\dot{q} \Delta z}{k} \\
& \bar{T}_{\text {surf }}=356.6753-\frac{95.539(.4572)}{1.37} \\
& \bar{T}_{\text {surf }}=324.792 \mathrm{k}\left(12.5^{\circ} \mathrm{F}\right)
\end{aligned}
$$

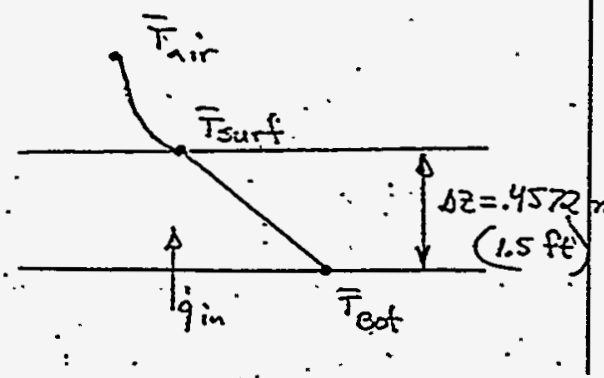


WSRC-TR-95-0288

pg. 49 of 60 .

APPENDIX A

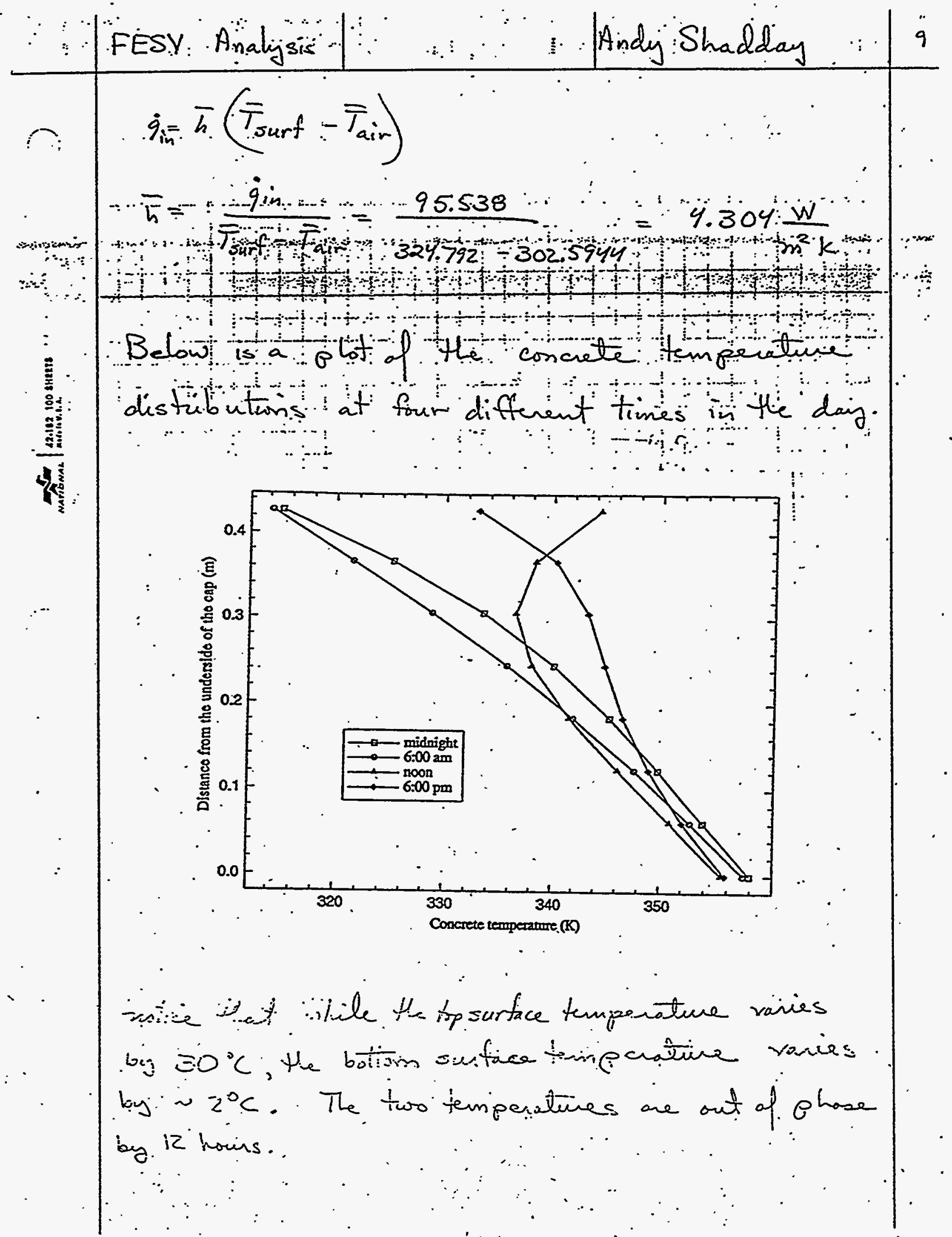




\section{APPENDIX A}

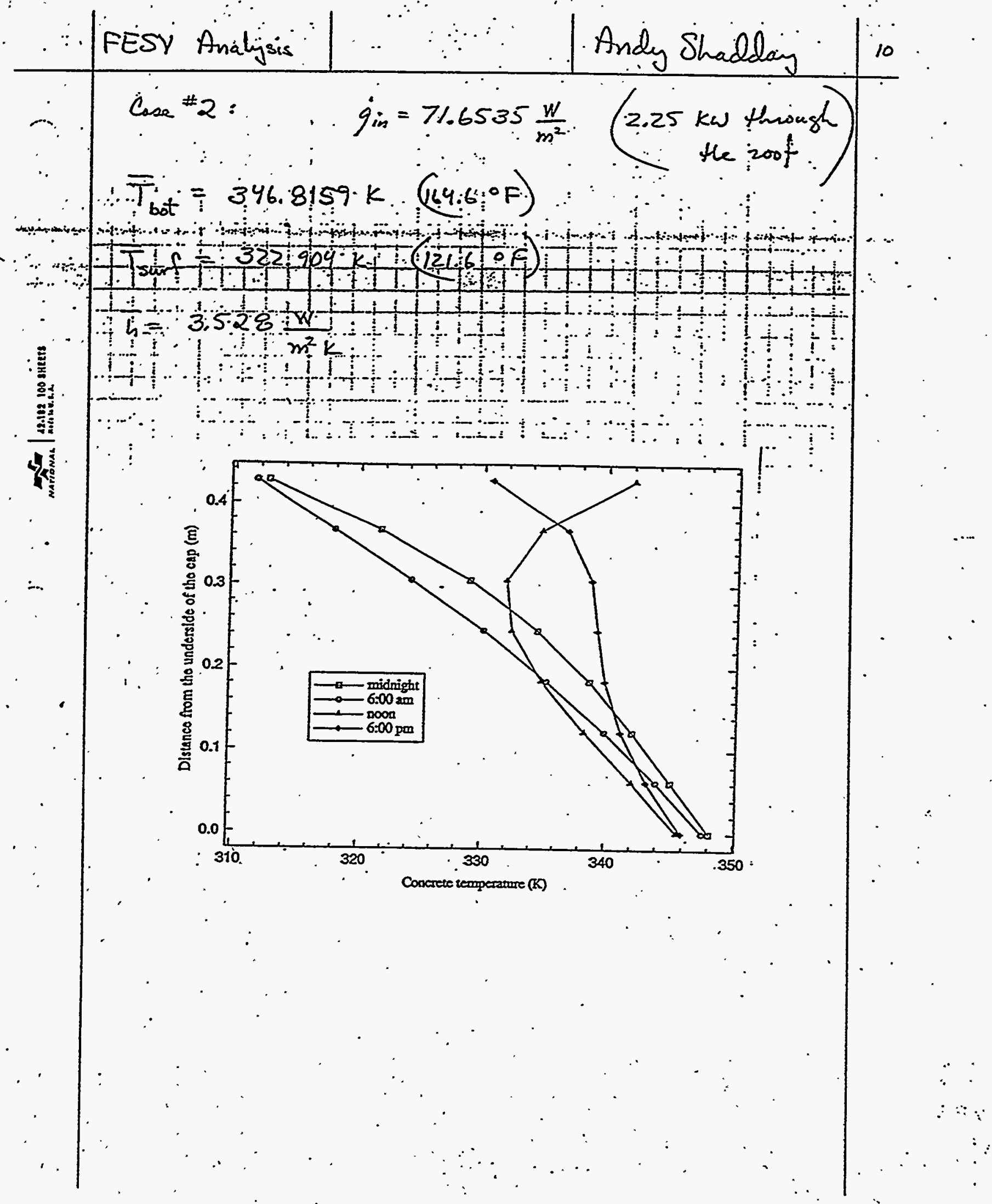


WSRC-TR-95-0288

pg. 51 of 60 .

APPENDIX A

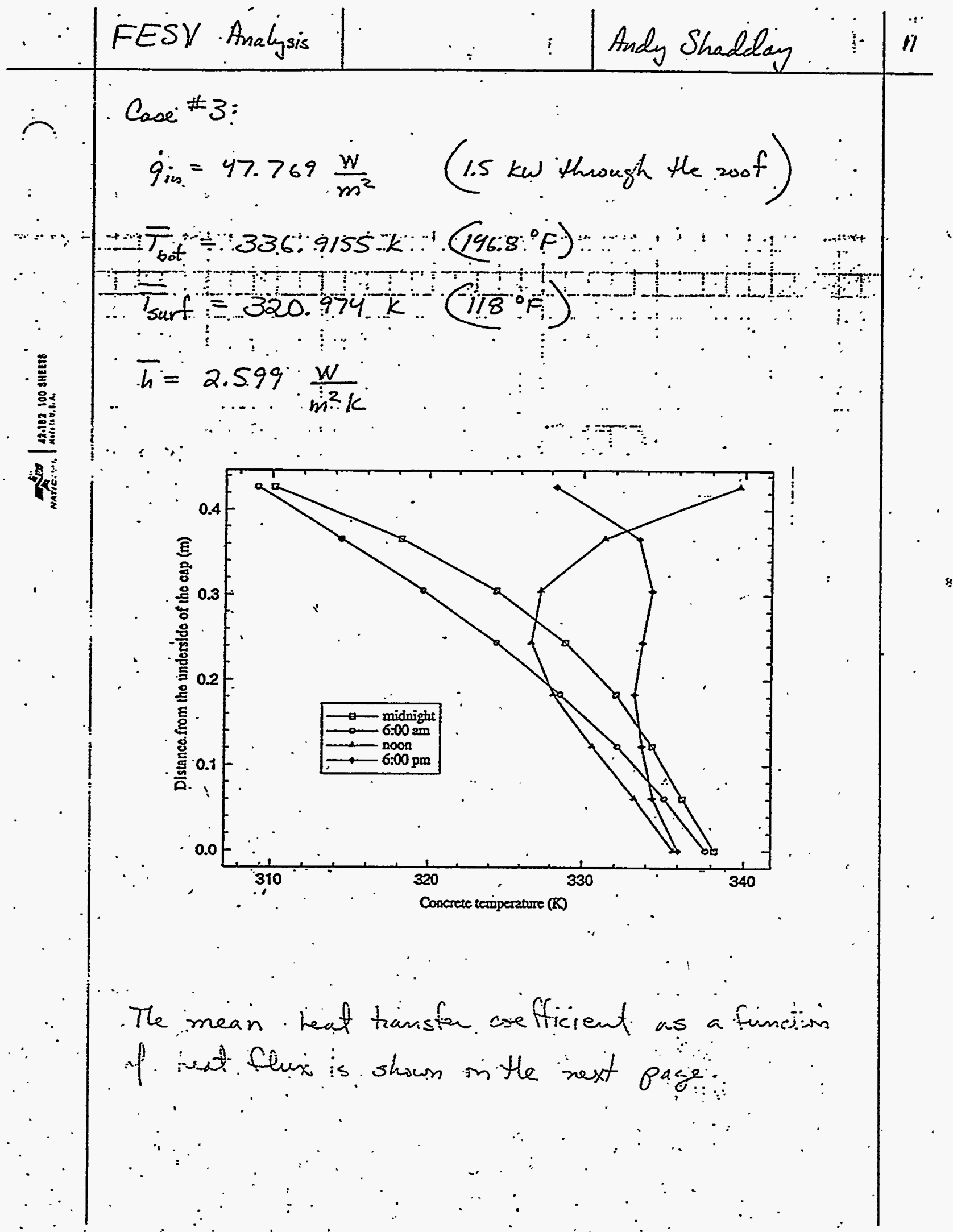




\section{APPENDIX A}

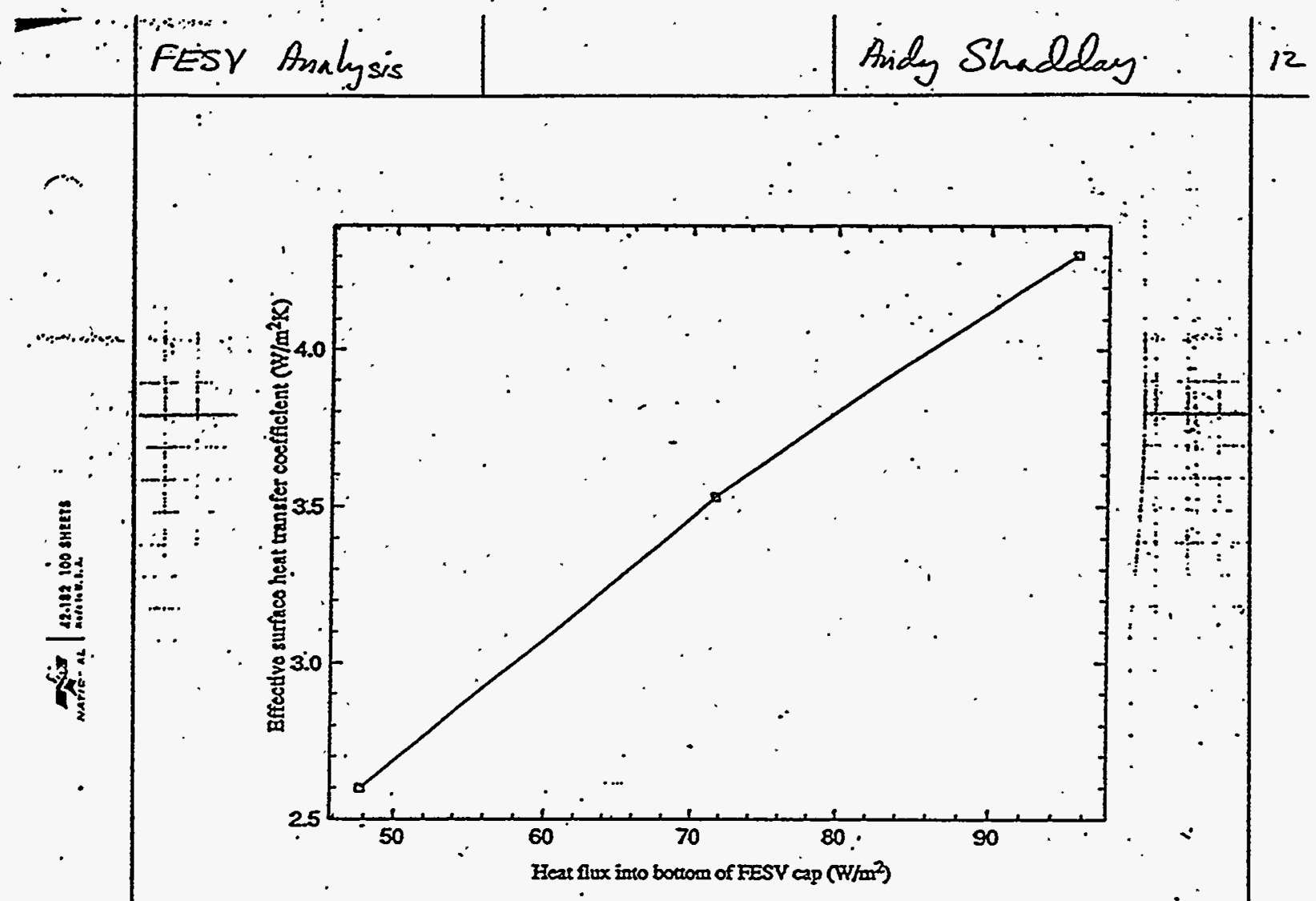


WSRC-TR-95-0288

pg. 53 of 60 .

APPENDIX B: Volume of Soil Surrounding Concrete

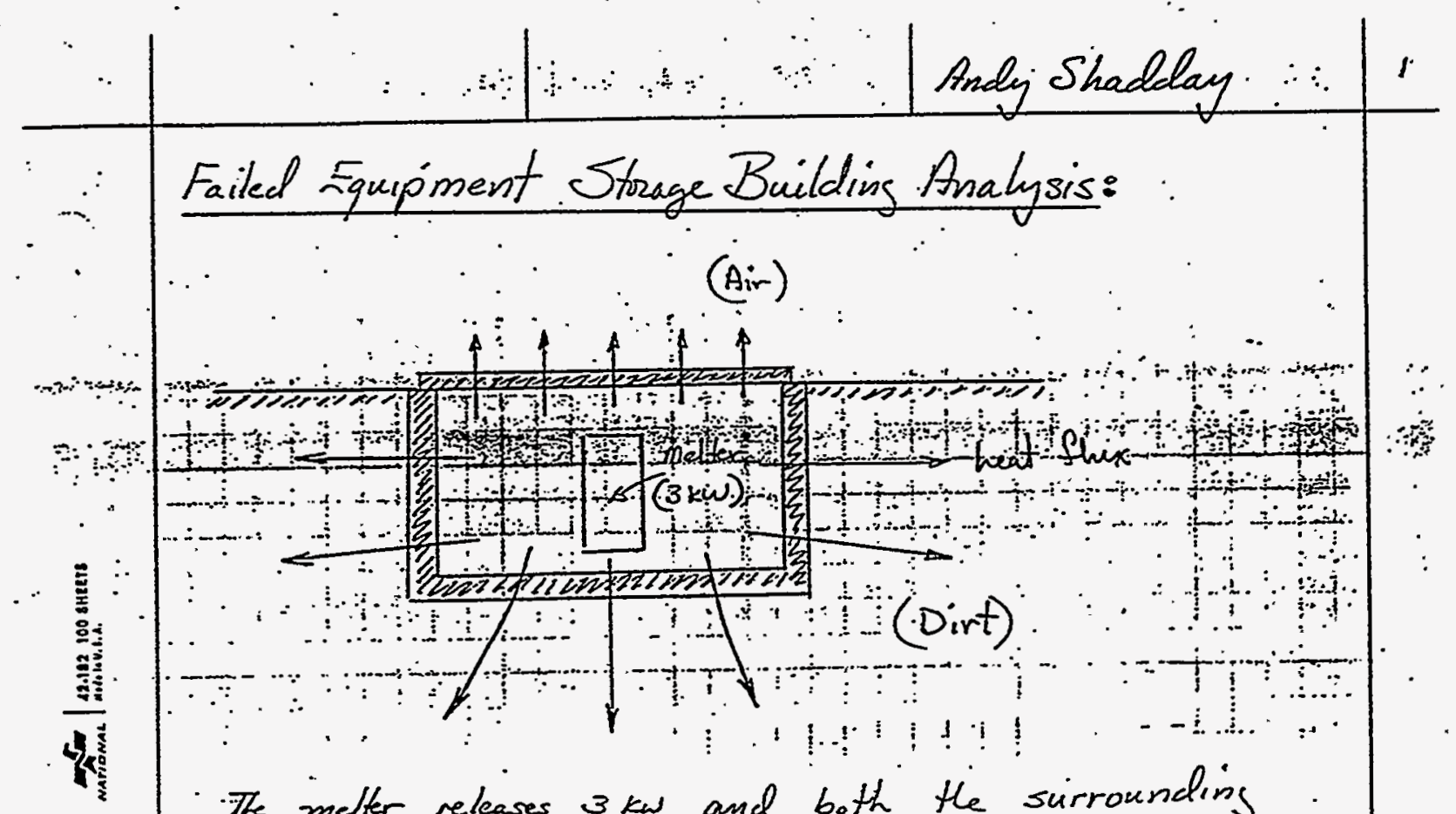

The melter releases $3 \mathrm{kw}$ and both the surrounding. earth and the air are heat sinks. This is an intrinsically transient problem: because of the periodic bouridary conditions, but it can be bounded with a steady-state calculation. As the earth under the vail t heats up, the earth becomes less of a heat sink. In the limit as $t \rightarrow \infty$, the lower boundary of the vault can be treated as adiabatic. This is not the case for the earth that surrounds the

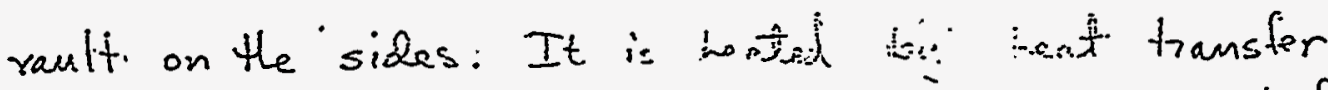
through the vertical wails of the rant and cook el in in eat hamster. to the air. The surrounding

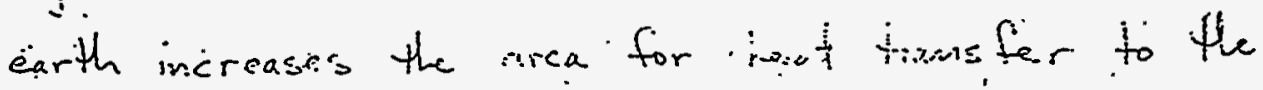




\section{APPENDIX B}

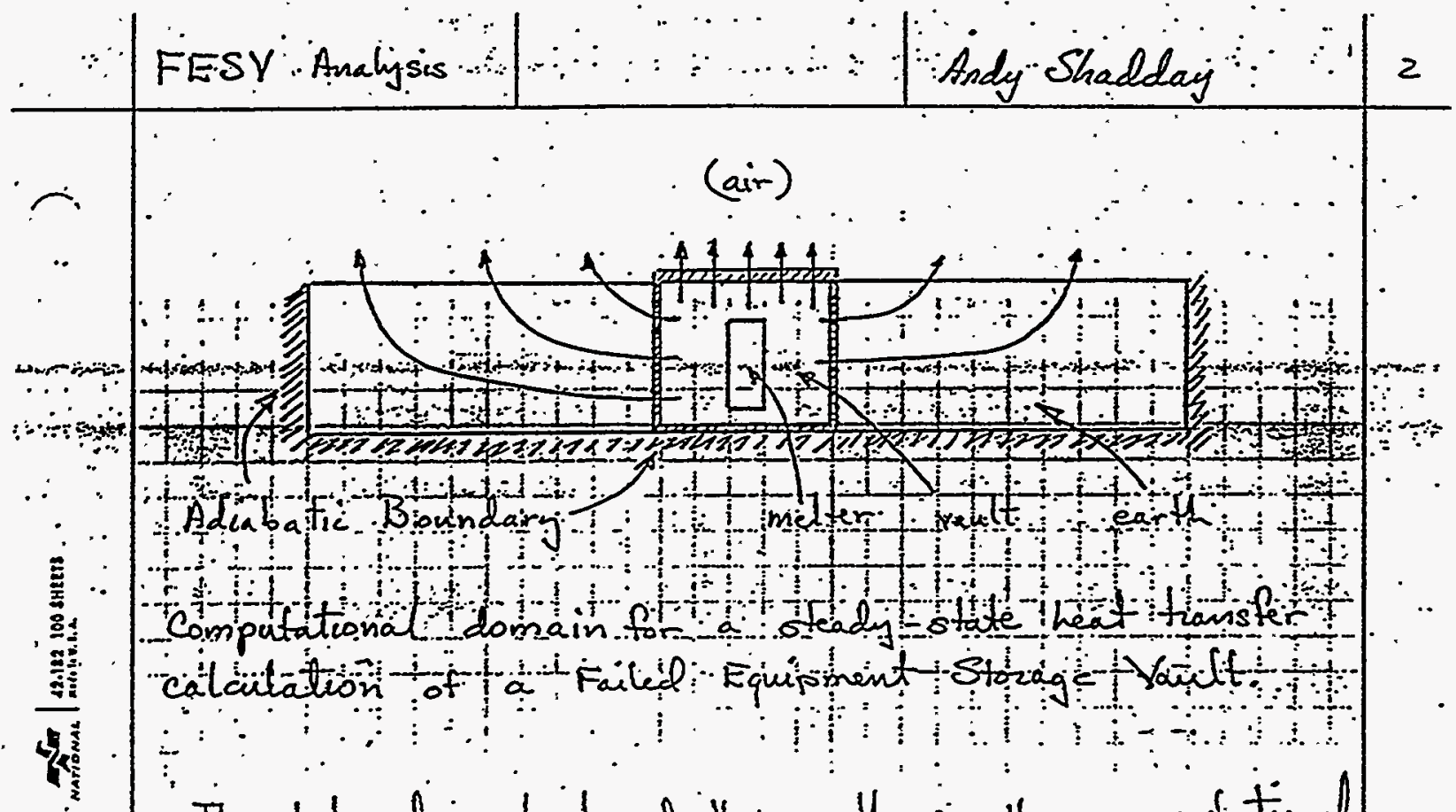

The lateral extent of the earth in the computational domiain should be sufficient such that the restical adiabatic bourdary does not substantially influence He solution. Ideally it should be at infinity.

In order. to determine an appropriate laterial extent for the earth in this problem; I wrote a Z-D cylindrical coordinates transient conduction model of earth. heated by constont heat flix on the inner rentical eurface and: cooled. by convectisn to the air at the top homital surface: 
WSRC-TR-95-0288

pg. 55 of 60 .

APPENDIX B

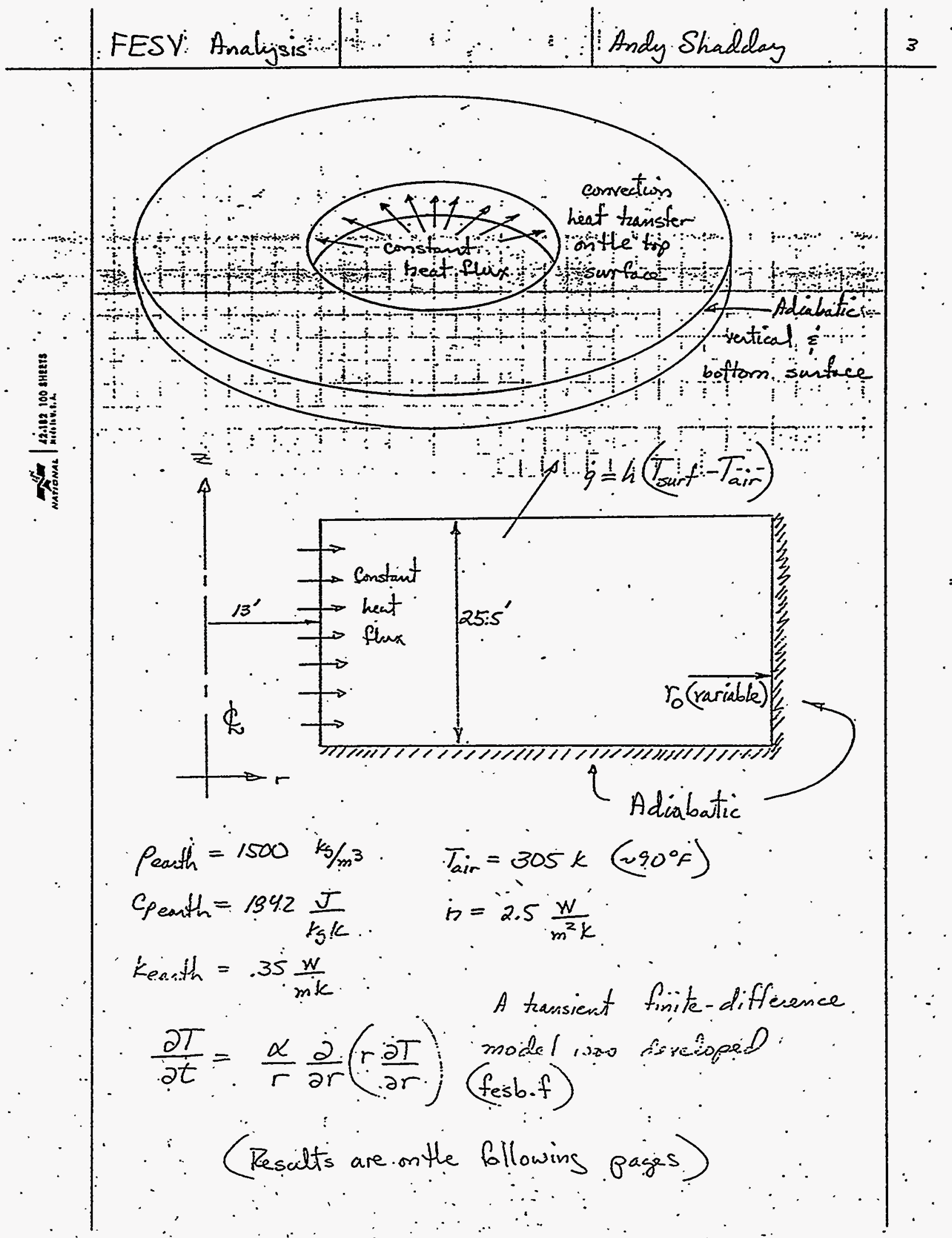


WSRC-TR-95-0288

pg. 56 of 60 .

APPENDIX B

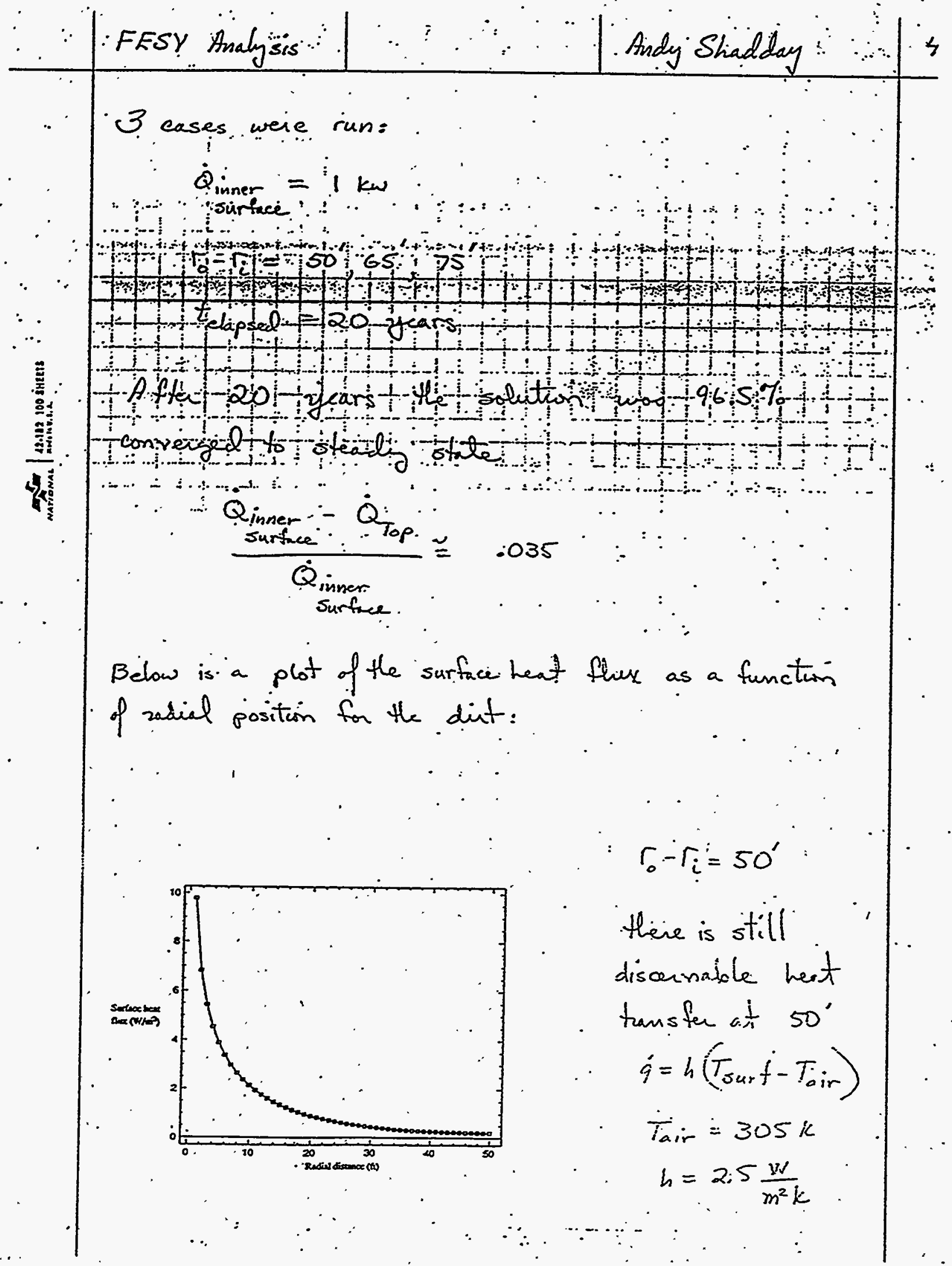


WSRC-TR-95-0288

pg. 57 of 60 .

APPENDIX B

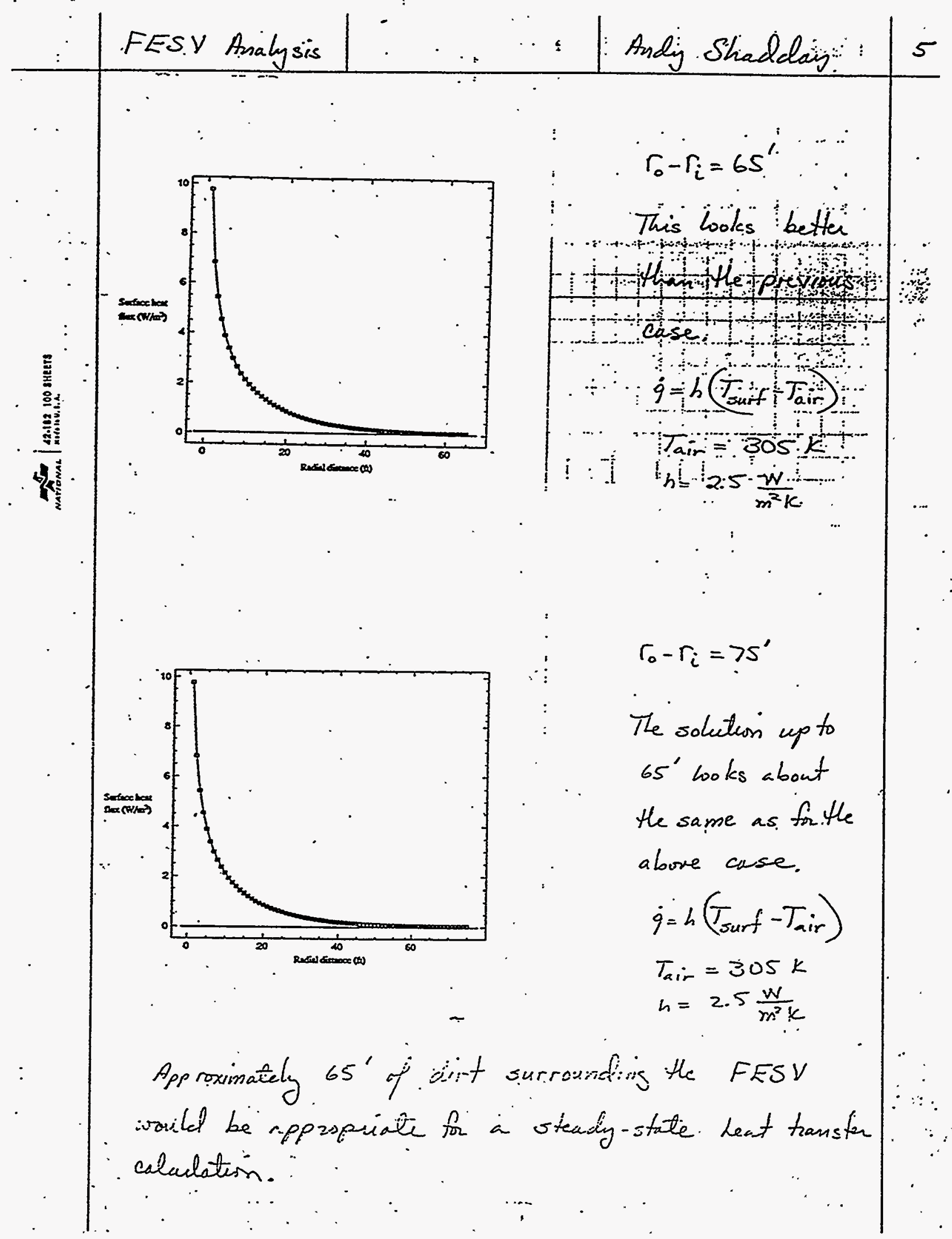




\section{APPENDIX C: Heat Transfer Coefficient Over Horizontal Flat Surface}

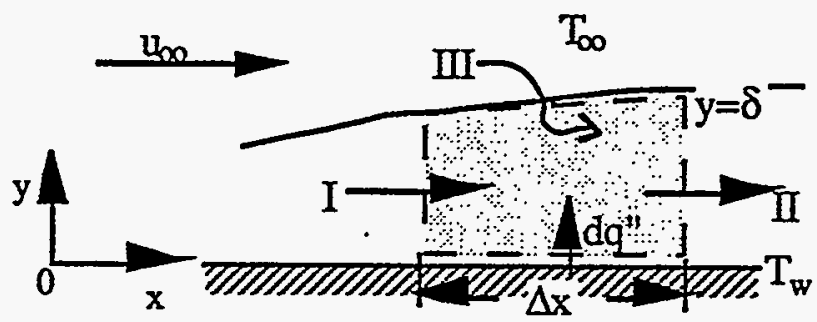

Figure C.1 Boundary layer control volume for energy balance.

From heat transfer rates integrated over the entire boundary, the energy balance for the dotted control volume in Figure C. 1 becomes

$$
\text { II - }(\mathrm{I}+\mathrm{III})=\mathrm{dq}
$$

where I, II, II, and dq" represent the energy flux crossing the given planes, and they are

$$
\begin{aligned}
& I=\int_{y=0}^{y=\delta}(\rho u i) d y \\
& I I=\int_{y=0}^{y=\delta}(\rho u i) d y+\frac{d}{d x}\left\{\int_{y=0}^{y=\delta}(\rho u i) d y\right\} \Delta x \\
& I I=i_{\infty} \frac{d}{d x}\left\{\int_{y=0}^{y=\delta}(\rho u) d y\right\} \Delta x \\
& d q^{\prime \prime}=-k\left(\frac{\partial T}{\partial y}\right)_{y=0} \Delta x
\end{aligned}
$$

Notations associated with the above model:

$$
\begin{aligned}
& h=\text { heat transfer coefficient } \\
& i=\text { enthalpy } \\
& k=\text { thermal conductivity } \\
& a=\text { thermal diffusivity }\left(=k / r C_{p}\right) \\
& r=\text { density } \\
& \delta=\text { energy boundary layer thickness } \\
& \delta_{m}=\text { momentum boundary layer thickness } \\
& v=\text { kinematic viscosity }(=\mu / \mathrm{r}) \\
& u=x \text {-direction velocity } \\
& v=y \text {-direction velocity } \\
& q "=h e a t \text { transfer rate } \\
& \text { subscript }:
\end{aligned}
$$

$$
\infty=\text { parameter value outside boundary layer region }
$$


When di $=C_{p} d T$ and $r$ and $C_{p}$ are assumed to be constant, equation (C.1) becomes

$$
\frac{d}{d x}\left[\int_{y=0}^{y=\delta}\left\{\left(T_{\infty}-T\right) u\right\} d y\right]=\frac{k}{\rho C_{p}}\left(\frac{\partial T}{\partial y}\right)_{y=0}
$$

For $\mathrm{Pr} \approx 1$, thermal boundary layer behavior is similar to that of momentum boundary layer. Velocity distribution within the control volume of Figure C.1 becomes

$$
\frac{\mathrm{u}}{\mathrm{u}_{\infty}}=\frac{3}{2}\left(\frac{\mathrm{y}}{\delta_{\mathrm{m}}}\right)-\frac{1}{2}\left(\frac{\mathrm{y}}{\delta_{\mathrm{m}}}\right)^{3}
$$

assuming that velocity profile is cubical and satisfying the following boundary conditions:

$$
\begin{aligned}
& u=0 \text { at } y=0 \\
& u=u_{\infty} \text { at } y=\delta_{m} \\
& \frac{\partial u}{\partial y}=0 \text { at } y=\delta_{m}
\end{aligned}
$$

The momentum integral balance for the same control volume as that of energy balance can be obtained by using equation (C.7). That is,

$$
\delta_{m} d \delta_{m}=\left(\frac{140}{13}\right)\left(\frac{v}{u_{\infty}}\right) d x
$$

Equation (C.9) can be integrated to yield

$$
\begin{aligned}
\frac{\delta_{\mathrm{m}}}{\mathrm{x}} & =\sqrt{\frac{280}{13}} \sqrt{\frac{v}{\mathrm{xu}_{\infty}}} \\
& =4.641 \frac{1}{\sqrt{\mathrm{Re}_{\mathrm{x}}}}
\end{aligned}
$$

satisfying the boundary condition, $\delta_{\mathrm{m}}=0$ at $\mathrm{x}=0$.

Now, the temperature distribution within boundary layer region is obtained by similarity as used in equation (C.7).

$$
\theta=\left(\frac{T-T_{W}}{T_{\infty}-T_{W}}\right)=\frac{3}{2}\left(\frac{y}{\delta}\right)-\frac{1}{2}\left(\frac{y}{\delta}\right)^{3}
$$

satisfying the boundary conditions

$$
q=0 \text { at } y=0
$$




$$
\begin{aligned}
& q=1 \text { at } y=\delta \\
& \frac{\partial \theta}{\partial y}=0 \text { at } y=\delta
\end{aligned}
$$

Equation (C.6) can be simplified by using equations (C.7) and (C.11).

$$
0.1\left(\xi \delta_{m}\right) \frac{d}{d x}\left[u_{\infty} \delta_{m}\left(\xi^{2}-\frac{1}{14} \xi^{4}\right)\right]=\frac{1}{\operatorname{Pr}} .
$$

where

$$
\xi=\frac{\delta}{\delta_{\mathrm{m}}} \text { and } \operatorname{Pr}=\frac{v}{\alpha}
$$

The second term within brackets of equation (C.13) is practically negligible compared to the first term for $\mathrm{Pr} \approx 1$. After manipulating equation (C.13) with equation (C.9) algebraically and then substituting equation (C.10) into the resulting equation, the thermal boundary layer thickness becomes

$\delta=\frac{4.641 \mathrm{x}}{\sqrt[3]{\operatorname{Pr}} \sqrt{\operatorname{Re}_{x}}}$

From the definition of the local convective wall heat transfer coefficient,

$$
\begin{aligned}
h_{x} & =\frac{q_{w}^{\prime \prime}}{\left(T_{w}-T_{\infty}\right)} \\
& =\frac{-k\left(\frac{\partial T}{\partial y}\right)_{y=0}}{\left(T_{w}-T_{\infty}\right)}
\end{aligned}
$$

From equations, (C.11), (C.14), and (C.15), the resulting equation for local heat transfer coefficient over flat wall surface $\left(h_{x}\right)$ becomes

$$
\begin{aligned}
h_{x} & =1.5\left(\frac{k}{\delta}\right) \\
& =0.3233\left(\frac{k}{x}\right) \sqrt[3]{\operatorname{Pr}} \sqrt{\frac{x u_{\infty}}{v}}
\end{aligned}
$$




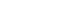





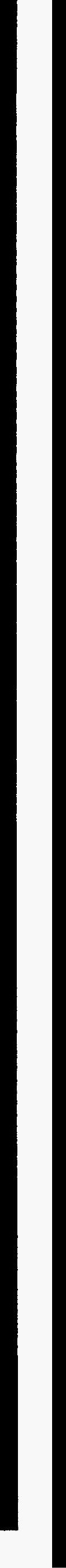

